\title{
Estudo das equações de referência dos parâmetros de função pulmonar em repouso e ao exercício em amostra de idosos hígidos da população brasileira.
}

Tese apresentada à Faculdade de Medicina da Universidade de São Paulo para obtenção do título de Doutor em Ciências

Programa de Pneumologia

Aluna: Juliana Martins Rocha do Nascimento

Orientador: Prof. Dr. Mario Terra Filho

Coorientador: Dr. João Marcos Salge

São Paulo 
Dados Internacionais de Catalogação na Publicação (CIP)

Preparada pela Biblioteca da

Faculdade de Medicina da Universidade de São Paulo

Creprodução autorizada pelo autor

Nascimento, Juliana Martins Rocha do

Estudo das equações de referência dos parâmetros de função pulmonar em repouso e ao exercício em amostras de idosos hígidos da população brasileira / Juliana Martins Rocha do Nascimento. -- São Paulo, 2016.

Tese(doutorado)--Faculdade de Medicina da Universidade de São Paulo.

Programa de Pneumologia.

Orientador: Mario Terra Filho.

Coorientador: João Marcos Salge.

Descritores: 1.Envelhecimento 2.Valores de referência 3.Espirometria 4.Pletismografia total 5.Capacidade de difusão pulmonar 6.Teste de esforço

USP/FM/DBD-434/16 
Ao meu amor, Carlos, por ser meu grande companheiro de todos os momentos, por tanto amor, pela enorme dedicação à nossa família e inspirador na minha evolução profissional e principalmente pessoal, ao seu lado quero a cada dia, ser uma pessoa melhor. Te amo muito amor.

Aos meus pais, Maria da Consolação e Antônio, por serem minha base, meu alicerce para tudo, meus exemplos de vida. Amo muito vocês.

Ao meu Irmão Braulino, que com sua pureza de coração me ensina todos os dias que a vida pode ser mais leve, cheia de humor e com muita cantoria. Sou sua fã. Te amo.

A minha vovó Gracinda, minha velhinha preferida, que quando fui morar em outro estado logo me ensinou que o amor supera as distâncias e por muitos dias ouvia dela: "longe dos olhos e perto do coração". Te amo. 
À Deus, por esse momento único e especial.

À Nossa Senhora de Nazaré, padroeira paraense, que sempre me guiou e iluminou minha trajetória.

Ao meu grande amor, Carlos, por ser tão especial na minha vida, parceiro, cumplice e meu melhor amigo; por você sempre se doar de coração, sempre estar ao meu lado nos momentos difíceis, por me incentivar sempre e nunca me deixar desistir, por você ser esse marido sensacional e presente! Não tenho palavras para agradecer a Deus por ter colocado você em minha vida, para hoje, estarmos juntos escrevendo mais esse capítulo da nossa história. Te amo!!

Aos meus pais, Antônio e Maria da Consolação, por vocês serem únicos, por vocês me incentivarem incondicionalmente, por vocês sempre terem uma palavra carinhosa e inspiradora, por vocês acreditarem nos meus sonhos e sempre fazerem tudo por mim. Muito obrigada por vocês serem tão amigos, parceiros, cumplices, muito obrigada por vocês serem os meus pais! Mamãe e Papai tenho muito orgulho e admiração por vocês e espero ser para meus filhos um pouquinho de tudo que vocês representam na minha vida.

À minha velhinha linda, vovó Gracinda, por sempre me receber com um sorriso lindo, abraços quentinhos e beijinhos cheios de amor toda vez que eu a vejo recarrego minhas baterias para voltar a "sampa".

Ao meu irmão, único e especial que tanto amo, muito obrigada por você ter abdicado de você para ter vindo comigo para São Paulo, me acompanhar nas minhas escolhas, por ir comigo de mãos dadas para o inicio de toda essa história, seu amor incondicional, sua proteção e sua amizade sempre foram meu talismã. Sempre serei grata a você pelo simples fato de seres o meu irmão!!! 
Aos meus sogros, Carlos Alcino e Maria José, pelo apoio e palavras de incentivo mesmo à distância.

Ao meu querido grande mestre e amigo João Marcos Salge, exemplo de cordialidade e disponibilidade. Obrigada por ter acreditado em mim, por me orientar na minha formação como pesquisadora, por ter me proporcionado a oportunidade de realização desse sonho, por tantos ensinamentos, por dividir comigo sua experiência, por horas de discussão sempre com toda a paciência do mundo e por sempre se preocupar com minha formação. Sinto-me lisonjeada de ser sua aluna "primogênita".

Ao meu querido professor Dr. Mario Terra Filho, por ter abraçado nossa ideia, por ter me acolhido em sua sala e por hoje fazer parte da minha formação como pesquisadora, o senhor foi fundamental para que hoje eu pudesse estar realizando este sonho, agradeço ainda, não só por ter encontrado tempo em sua rotina corrida para mim, mas por sempre me receber com um sorriso no rosto, tenho o senhor mais que um professor; e sim um amigo.

À todos do Laboratório de Função Pulmonar, Prof. André Albuquerque (Bauru), Prof. Frederico (Fred) por seus ensinamentos com fisiologia, a minha querida amiga Fabiane (Fabis) por ter me ensinado e capacitado a fazer meus exames de função pulmonar, sua experiência foi fundamental para minha formação. As minhas queridas amigas, Leila (Leiloca), Sibila (Si) e Edilene (Edi), por sua amizade, disponibilidade, por vibrarem comigo a cada exame realizado, por almoços regados a risadas, chocolates nos melhores momentos e por em algum momento vocês atuarem diretamente ou indiretamente me auxiliando e/ou executando meus exames. Muito Obrigada!

Aos Geriatras Dr. Omar Jaluul e ao Dr. Alexandre Busse por terem me recebido com maior carinho no ambulatório de Geriatria (Grupo "4s"), vocês foram fundamentais no meu estudo auxiliando na captação inicial dos meus pacientes e por dividirem comigo seus conhecimentos. 
Ao Geriatra Marcel Hiratsuka (CEDEPS) que me auxiliava pelo "whatsapp", repassando lista de possíveis participantes.

À todos do Enkyo (Nipo-Brasileiro) que me receberam de braços abertos para recrutar idosos saudáveis.

Ao programa de Pneumologia, por ter professores que de fato, se preocupam com a capacitação dos seus alunos e acima de tudo, nos incentivam multiplicar conhecimento.

À essencial, atenciosa, carinhosa e amiga Luciana Vitale, que sempre estava com sua atenção fraternal para solucionar tudo e tirar a qualquer momento todas as dúvidas.

À minhas queridas amigas Solange (Sol) e Lúcia (Lu), pelas energias positivas e por vibrarem sempre comigo quando meus voluntários não faltavam.

E a todos meus voluntários, "meus idosos saudáveis", meus exemplos de vida e de alegria, meus mais sinceros agradecimentos, nada disso teria feito sentido se vocês não tivessem de coração se envolvido nesse estudo. Muito obrigada por deixarem eu fazer parte da vida de vocês. 
Este é o dia que o Senhor fez: Seja para nós dia de alegria e de felicidade.

(Salmos 118, 24) 
Esta tese está de acordo com as seguintes normas, em vigor no momento de sua publicação:

Referências: adaptado de International Committee of Medical Journals Editors (Vancouver).

Universidade de São Paulo. Faculdade de Medicina. Divisão de Biblioteca e Documentação. Guia de apresentação de dissertações, teses e monografias. Elaborado por Anneliese Carneiro da Cunha, Maria Julia de A.L.Freddi, Maria F.Crestana, Marinalva de Souza Aragão, Suely Campos Cardoso, Valéria Vilhena. $3^{\underline{a}}$ ed. São Paulo: Divisão de Biblioteca e Documentação; 2011.

Abreviatura dos títulos e periódicos de acordo com List of Journals Indexed in Index Medicus. 
Nascimento, JMR. Estudos das equações de referência dos parâmetros de função pulmonar em repouso e ao exercício em amostra de idosos hígidos da população brasileira. [Tese]. São Paulo: Faculdade de Medicina, Universidade de São Paulo; 2016.

Introdução: A diferenciação entre saúde e doença do sistema respiratório torna-se mais difícil devido à tendência de envelhecimento populacional e da necessidade de identificação das alterações próprias da senescência. Os testes de função pulmonar constituem ferramentas clínicas importantes para avaliação respiratória e sua interpretação está baseada em equações de referência derivadas de amostra de indivíduos saudáveis, que podem não expressar adequadamente o comportamento nesta faixa etária específica, dada a reduzida representatividade de indivíduos idosos nos estudos que postularam tais equações. Objetivo: Verificar a acurácia das equações de referência disponíveis para testes de função pulmonar e cardiopulmonar de esforço em relação aos valores obtidos em amostra de indivíduos idosos hígidos e o impacto clínico na interpretação funcional baseada nestas equações. Metodologia: Estudo prospectivo observacional transversal, com voluntários saudáveis, com idade igual ou superior a 65 anos, não tabagistas, urbanos. Em uma única visita, foram coletados dados demográficos, antropométricos e clínicos, seguidos da realização de provas de função pulmonar em repouso (espirometria, medidas de volumes pulmonares e difusão) e do teste cardiopulmonar de exercício máximo (TCPE). Os resultados obtidos foram comparados com os valores esperados de acordo com equações de referência rotineiramente utilizadas para a interpretação (teste-T pareado e avaliação de concordância pelo diagrama de Bland-Altman) e a frequência de casos fora das faixas previstas foi determinada. Novas equações de referência foram geradas por regressão linear múltipla. Resultados: Foram incluídos 95 indivíduos (55 mulheres), com idade (anos) $75 \pm 6$ (feminino) e $74 \pm 6$ (masculino). Caracterizou-se diferença significativa entre as médias dos parâmetros de função pulmonar em repouso observados e previstos por pelo menos 2 das 3 equações testadas para CVF, VEF1, CPT, VR e difusão para ambos os sexos. O mesmo ocorreu para os parâmetros funcionais ao exercício (carga e VO2 no pico do esforço) para 3 de 4 equações testadas. Não houve homogeneidade de um autor específico em predizer com melhor acurácia os valores observados na amostra testada para todos os parâmetros funcionais em ambos os sexos. A frequência de classificação de parâmetros fora das faixas de referência foi elevada para todas as equações avaliadas. Novas equações de referência foram apresentadas a partir dos dados obtidos. Conclusões: A utilização das equações de referência existentes apresentou aplicabilidade limitada à amostra de idosos saudáveis estudada, gerando elevados índices de valores sub e superestimados, potencialmente comprometendo a sensibilidade e especificidade dos testes. Foram derivadas equações idade-específicas para uma amostra de idosos suadáveis brasileiros, visando contemplar as mudanças fisiológicas nesta faixa etária.

Descritores: envelhecimento; valores de referência, espirometria; pletismografia total; capacidade de difusão pulmonar; teste de esforço. 
Nascimento, JMR. Studies of reference equations of pulmonary function parameters at rest and exercise in a sample of healthy elderly individuals of the Brazilian population. [Thesis]. São Paulo: Faculty of Medicine, University of São Paulo; 2016.

Introduction: Differentiating between health and disease of the respiratory system becomes more challenging due to the tendency of population aging and the need to identify themselves senescence changes. Pulmonary function tests are important tools for respiratory evaluation. Its interpretation is based on reference equations derived from healthy people studies that possibly not accordingly express the behavior at this particular age group, due to the low representativity of elderly individuals in the studies that postulated such equations. Objective: To verify the accuracy of reference equations available for pulmonary function and cardiopulmonary exercise tests in comparison to values obtained in a sample of healthy elderly subjects and assess the clinical impact on functional interpretation based on these equations. Methodology: Cross-sectional observational prospective study in healthy volunteers, aged over 65 years, non-smokers, urban living. Demographic, anthropometric and clinical data, were collected and pulmonary function tests at rest (spirometry, lung volumes measures and diffusing capacity pulmonary), and the maximal cardiopulmonary exercise test (CPET) were performed. Results were compared to the expected values according to reference equations routinely used for interpretation (paired t-test and evaluation agreement by Bland-Altman plot) and the frequency of cases outside the reference ranges were determined. New reference equations elderly-specific were generated using multiple linear regression. Results: 95 subjects (55 women), age (years) $75 \pm 6$ (female) and $74 \pm 6$ (male) were included. Significant difference between the mean lung function parameters observed versus predicted by at least 2 of 3 tested equations for FVC, FEV1, TLC, RV for both sexes were identified. The same occured for exercise measurements (load and VO2 at peak exercise) for 3 of 4 tested equations. There was no homogeneity of a particular author to predict more accurately values observed in the sample tested for all functional parameters in both sexes. There was high rates of out of reference range classification for all evaluated equations. New elderly-specific reference equations were presented from the data obtained. Conclusions: The use of existing reference equations had limited applicability to the sample of healthy elderly studied, generating high rates of under and overestimated values, potentially compromising the sensitivity and specificity of the tests. Age-specific equations were derived from a sample of Brazilian healthy elderly, aiming to represent the physiological changes in this age group.

Descriptors: aging; reference values, spirometry; plethysmography, whole body;

pulmonary diffusion capacity; exercise test. 


\section{LISTA DE GRÁFICOS}

\section{LISTA DE FIGURAS}

\section{LISTA DE TABELAS}

\section{RESUMO}

\section{ABSTRACT}

1 INTRODUÇÃO

1.1 Idoso 01

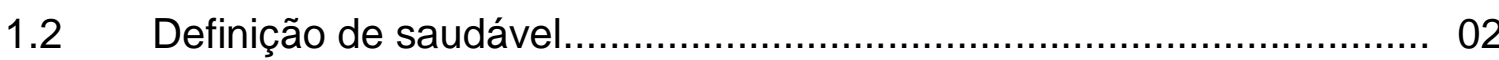

$1.3 \quad$ Expectativa de vida............................................................... 03

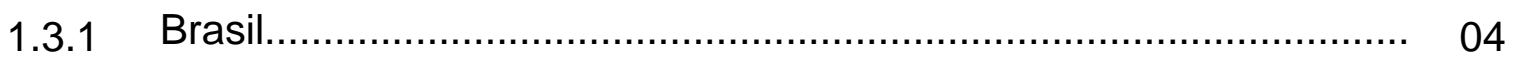

1.3.2 Região metropolitana de São Paulo................................................ 05

1.4 Função pulmonar e teste cardiopulmonar de esforço.......................... 06

$1.5 \quad$ Alterações fisiológicas do idoso.................................................... 07

1.6 Idade e sistema respiratório: repercussão nos testes de função pulmonar e na capacidade aeróbica............................................... 11

1.7 Equações de referência de função pulmonar e exercício.................... 14

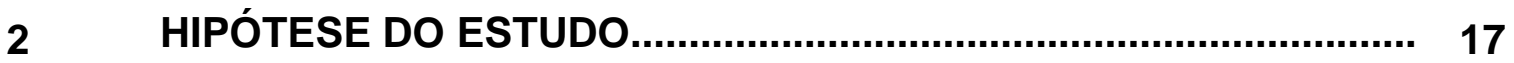

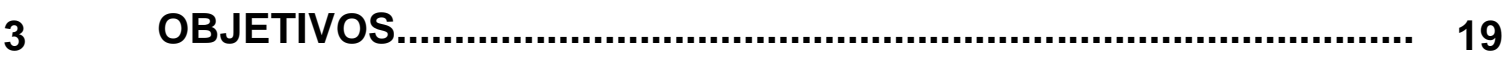

3.1 Objetivo primário................................................................. 20

3.2 Objetivo secundário............................................................... 20

$4 \quad$ METODOLOGIA

4.1 Desenho do estudo............................................................... 22

4.2 População .............................................................................. 22

4.2.1 Critérios de inclusão................................................................... 22

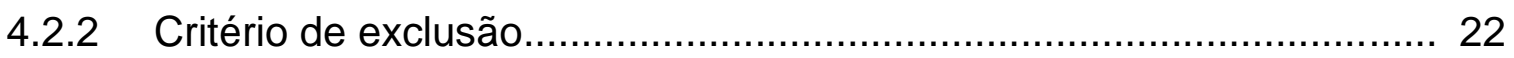

4.3 Aprovação e registro da pesquisa................................................ 23

4.4 Delineamento do estudo............................................................ 24

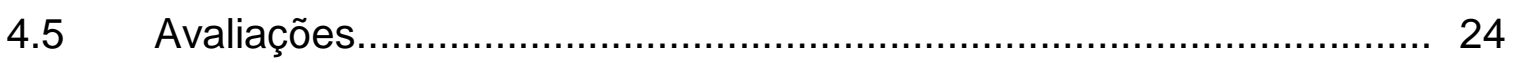

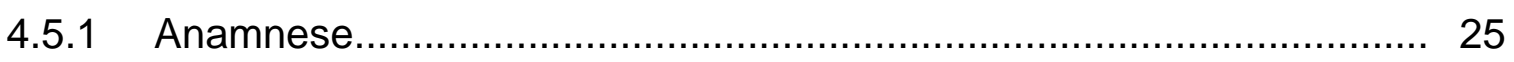


4.5.2 Avaliação do nível de atividade física.......................................... 25

4.5.3 Espirometria forçada............................................................. 26

4.5.4 Pletismografia de corpo inteiro................................................. 27

4.5.5 Capacidade de difusão de monóxido de carbono (dlco)...................... 28

4.5.6 Este de exercício cardiopulmonar máximo incremental através de cicloergômetro.................................................................... 28

4.5.7 Avaliação de dispneia e fadiga em membros inferiores....................... 30

4.6 Análise estatística.................................................................. 31

$5 \quad$ RESULTADOS............................................................................... 33

5.1 Casuística e características gerais................................................. 34

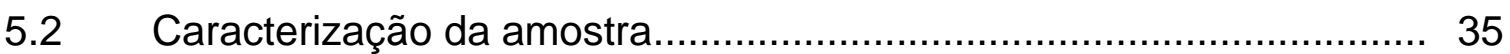

5.3 Comparação entre os dados observados e equações de referência

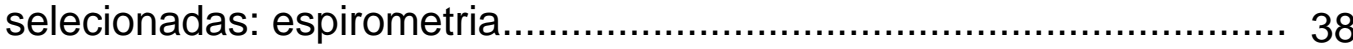

5.4 Comparação entre os dados observados e equações de referência selecionadas: volumes pulmonares e difusão.

5.5 Comparação entre os dados observados e equações de referência selecionadas: teste cardiopulmonar de exercício.

5.6 Avaliação do potencial impacto das diferenças observadas na interpretação dos dados de função pulmonar.

5.7 Derivação de novas equações de referência idade-específico para idosos na população brasileira.......................................................... 48

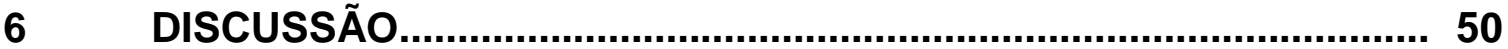

6.1 Análise da aderência entre as equações de referência disponíveis e a amostra de idosos saudáveis estudada......................................... 51

6.1.1 Teste de função pulmonar - Espirometria....................................... 52

6.1.2 Teste de função pulmonar - Volumes pulmonares............................ 55

6.1.3 Teste de função pulmonar - Difusão................................................ 58

6.1.4 Teste cardiopulmonar de esforço................................... 60

6.2 Limitação do estudo e pontos fortes............................................... 62

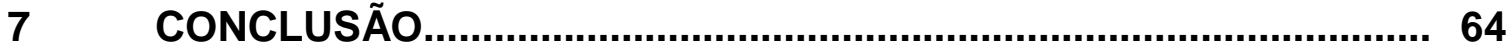

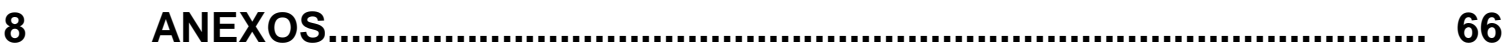

9 REFERÊNCIAS BIBLIOGRÁFICAS............................................... 76

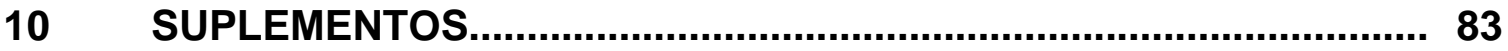


Listas 
Gráfico 1. Histograma de distribuição das idades entre os grupos...... 
Figura 1. Imagem adaptada e representativa da projeção da mudança demográfica da pirâmide etária.

Figura 2. A. Imagem radiográfica de coluna vertebral, ressaltando as alterações ósseas suscetíveis com o avançar da idade, como presença de osteófitos no processo transverso da vertebra, diminuição da massa óssea no corpo vertebral (Osteopenia) e perda de água nos discos intervertebrais. B. Imagem radiográfica torácica destacando a mudança conformacional do tórax com aumento da curvatura da coluna, caracterizada como "tórax em tonel" ou "tórax senil". Imagem adaptada e disponível em: http://www.radiology.uthscsa.edu eRadiol Clin N Am 46. 2008.

Figura 3. Corte histológico comparando um parênquima pulmonar de um adulto jovem com de um idoso. Note na mudança morfológica alveolar, alvéolos rasos e largos, redução de área de troca gasosa ${ }^{(35)}$

Figura 4. Curva de fluxo-volume adaptada, comprando padrão de adulto jovem com idoso. Adaptado de P.M. Lalley / Respiratory Physiology \& Neurobiology (2013).....

Figura 5. Comportamento de volumes e capacidades pulmonares com o avançar da idade. Adaptado de P.M. Lalley / Respiratory Physiology \& Neurobiology (2013)

Figura 6. Declínio funcional da capacidade aeróbica com a progressão da idade em ambos os sexos ${ }^{(40)}$

Figura 7. Fluxograma de avaliação e medidas funcionais

Figura 8.

Esquema ilustrativo das fases de avaliação dinâmica durante

Figura 9. Escala de Borg Modificada.

Figura 10 recrutados para o presente estudo.

Fluxograma representativo do número de participantes 
Tabela 1. Caracterização demográfica dos indivíduos

Tabela 2. Média e desvio padrão dos valores absolutos da função pulmonar: espirometria, volumes pulmonares e difusão de ambos os sexos.

Tabela 3. Média e desvio padrão dos valores absolutos do Teste cardiopulmonar de esforço (TCPE): parâmetros funcionais no pico do esforço de ambos os sexos.

Tabela 4. Espirometria: comparação entre os parâmetros observados e derivados das equações de referência selecionadas para sexo feminino

Tabela 5. Espirometria: comparação entre os parâmetros observados e derivados das equações de referência selecionadas para o sexo masculino.

Tabela 6. Volumes pulmonares e difusão: comparação entre os parâmetros observados e derivados das equações de referência selecionadas para o sexo feminino.

Volumes pulmonares e difusão: comparação entre os

Tabela 7. parâmetros observados e derivados das equações de referência selecionadas para o sexo masculino

Tabela 8. Teste cardiopulmonar de esforço: comparação entre os parâmetros observados no pico do esforço com as equações de referência selecionadas para o sexo feminino

Tabela 9 Teste cardiopulmonar de esforço: comparação entre os parâmetros observados no pico do esforço com as equações de referência selecionadas para o sexo masculino

Tabela 10 Espirometria: frequência de observação de valores fora da faixa de referência em relação às equações de referência selecionadas para o sexo feminino.

Tabela 11 Espirometria: frequência de observação de valores fora da faixa de referência em relação às equações de referência selecionadas para o sexo masculino 
Tabela 12 Volumes pulmonares: Frequência de observação de valores fora da faixa de referência em relação às equações de referência selecionadas para o sexo feminino.

Tabela 13 Volumes pulmonares: Frequência de observação de valores fora da faixa de referência em relação às equações de referência selecionadas para o sexo masculino

Tabela 14 Difusão: Frequência de observação de valores fora da faixa de referência em relação às equações de referência selecionadas para ambos os sexos

Tabela 15 Espirometria: Coeficientes propostos para derivação das equações lineares das variáveis espirométricas para ambos os sexos

Tabela 16 Volumes e Difusão Coeficientes propostos para derivação das equações lineares das variáveis volumes pulmonares e difusão para ambos os sexos.

Tabela 17 TCPE: Coeficientes propostos para derivação das equações lineares das variáveis selecionadas de TCPE para ambos os sexos 
1. Introdução 


\subsection{Idoso}

O conceito de idoso é diferente para países desenvolvidos daqueles em desenvolvimento. Nos países desenvolvidos considerasse idoso, indivíduos com idade igual ou maior que 65 anos, já nos países em desenvolvimento considerasse idoso, todos com idade igual ou maior de 60 anos ${ }^{(1)}$ Segundo 0 Estatuto do Idoso no Brasil e a Organização das Nações Unidas (ONU), considerasse idoso, todos os indivíduos com idade igual ou superior a 60 anos. Já para a Organização Mundial da Saúde (OMS), 65 anos de idade é o início dessa fase ${ }^{(2)(3)}$.

Para alguns autores o processo de envelhecimento é considerado múltiplo e complexo, contemplando contínuas mudanças no domínio biopsicossocial que podem vir acompanhado de perdas psicomotoras, sociais, culturais e etc.; já outros acreditam que a "velhice" é uma experiência subjetiva e cronológica ${ }^{(4)}$.

Reforçando essa temática, a American College of Sports Medicine (ACSM), resume o envelhecimento como um acúmulo de eventos biológicos que ocorrem ao longo de um período de tempo, através de uma adaptação constante, pois ele começa a partir do momento que nascemos ${ }^{(5)}$. Dentre os tipos de envelhecimento, vamos nos deter ao "Envelhecimento fisiológico", senescente, caracterizando um perfil de idoso ativo.

Neste contexto de envelhecimento biológico saudável, a senescência é caracterizada pelo processo de envelhecimento fisiológico, natural que atinge 0 organismo de forma gradual e progressiva, possuindo efeito acumulativo, estando presente em todas as pessoas, independentemente de influências ambientais e de doenças ${ }^{(2)}$.

Alguns autores ainda conceituam o envelhecimento saudável dentro de um quadro da vida, onde faz parte: a senescência e o desacelerar do início do declínio funcional (retardar o aparecimento de distúrbios clínicos) e de doenças crônicas, através do acesso ao diagnóstico precoce, diminuição da letalidade, 
resultantes de avanços na saúde, permitindo as pessoas idosas mais qualidade de vida para continuarem ativos na sociedade ${ }^{(6)(7)}$.

Portanto, a categorização funcional do idoso não depende apenas da idade, mas também do estilo de vida, da saúde, de fatores socioeconômicos e influências constitucionais, estando caracterizado, assim, que não há homogeneidade na população idosa ${ }^{(1)}$. O envelhecimento saudável é um privilégio e precisa ser visto como uma tendência singular e atual. A longevidade, juntamente com outras tendências importantes, está remodelando o curso da vida de forma complexa e diversa. Adicionalmente, a crescente presença dos idosos ativos confronta atuais paradigmas sobre o significado da vida, sobre o meio em que vivemos e como nos responsabilizamos por nossa qualidade de vida. ${ }^{(8)}$

\subsection{Definição de saudável}

De Acordo, com a OMS, "Saúde é o estado de completo bem-estar físico, mental e social e não apenas a ausência de doença", ou seja, é um conceito multidimensional. Nenhum ser humano (ou população) será totalmente saudável ou totalmente doente. Ao longo de sua existência, viverá condições de saúde/doença que se entrelaçam e variam de acordo com suas potencialidades, suas condições de vida e sua interação com elas. ${ }^{(9)}$ (10) (11) (12) Para que o envelhecimento seja uma experiência positiva, deve ser acompanhado de oportunidades contínuas de saúde, participação social e segurança.

A OMS adotou em 2002, o termo "envelhecimento ativo" para expressar o processo de participação em questões sociais, econômicas, culturais, civis e não somente à capacidade de estar fisicamente ativo ou de fazer parte da força de trabalho. O objetivo é aumentar a expectativa de uma vida saudável e a qualidade de vida para todas as pessoas que estão 
envelhecendo, inclusive as que são frágeis, fisicamente incapacitadas e que requerem cuidados ${ }^{(13)(14)}$.

\section{$1.3 \quad$ Expectativa de vida}

Ao longo do século passado, o mundo vivenciou queda nas taxas de mortalidade, levando ao acelerado aumento da população mundial, caracterizando o século XX como "Século do Crescimento populacional" (Primeira fase de transição demográfica), tornando o aumento da expectativa de vida, uma das maiores conquistas da humanidade ${ }^{(15)}$.

Essa mudança demográfica é praticamente irreversível. Para alguns autores, como Lesthaeghe (2010), as populações estão atravessando uma "segunda transição demográfica" que se caracteriza pelo declínio persistente dos níveis de fecundidade e queda da mortalidade, ambos os fatores associados à longevidade ${ }^{(16)}$.

O mundo assiste ao processo de envelhecimento populacional de forma universal, tanto nos países desenvolvidos quanto naqueles em desenvolvimento ${ }^{(17)}$. Entre 1970 e 2025, espera-se um crescimento de 223\% de pessoas acima de 60 anos ${ }^{(13)}$. Não é apenas a população mundial se tornando idosa, mas vivendo mais e com mais qualidade de vida, tudo isso graças aos avanços tecnológicos na área da saúde, que vêm proporcionando aumento na expectativa de vida ${ }^{(15)(18)}$.

De acordo com o relatório de projeções da ONU referente ao ano de 2015, a população mundial atual de 7,3 bilhões deverá alcançar os 8,5 bilhões em 2030, com previsão para alcançar 9,7 bilhões em 2050 chegando a 11,2 bilhões em 2100 , sendo 3,2 bilhões somente de idosos ${ }^{(19)}$.

Neste contexto de crescimento, é previsto um envelhecimento significativo da população em alguns países, a exemplo da Suíça, onde 34\% da população é projetada para ter mais de 60 anos em 2050. Já no Brasil, México, Caribe, Bangladesh, China, Índia, Indonésia e Paquistão, a população 
com idade acima de 60 anos terá aumento de 14\% até 2050 (passando de 11\% para $25 \%$ da população) ${ }^{(19)}$.

Hoje, a expectativa de vida varia entre aproximadamente 74 a 83 anos, nas diferentes regiões do planeta. Indivíduos com idade acima de 80 anos fazem parte de grupo populacional crescente. A população de nonagenários em 2050 será 16 vezes maior do que em 2000 (2,2 milhões, em comparação com 135.000). Contudo, essa expectativa de vida é desigual para ambos os sexos representando uma relação aproximada de um homem para cada quatro mulheres nessa faixa etária ${ }^{(15)(19)(20) .}$

Essa realidade de longevidade, traz para o século $X X I$, o título de "Século do Envelhecimento" e vale ressaltar que nossa população projetada de idosos para 2050 já está a nossa volta como adolescentes e jovens ${ }^{(15)}$.

\subsubsection{Brasil}

No Brasil, o ritmo de crescimento da população idosa tem sido sistemático e consistente, caracterizado por alterações em seu regime demográfico e estrutura etária. O formato triangular da pirâmide populacional, com base larga, vem dando lugar a pirâmide etária típica de população envelhecida (Fig.1), com a redução notória de crianças e jovens e o aumento proporcional de adultos e idosos, alcançando uma expectativa de vida de 74,8 anos em $2013^{(16)(21)(22)}$. Segundo as mudanças demográficas relatadas pelo IBGE (2015), os idosos constituem população brasileira em ascensão com taxas de crescimento superiores a 4\% ao ano no período de 2012 a 2022 . Até 2025, segundo a OMS, o Brasil será o sexto país do mundo em número de idosos ${ }^{(13)}$.

A população com 60 anos de idade ou mais passou de 14,2 milhões em 2000 para 19,6 milhões em 2010, com projeção de atingir 41,5 milhões em 2030 e em 2060 ter um aumento de 32 milhões de pessoas ${ }^{(16)}$. 


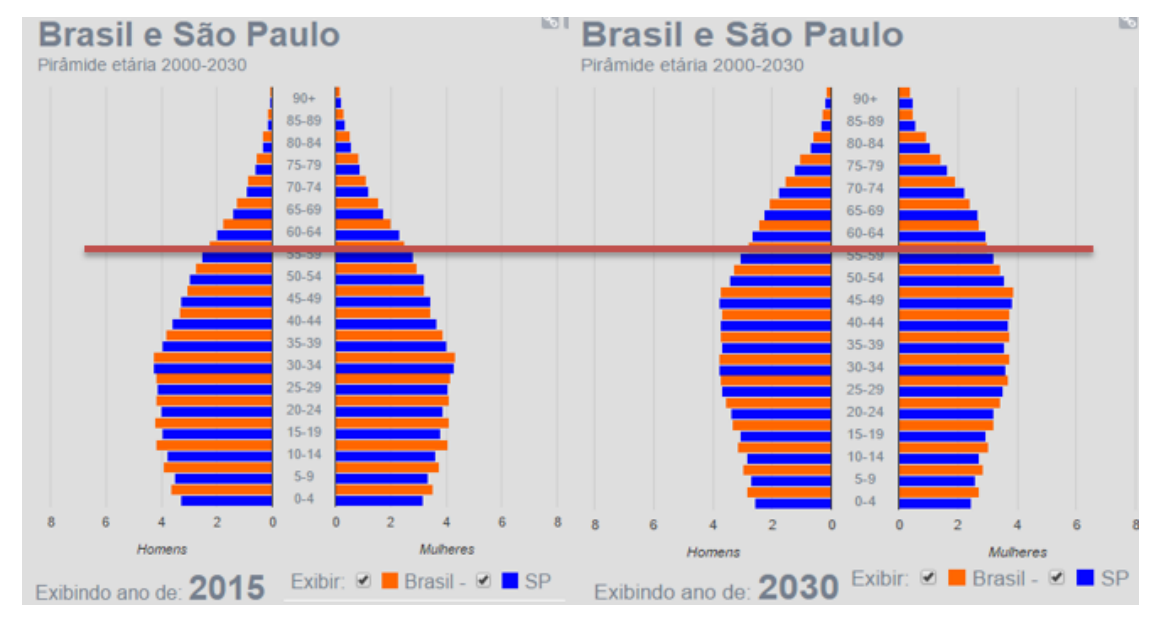

Fig. 1. Imagem adaptada e representativa da projeção da mudança demográfica da pirâmide etária.

FONTE:http://www.ibge.gov.br/apps/populacao/projecao/

\subsubsection{Região metropolitana de São Paulo}

$\mathrm{Na}$ região metropolitana de São Paulo segundo informações atualizadas do IBGE em julho 2015, atualmente a estimativa da população é de aproximadamente 12 milhões de indivíduos, sendo $11 \%$ acima de 60 anos ${ }^{(22)}$ (23).

Nesse contexto, a preocupação com as condições necessárias à manutenção da qualidade de vida das pessoas idosas tem crescido, e os temas relacionados a políticas públicas e a ações de proteção e cuidados específicos para idosos vêm adquirindo relevância inédita na agenda pública, conforme aponta estudo do Instituto de Pesquisa Econômica Aplicada (IPEA) (24)

Com isso, de acordo com abordagem poética de Mario Prata, "se você tem entre 45 e 65 anos, preste bastante atenção no que se segue. Se for mais novo, preste também, porque um dia vais chegar lá. E, se já passou, confira. (25)«. 


\subsection{Função pulmonar e teste cardiopulmonar de esforço}

Os Testes de Função Pulmonar (TFP) e o Teste Cardiopulmonar de Esforço (TCPE) apresentam aplicabilidades para auxiliar no diagnóstico, avaliação da gravidade da doença e monitorar o progresso e os efeitos do tratamento (26) (27) (12) (28).

Os Testes de Função Pulmonar contemplam várias técnicas dentre as quais se destacam a (i) espirometria, que permite a mensuração de volumes pulmonares dinâmicos e dos fluxos inspiratórios e expiratórios derivados de manobras forçadas, (ii) a pletismografia de corpo inteiro para determinação dos (volumes pulmonares estáticos, que incluem o volume residual e ainda permite a mensuração de resistência e condutância das vias aéreas) e ainda (iii) a difusão de monóxido de carbono que mensura a transferência dos gases dos alvéolos até o interior das hemácias ${ }^{(27)}$.

Os métodos citados referem-se à avaliação funcional respiratória em condição de repouso. Para o estudo do comportamento dinâmico do sistema respiratório frente ao esforço, é frequentemente utilizado na prática clínica o TCPE, também designado por Ergoespirometria. Trata-se de um recurso diferenciado que oferece informações sobre os processos fisiológicos envolvidos no exercício dinâmico, tais como: consumo de oxigênio e produção gás carbônico $\left(\mathrm{VO}_{2}\right.$ e $\left.\mathrm{VCO}_{2}\right)$, ventilação minuto $(\mathrm{VE})$ e seus integrantes (frequência respiratória e volume corrente), reserva ventilatória, relação de troca respiratória (RER), limiares ventilatórios. Permite avaliar de maneira integrada o comportamento de variáveis ventilatórias, cardiovasculares e metabólicas. Esses dados são clinicamente úteis em diversas situações, como na investigação de sintomas respiratórios (sobretudo dispneia), na exploração do mecanismo de intolerância aos esforções, na avaliação pré-operatória, no estudo do condicionamento aeróbico para orientar a prática de atividade física e na prescrição de exercícios para reabilitação ${ }^{(12)(28)}$. 


\subsection{Alterações fisiológicas do idoso}

É sabido que o processo de maturação do pulmão ocorre nas duas primeiras décadas de vida, chegando a sua função máxima nas mulheres com idades próximas de 20 anos e em homens ao redor dos 25 anos ${ }^{(29)}$. Porém,

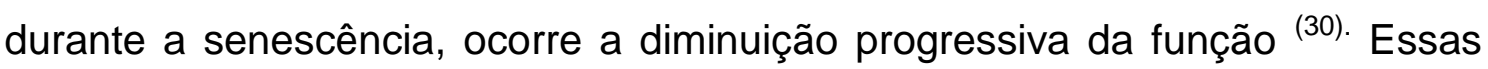
mudanças que ocorrem, podem ser clinicamente relevantes quando associadas à comorbidades, favorecendo aumento na taxa de mortalidade e, com isso saber a diferenciação do fisiológico do que é patológico, contribui para a detecção e prevenção de disfunções respiratórias em idosos ${ }^{(31)}$.

Existem três discretas mudanças principais que se relacionam com a idade: diminuição da complacência torácica, diminuição do recolhimento elástico pulmonar, e diminuição da força dos músculos respiratórios inspiratórios e expiratórios ${ }^{(29)(31)(32)}$.

Com o envelhecimento biológico, a morfologia da parede torácica sofre várias alterações relacionadas com calcificações e outras mudanças que ocorrem tais como: calcificações de cartilagens da coluna vertebral e calcificação das junções costocondrais das costelas e do esterno, estreitamento de discos intervertebrais (desidratação) e certa fragilidade óssea com presença de osteopenia, favorecendo o enrijecimento da parede torácica e uma nova conformação geométrica com cifose e aumento anteroposterior do tórax, ou seja, formação do conhecido "tórax em tonel" ou "tórax senil" (29) (31) (30) (32) (33) (34). (Fig2) 


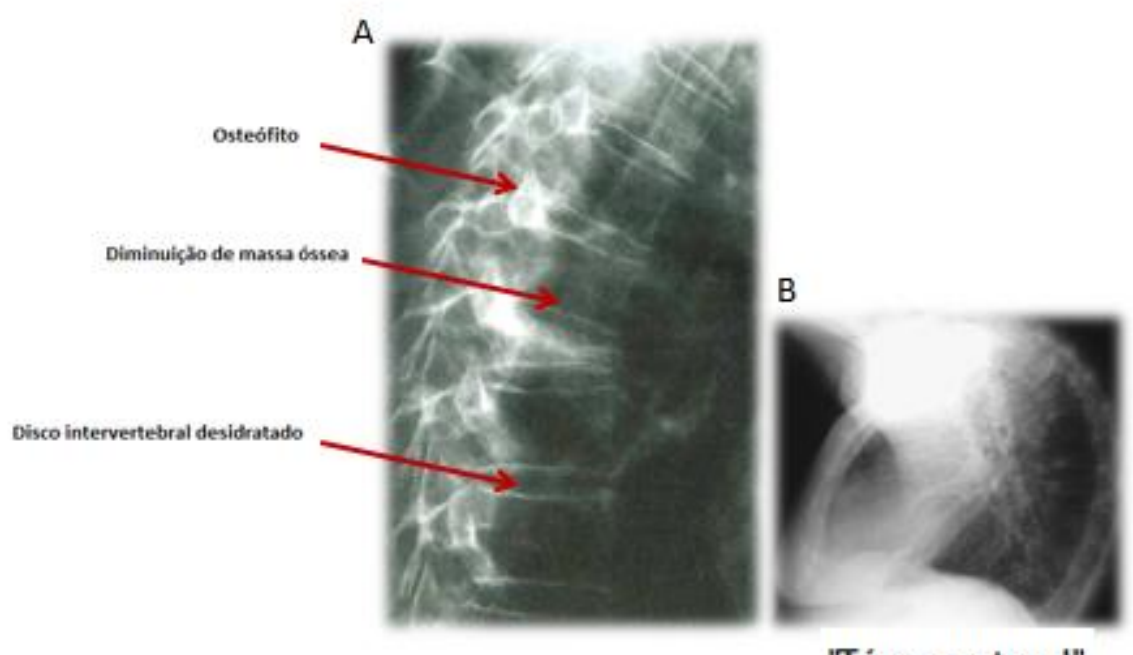

Fig.2. A. Imagem radiográfica de coluna vertebral, ressaltando as alterações ósseas suscetíveis com o avançar da idade, como presença de osteófitos no processo transverso da vertebra, diminuição da massa óssea no corpo vertebral (osteopenia) e perda de água nos discos intervertebrais. B. Imagem radiográfica torácica destacando a mudança conformacional do tórax com aumento da curvatura da coluna, caracterizada como "tórax em tonel" ou "tórax senil". Imagem adaptada e disponível em: http://www.radiology.uthscsa.edu e Radiol Clin N Am 46. 2008.

Simultaneamente à diminuição da complacência torácica, o parênquima pulmonar passa por alterações que proporcionam aumento de sua complacência estática. A presença de pseudo-elastina nas ligações cruzadas intermoleculares promove alterações na estrutura de sustentação do tecido pulmonar, favorecendo a ruptura de septos interalveolares, perda de elasticidade de ductos alveolares, modificando suas características morfológicas, que passam a achatados e com alargamento homogêneo. Essa redução de tecido de suporte na região das vias áreas gera uma tendência ao fechamento precoce de suas porções menores $(<2 \mathrm{~mm})^{(29)(30)(31)(34)}$. (Fig.3) 
Esta diminuição do número de alvéolos, devido à ruptura dos septos interalveolares e consequente fusão alveolar, também proporciona diminuição da superfície total de troca gasosa, aumento do volume residual e da complacência pulmonar estática (29) (30) (31) (32) (33).

O comprometimento da superfície tecidual também acarreta em aumento na heterogeneidade da relação ventilação-perfusão $(V / Q)$, redução na área de superfície alveolar, diminuição da densidade de capilares pulmonares e declínio no volume de sangue do capilar pulmonar com sutil redução, em indivíduos de meia idade saudáveis, na capacidade de transferência de monóxido de carbono 0,2 a $0,3 \mathrm{ml} / \mathrm{min} / \mathrm{mmHg}$ em homens e de 0,06 a 0,18 $\mathrm{ml} / \mathrm{min} / \mathrm{mmHg}$ em mulheres senescentes ${ }^{(29)}$ (31) (32).

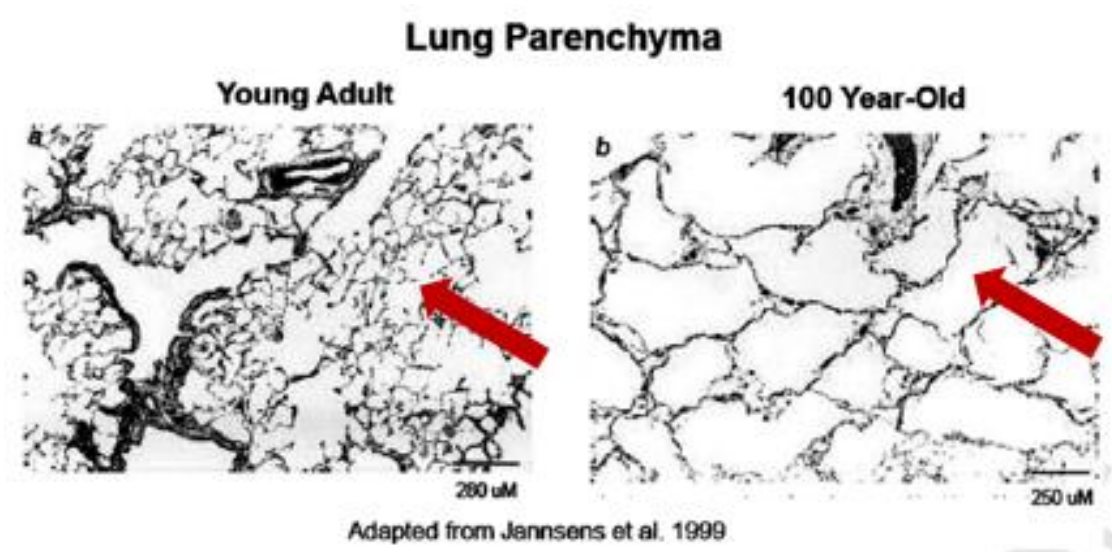

Fig.3. Corte histológico comparando um parênquima pulmonar de um adulto jovem com de um idoso. Note na mudança morfológica alveolar, alvéolos rasos e largos, redução de área de troca gasosa ${ }^{(35)}$.

A partir dos 50 anos ocorre diminuição da pressão elástica pulmonar estando mais evidente em volumes pulmonares elevados. Os bronquíolos tornam-se menos resistentes atingindo seu pico de maturação na $4^{\circ}$ década de vida com posterior declínio funcional, provavelmente por alteração na estrutura e no alinhamento das fibras elásticas juntamente com a diminuição no teor de colágeno, podendo contribuir para o aumento da complacência pulmonar, 
redução do diâmetro das vias aéreas e limitação do fluxo aéreo favorecendo o colapso expiratório precoce ${ }^{(29)(30)(31)(33)}$.

Em razão dessas alterações terem certa semelhança com o enfisema patológico, são por isso denominadas de "Enfisema Senil" e esta nomenclatura está descrita na literatura médica desde o início do século XX, sendo usada para descrever mudanças na forma e conformação do tórax e observações histológicas consistentes de alargamento do espaço aéreo com a idade ${ }^{(34)(31)}$.

Devido às alterações simultâneas nas propriedades mecânicas do pulmão, troca gasosa e parede torácica, é mais fácil percebermos que a mudança da conformação geométrica do tórax impõe ao diafragma uma desvantagem mecânica, ficando mais retificado e passando a ter necessidade de gerar mais pressão para mesma variação de volume. Além disso, estudos que compararam jovens (com média de 26 anos de idade) com idosos (média de 73 anos de idade) mostraram diminuição $13 \mathrm{cmH}_{2} \mathrm{O}$ da pressão transdiafragmática com o envelhecimento (29) (32) (34).

O processo de senescência também está associado à diminuição da força muscular periférica, sendo descritas redução da quantidade e mudança da composição das fibras musculares (especialmente fibras tipo II), além de alterações nas junções neuromusculares com perdas de neurônios motores e nas respostas de excitação-contração ${ }^{(35)}{ }^{(36)}$. Ocorre ainda comprometimento nos canais de cálcio do retículo sarcoplasmático, que contribui negativamente para contração e relaxamento muscular, além de diminuição de sua capacidade reparadora por declínio da função mitocondrial ${ }^{(31)(35)(36)(37)}$.

Essas alterações estão presentes em toda estrutura muscular e sugerem que o declínio na capacidade aeróbica esteja associado à ineficiência em consumir oxigênio, assim como à lentificação da cinética do oxigênio na fase de recuperação ${ }^{(36)}$. Essas alterações refletem, em grande parte, o declínio da capacidade oxidativa mitocondrial, gerando maior dependência de metabolismo anaeróbico em pessoas idosas ${ }^{(36)(38)}$. 
Alterações na capacidade de integração sensorial também são descritas com o envelhecimento. Redução da eficiência de quimioceptores periféricos e mecanoceptores tende a produzir percepção atenuada das oscilações fisiológicas, possibilitando a diminuição da percepção de dispneia e a respostas broncoconstritoras, assim como diminuição da frequência cardíaca máxima e de repouso (dessensibilização no sistema simpático) com alteração direta na modulação compensatória da frequência cardíaca em resposta a estressores externos ${ }^{(35)}$ (36).

Mediante as evidências das tantas diferenças fisiológicas atribuídas ao processo de envelhecimento, o seguinte questionamento foi proposto por Zeleznik: "Existem particularidades ao fazermos medições em pessoas idosas?". Ressalta, ainda, que não deveríamos utilizar fórmulas para "normalizar" uma medida extrapolada para os extremos etários e nem assumir que um valor de referência estabelecido de um teste de diagnóstico feito em adultos jovens possa ser utilizado em uma população geriátrica ${ }^{(33)}$.

\subsection{Idade e sistema respiratório: repercussão nos testes de função pulmonar e na capacidade aeróbica}

Quando é avaliada a função pulmonar do idoso torna-se, assim, necessário discriminar o que é causa do envelhecimento biológico (senescência), a causa patológica (senilidade), ou determinada por outros fatores não patológicos, genéticos, influências externas ou se trata de uma associação.

De acordo com diversas pesquisas, após a fase de crescimento e maturação do sistema respiratório, a partir da $4^{\text {a }}$ década de vida passa a ocorrer redução gradual dos parâmetros espirométricos, sendo que aos 65 anos estima-se atingir uma diminuição da capacidade vital da ordem de 30 a $40 \%$ dos valores observados aos 35 anos. O declínio fisiológico anual estimado para $V_{E F}$ e CVF é da ordem de $30 \mathrm{ml} / \mathrm{ano}$. Observa-se também redução 
progressiva da relação $\mathrm{VEF}_{1} / \mathrm{CVF}$ com a idade, decorrente de redução da tração de recolhimento elástico do parênquima, fazendo com que a alça fluxovolume expiratória adquira uma morfologia levemente côncava, caracterizando relativa limitação ao fluxo aéreo se comparada com o indivíduo jovem ${ }^{(30)}$ (33) (Fig.4).

Flow-Volume Loops vs. Age

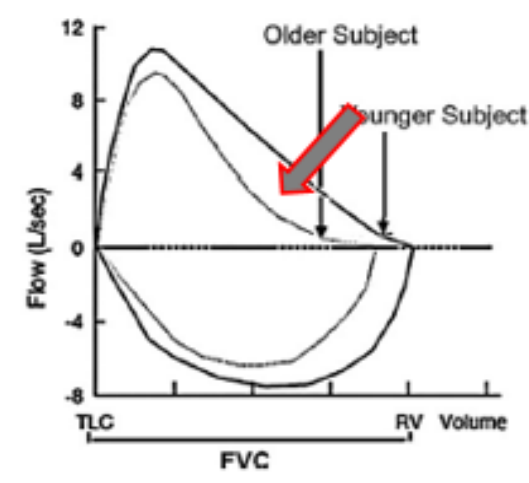

Fig.4. Curva de fluxo-volume adaptada, comprando padrão de adulto jovem com idoso. Adaptado de P.M. Lalley / Respiratory Physiology \& Neurobiology (2013)

A capacidade pulmonar total (CPT) não sofre alterações significativas relacionadas ao envelhecimento, entretanto a capacidade residual funcional (CRF) e volume residual (VR) tendem a aumentar com o passar do tempo, também em decorrência das modificações nas propriedades elásticas do parênquima pulmonar e da caixa torácica nos idosos ${ }^{(32)(34)(39)}$ (Fig. 5).

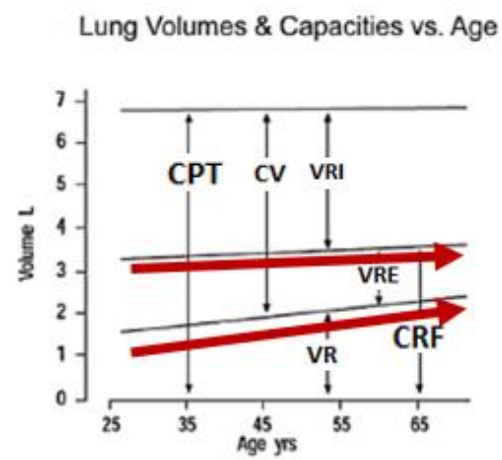

Fig.5. Comportamento de volumes e capacidades pulmonares com o avançar a idade. Adaptado de P.M. Lalley / Respiratory Physiology \& Neurobiology (2013) 
Em relação às trocas gasosas, estudos longitudinais que compararam grupos de jovens com idosos, identificaram diminuição na pressão parcial de oxigênio $\left(\mathrm{PaO}_{2}\right)$, diminuição na difusão de monóxido de carbono (DLCo), aumento do gradiente alvéolo-arterial de oxigênio (DA-a) $\mathrm{O}_{2}$, além de apresentar aumento de espaço sem troca gasosa eficiente. Entre outros mecanismos, a redução da $\mathrm{PaO}_{2}$ pode estar relacionada a aumento do shunt fisiológico, possivelmente associado à ocorrência de fechamento mais precoce de pequenas vias aérea ${ }^{(32)(33)}$.

Estudo de seguimento de aproximadamente 8 anos demonstrou uma queda progressiva da capacidade aeróbica do idoso, com taxa de declínio longitudinal de $\mathrm{VO}_{2}$ máximo em adultos saudáveis, e constatou que ocorre queda não linear com o avançar da idade. $\mathrm{O}$ declínio do $\mathrm{VO}_{2}$ máximo pode ser da ordem de $5 \%$ por década a partir dos 30 anos de idade, com acelerado declínio a partir dos 50 anos em homens e de 60 anos nas mulheres. Já próximo de 70 anos de idade, a taxa de queda aumenta para algo em torno de 17,2\% em ambos os sexos ${ }^{(40)}$ (Fig.6).

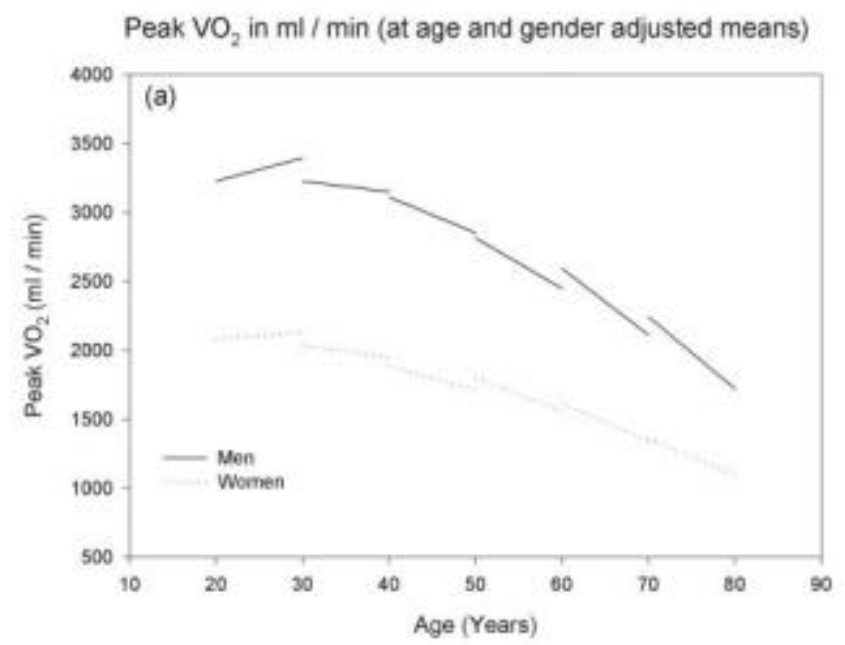

Fig.6. Declínio funcional da capacidade aeróbica com a progressão da idade em ambos os sexos ${ }^{(40)}$.

Em relação ao comportamento das variáveis cardiovasculares associados com a idade, observa-se diminuição de frequência cardíaca 
máxima ( $F C$ máx.), da fração de ejeção ( $F E)$. Em consequência, há declínio do débito cardíaco (DC), sendo estimada redução de 1,7 L/min por década a partir dos 60 anos ${ }^{(41)}$. A redução acentuada do pulso de $\mathrm{O}_{2}\left(\mathrm{VO}_{2} / \mathrm{FC}\right)$ com a idade já foi também demonstrada, entretanto sem esclarecer a contribuição exata dos componentes cardíacos ou periféricos que determinaram comportamento ${ }^{(40)}$.

\subsection{Equações de referência de função pulmonar e exercício}

Habitualmente, os valores de referência de normalidade para os parâmetros derivados dos testes de função pulmonar são obtidos estudando-se uma amostra representativa de indivíduos normais e gerando equações de predição de normalidade através de técnica de regressão linear múltipla ${ }^{\left({ }^{42)}\right.}$. Há grande número de estudos deste tipo para populações adultas, sempre obtendo uma única equação de regressão para a faixa etária adulta, que é muito ampla, habitualmente incluindo indivíduos entre cerca de 20 e 80 anos de idade. Assim, embora a seleção de indivíduos normais habitualmente inclua representantes idosos, frequentemente eles constituem apenas uma pequena parcela da amostra. Além disto, ao derivar uma única equação para faixa etária tão ampla, pode-se limitar a identificação de características específicas, sobretudo nos extremos etários ${ }^{(43)}$.

Diversos estudos para obtenção de equações de normalidade foram realizados ao longo dos anos. Aquele com maior contingente de idosos saudáveis foi realizado em 1972, por Milene e Williamson, que incluíram 487 indivíduos com mais de 62 anos, contudo estando a maioria abaixo dos 70 anos. Outra pesquisa com um número expressivo de voluntários idosos foi realizada em 1985 por Michael, com 418 indivíduos com idade superior a 70 anos. Nesta linha, destaca-se ainda o estudo realizado em 1987 em Londres, que contava com 136 voluntários com idade acima de 60 anos ${ }^{(44)(45)}$.

Entretanto, equações derivadas de amostras específicas de idosos habitualmente têm pouco destaque na literatura e não estão entre as mais frequentemente utilizadas nos laboratórios de função pulmonar. Em 1983 foi 
proposto conjunto de equações por Quanjer e cols. para a população europeia, associadas à European Community for Coal and Steel (ECCS). Estas equações foram revisadas em 1993 e são frequentemente utilizadas para interpretação clínica de função pulmonar ${ }^{(46)}$.

Neste levantamento, que contempla dados de espirometria, volumes pulmonares e difusão, foram incluídos indivíduos com faixa etária ampla (entre 20 e 80 anos) e não foram descartados fumantes ou ex-fumantes, com risco da amostra não ser apropriadamente representativa da população saudável. Nos EUA em 1999, foram propostas equações para a população americana, derivada a partir de três grupos étnicos (caucasianos, africanos-americanos e mexicanos-americanos). Este estudo, conhecido como NHANES III, também combinou indivíduos com intervalo etário amplo (8 a 80 anos), entretanto apenas $18 \%$ acima de acima de 50 anos ${ }^{(47)}$. Além disto, foram mensuradas apenas as variáveis espirométricas, não contemplando dados de volumes pulmonares estáticos ou difusão. Atualmente estas equações são recomendadas na literatura para utilização para a população americana ${ }^{(42)}$. Há diversas equações de referência para volumes e difusão disponíveis para a população norte-americana, com destaque para as derivadas por Crapo et al ${ }^{(48)}$, que têm grande aceitação.

Mais recentemente, em 2012, iniciativa chancelada pela European Respiratory Society (ERS) e capitaneada por Quanjer, reuniu dados de dezenas de estudos de equações de referência fornecidos por autores de todo o mundo, para propor equações únicas, multiétnicas, abrangendo indivíduos de 3 a 95 anos, para determinação dos valores de referência. Nesta compilação de amostras, a representatividade de indivíduos acima de 80 anos de $8 \%$. Além disto, também este estudo se restringe às variáveis espirométricas ${ }^{(49)}$.

No Brasil, há também equações de referência disponíveis derivadas da nossa população. Em 1992 foi realizada a primeira equação de referência de valores espirométricos no nosso meio. Entretanto, em 2007, novo levantamento foi realizado e novas equações de referência para espirometria em adultos brasileiros, saudáveis, que nunca fumaram, foram publicadas. Este estudo incluiu indivíduos entre 20 e 85 anos, sendo $10 \%$ da amostra de indivíduos acima de 75 anos ${ }^{(50)}$. Os parâmetros de volumes pulmonares estáticos e 
difusão foram contemplados em outro estudo, publicado por Neder e cols. em 1999, com indivíduos saudáveis não tabagistas (20-80 anos). Trata-se de um estudo com grande representatividade de idosos (33\% da amostra) que, no entanto, assim como a maior parte da literatura, derivou equações únicas contemplando toda a extensão etária estudada ${ }^{(51)(52)}$.

Este aspecto torna-se ainda mais relevante em se tratando das variáveis ao exercício, obtidas com o teste cardiopulmonar de esforço, onde a participação de idosos nos estudos de normalidade é ainda mais escassa e os cálculos existentes são mais antigos. Em 1989, dois pesquisadores canadenses, Blackie e Jones, propuseram equações de referência para as variáveis do TCPE. Blackie avaliou indivíduos acima de 55 anos e Jones realizou o estudo com indivíduos com intervalo de idade de 20 a 70 anos com média de idade de 60 anos ${ }^{(53)}{ }^{(54)}$. Equações brasileiras de referência para variáveis do TCPE também foram produzidas por Neder e cols. em 1999, e posteriormente acrescidas de variáveis dinâmicas submáximas em $2001^{(55)(56)}$.

Estudo de revisão publicado em 2013 analisou 18 artigos sobre equações preditivas de $\mathrm{VO}_{2}$ máx mais citadas, contudo, e ratificando essa realidade pouco representativa, quando se trata da equação de referência de $\mathrm{VO}_{2}$ máx para mulheres apenas 4 artigos comtemplam a população acima de 65 anos ${ }^{(57)}$.

Portanto, as equações de normalidade de função pulmonar disponíveis para aplicação em indivíduos idosos são as mesmas utilizadas para adultos em geral, derivadas de estudos cujas amostras populacionais incluem variação etária muito grande. Não é claro se as alterações fisiológicas decorrentes do envelhecimento pulmonar estão adequadamente expressas nestas equações, ou se deveríamos utilizar equações específicas para a faixa etária. Neste contexto, torna-se, portanto, pertinente à verificação da adequação das equações disponíveis, para amostra de indivíduos idosos para os parâmetros de função pulmonar estática e para as variáveis dinâmicas do exercício. 
2. Hipótese do estudo 
A Hipótese formulada no presente estudo foi que as equações preditivas de normalidade amplamente utilizadas para os testes de função pulmonar e teste cardiopulmonar de esforço, por serem derivadas de amostras com faixa etária ampla, não contemplam valores adequados para os indivíduos acima de 65 anos. Esta hipótese é particularmente reforçada diante da baixa representatividade desta faixa etária específica nas amostras dos diversos estudos disponíveis, que pode levar a modelos matemáticos de declínio funcional com a idade não aderente à condição real deste extremo etário específico. 


\section{Objetivos}




\subsection{Objetivo primário}

Verificar a acurácia das equações de referência disponíveis para Função Pulmonar e Teste Cardiopulmonar de Esforço em relação aos valores obtidos em amostra de indivíduos idosos hígidos

\subsection{Objetivos secundários}

$\checkmark \quad$ Avaliar o impacto das eventuais discrepâncias observadas sobre a interpretação dos dados de função pulmonar;

$\checkmark$ Avaliar o impacto das eventuais discrepâncias observadas sobre a interpretação dos dados funcionais de exercício;

$\checkmark$ Derivar equações para as variáveis de espirometria, volumes pulmonares e difusão;

$\checkmark \quad$ Derivar equações para carga (W) e consumo máximo de oxigênio ( $\mathrm{VO}_{2}$ máx.) 
4. Metodologia 


\subsection{Desenho do estudo}

Trata-se de um estudo prospectivo observacional de corte transversal.

\subsection{População}

Idosos saudáveis sem comorbidades sistêmicas sintomáticos, ativos, praticantes de atividade física (supervisionada ou não), urbanos, que frequentam unidades de cuidado e prevenção à saúde, dedicados a esta faixa etária foram recrutados para o estudo. Foi disponibilizada a relação de participantes regulares (I) do Ambulatório de Geriatria HC/FMUSP (Grupo '4S' - Idosos sem senilidade sistêmica sintomáticos), (II) da USP-Leste, (III) do Centro de Estudos e Projetos em Educação, Cidadania e Desenvolvimento Social (CEDEPS) e (IV) do Centro cultural Nipo-Brasileiro para seleção para participação no estudo. Os indivíduos foram convidados a integrar o estudo de acordo com os critérios de inclusão e exclusão, conforme segue:

\subsubsection{Critérios de inclusão}

$\checkmark \quad$ Idade entre 65 e 95 anos;

$\checkmark \quad$ Saúde geral preservada

$\checkmark$ Ambos os sexos;

$\checkmark \quad$ Concordância em participar do projeto, demonstrada por meio da assinatura do Termo de Consentimento Livre e Esclarecido (Anexo1).

\subsubsection{Critério de exclusão}

$\checkmark \quad$ Atletas;

$\checkmark \quad$ História de tabagismo atual ou prévio, independentemente de carga tabágica; 
$\checkmark \quad$ Portadores de doenças clínicas com repercussão funcional importante, tais como doenças cardíacas, pulmonares, renais, hepáticas ou neurológicas; $\checkmark \quad$ Portadores de condições ortopédicas que constituíssem fator limitante para o exercício em bicicleta ergométrica;

$\checkmark \quad$ Portadores de déficit cognitivo limitante para a realização dos testes funcionais;

$\checkmark$ Incapacidade de realização de testes de função pulmonar e cardiopulmonar de exercício que atingissem os requisitos de qualidade técnica estipulados;

$\checkmark \quad$ Uso de fármacos com ação cronotrópica negativa, tais como $\beta$ bloqueadores;

A presença de hipertensão arterial leve ou dislipidemia controlada com medicações regulares não constitui critério para exclusão de voluntários.

\subsection{Aprovação e registro da pesquisa}

O projeto foi aprovado pela comissão Científica do Hospital das Clinicas FMUSP e pela comissão de Ética para análise de Projetos de Pesquisa - CAPPesq (Número do protocolo 0142/08), como subprojeto de um estudo anterior já registrado no Conselho Nacional de Ética em pesquisa CONEP (CAAE - 0140.0.015.000-08) (Anexo 2). Os voluntários foram previamente informados sobre os objetivos do projeto e os procedimentos a serem realizados, assinaram o termo de consentimento livre e esclarecido (TCLE) (Anexo1) e, a seguir, foram incluídos no estudo. 


\subsection{Delineamento do estudo}

A seleção dos voluntários foi realizada a partir de uma triagem realizada por meio de ligação telefônica, em que eram convidados a participar do estudo e respondiam a um questionário de avaliação inicial (Anexo 3). Após passarem nesta primeira fase, os voluntários eram convidados a comparecer ao Laboratório de Função Pulmonar - InCor/FMUSP.

Em uma única visita, conforme fluxograma abaixo (Fig.7) eram coletados seus dados antropométricos e aplicado questionário de avaliação sobre nível de atividade física (Questionário de Baecke) (Anexo 4). Em seguida, era realizada prova de função pulmonar em repouso, incluindo espirometria, medidas dos volumes pulmonares estáticos e medida da difusão e, por fim, o teste cardiopulmonar de exercício máximo (TCPE) incremental limitado por sintomas.

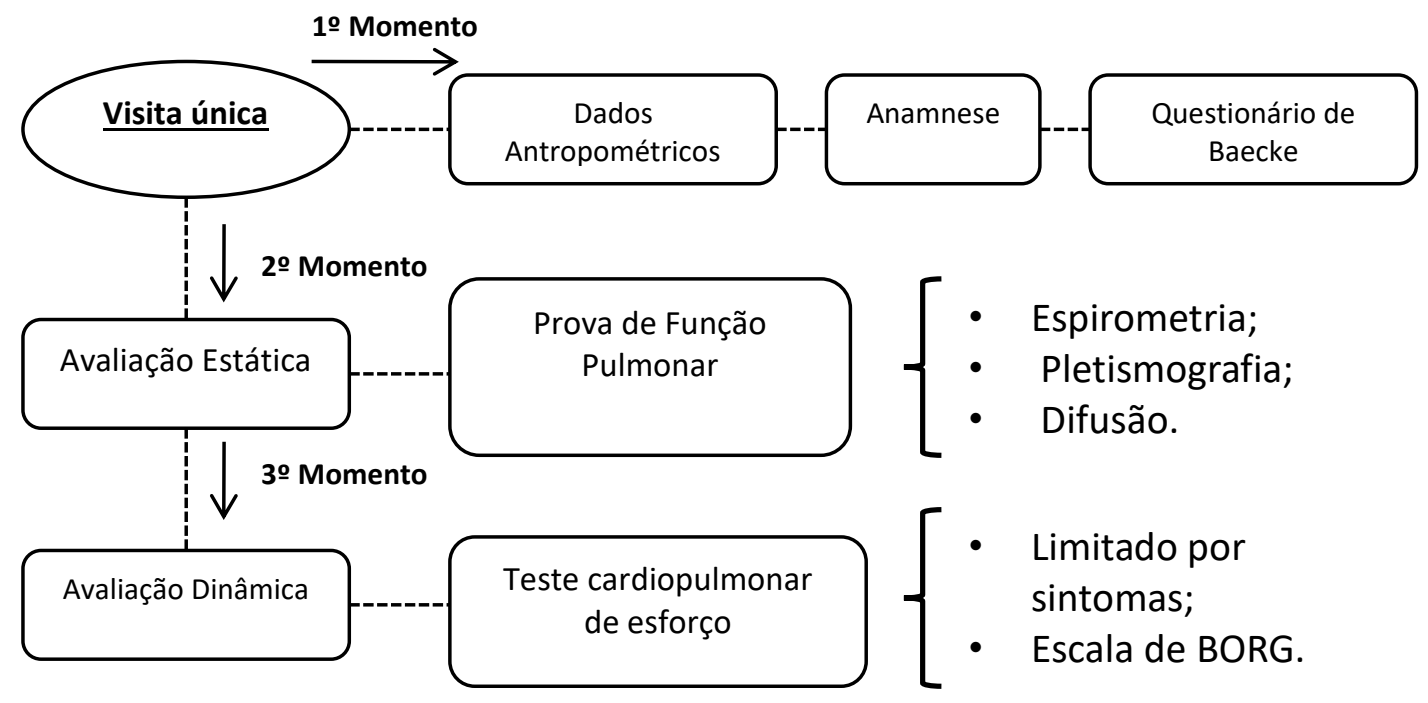

Fig.7. Fluxograma de avaliação e medidas funcionais

\subsection{Avaliações}

Todas as avaliações foram realizadas no período da manhã, no Laboratório de Função Pulmonar da Divisão de Pneumologia do Instituto do 
Coração do HC-FMUSP. Os testes foram realizados por profissionais treinados e capacitados. Vale ressaltar que os mesmos profissionais realizaram os exames durante toda a pesquisa, sem mudança de técnica de incentivo.

Orientações de preparo para os exames foi fornecida a todos os voluntários e consistiam em:

- Não ingerir café, chocolate ou refrigerante no dia do exame;

- Não comparecer em jejum;

-Quando pertinente, manter o uso de medicação anti-hipertensiva conforme prescrito;

- Utilizar vestimentas confortáveis, apropriadas para o exame de esforço na bicicleta;

- Utilizar calçados fechados e sem salto, preferencialmente tênis.

\subsubsection{Anamnese}

Foram realizados anamnese e exame físico sucinto para coletada de histórico de saúde do voluntário. Foram obtidos dados demográficos e antropométricos, incluindo informações como idade, sexo, peso, altura, além de antecedente de tabagismo, história pessoal e familiar de doenças, ausculta pulmonar e cardíaca.

\subsubsection{Avaliação do nível de atividade física}

Para a avaliação do nível da atividade física, utilizou-se o Questionário de Baecke ${ }^{(58)(59)(60)}$, que contempla informações sobre prática de atividade física nos últimos 12 meses, sendo composto por 16 questões subdivididas em três domínios: (I) atividades físicas ocupacionais (AFO), (II) exercícios físicos praticados durante o tempo de lazer (EFL) e (III) atividades de locomoção, excluindo exercícios físicos (ALL). O cálculo do Escore Total (ET) é obtido pela 
soma dos escores de AFO, EFL e ALL, podendo variar de 3 a 15 pontos, sendo que quanto maior a pontuação, maior seu nível de atividade física. Embora este questionário tenha sido delineado para ser autoaplicável, neste estudo ele foi realizado por intermédio do pesquisador principal.

\subsubsection{Espirometria forçada}

A espirometria foi realizada com o equipamento Elite Dx, Elite Series ${ }^{\mathrm{TM}}$ Plethysmograph - MedGraphics Cardiorespiratory Diagnostic Systems (Medical Graphics Corporation, St Paul, MN, USA). Em posição sentada, com clipe nasal e peça bucal acoplados, os indivíduos eram orientados a realizar inspiração máxima seguida de expiração forçada máxima e contínua por alguns segundos, até o esvaziamento completo dos pulmões. Por meio de um pneumotacógrafo eram obtidos sinais de fluxo, permitindo a determinação secundária dos volumes inspiratórios e expirados. Variáveis espirométricas convencionais como volume expiratório forçado do primeiro segundo $\left(\mathrm{VEF}_{1}\right)$, capacidade vital forçada $(\mathrm{CVF})$, relação $\mathrm{VEF}_{1} / \mathrm{CVF}$, pico de fluxo expiratório (PFE) e fluxos expiratórios intermediários eram obtidas. Os critérios de qualidade para aceitação dos testes foram alinhados às recomendações Sociedade Brasileira de Pneumologia e Tisiologia (SBPT) ${ }^{(27)}$. Resumidamente, as manobras deveriam ter início abrupto, sem hesitação, caracterizado por pico de fluxo nítido e precoce e volume retroextrapolado menor que 5\% da CVF (ou $150 \mathrm{ml}$ ), além de duração maior ou igual a 6 segundos e platô final de volume de 1 segundo, sem artefatos como tosse ou fechamento de glote. Eram obtidas pelo menos 3 curvas com estas características e com variação de CVF e VEF 1 menores que $150 \mathrm{ml}$ entre as 2 melhores. $O$ sensor de fluxo foi calibrado antes de cada exame, utilizando seringa apropriada para este fim. Posteriormente, os valores obtidos foram comparados com os valores previstos de acordo com Pereira ${ }^{(50)}$, NHANES III ${ }^{(47)}$ e GLI $_{2012}{ }^{(49)}$. 


\subsubsection{Pletismografia de corpo inteiro}

As medidas de volumes pulmonares foram realizadas no mesmo equipamento da espirometria, com a utilização, além do sensor de fluxo, da cabine pletismografia de volume constante e pressão variável. O indivíduo em posição sentada, no interior da cabine hermeticamente fechada, narinas vedadas com clipe nasal mãos apoiadas ao rosto para sustentar as bochechas e assoalho da boca, respira por alguns ciclos em volume corrente e é solicitado para realizar manobra de arquejamento (respiração rápida e superficial) contra o bucal do circuito fechado, realizando movimentos inspiratórios e expiratórios curtos e alternados com frequência entre 30 e 60 ciclos por segundo, por cerca de 3 segundos ${ }^{(61)}$. Durante esta manobra, são registradas simultaneamente as variações de pressão na cabine e na via aérea proximal (boca). A correlação entre estas oscilações de pressão permite a determinação do volume gasoso torácico (VTG), que corresponde à capacidade residual funcional (CRF). Em seguida, imediatamente após a abertura do obturador, é realizada manobra de inspiração máxima sucedida por expiração não forçada, até o esvaziamento completo dos pulmões. Esta manobra permite a determinação da capacidade vital lenta $(C V L)$, do volume de reserva expiratório (VRE) e da capacidade inspiratória $(\mathrm{CI})$. Foram reportadas a média de 3 manobras de VTG com variabilidade inferior a $5 \%$ e o maior valor de CVL, desde que a diferença para o segundo maior valor fosse inferior a $200 \mathrm{ml}$. A combinação das duas manobras permite a determinação da capacidade pulmonar total e do volume residual, conforme abaixo:

$$
\begin{aligned}
& \mathrm{CPT}=\mathrm{CRF}+\mathrm{Cl}(1) \\
& \mathrm{VR}=\mathrm{CPT}-\mathrm{CVL}(2)
\end{aligned}
$$

Os parâmetros obtidos foram registrados e posteriormente comparados com os valores previstos de acordo com equações disponíveis na literatura: Crapo et al ${ }^{(48)}$, ECCS ${ }^{(46)}$, Neder et al ${ }^{(51)}$. 


\subsubsection{Capacidade de difusão de monóxido de carbono (DLco)}

A determinação da difusão de monóxido de carbono (DLco) foi realizada pela técnica do monóxido de carbono em respiração única, de acordo com Ogilvie e com as modificações de Jones-Mead. Foi utilizado o mesmo equipamento Elite $D x$, Elite Series TM Plethysmograph - MedGraphics Cardiorespiratory Diagnostic Systems (Medical Graphics Corporation, INC, 2005, St Paul, MN, USA), que contém módulo de análise de gases por cromatografia gasosa e utiliza Neônio com traçador. O indivíduo conectado ao sistema por peça bucal e com narinas vedadas por clipe, realiza expiração máxima, seguida de inspiração máxima em que inala a mistura gasosa teste, contento $\mathrm{CO}(0,3 \%)$ e $\mathrm{Ne}(0,5 \%)$. Após pausa inspiratória de cerca de 10 segundos, o indivíduo exala o ar dos pulmões, sendo colhida amostra do gás alveolar (uma vez descartado volume suficiente para lavagem do espaço morto), que terá suas concentrações de $\mathrm{CO}$ e $\mathrm{Ne}$ determinadas, permitindo o cálculo da DLco. Foram realizadas pelo menos 2 manobras para cada indivíduo, com intervalo entre elas igual ou superior a 4 minutos, tendo sido reportada a média de pelo menos 2 medidas com diferença menor que 3 unidades ou $10 \%{ }^{(27)}$.

Assim como para os demais parâmetros mensurados, os valores obtidos foram comparados com aqueles esperados de acordo com equações de referência selecionadas (Crapo et al ${ }^{(48)}$, ECCS ${ }^{(46)}$, Neder et al ${ }^{(52)}$ ).

\subsubsection{Teste de exercício cardiopulmonar máximo incremental através de cicloergômetro}

Para avaliação das respostas dinâmicas ao esforço, foi realizado TCPE incremental em cicloergômetro (Corival - Lode B. V. Medical Technology, 
Groningen, The Netherlands). Os parâmetros metabólicos e de trocas gasosas foram determinados com utilização de equipamento CardiO2 (CPX/D MedGraphics Corporation - MGC - St Paul, MN, USA, 2005), composto por um analisador de Gases (Gas Module CE), acoplado a um pneumotacógrafo, que realiza leitura do fluxo (Flow Module CE), tudo conectado a um microprocessador, que integra os sinais colhido simultaneamente. A calibração do equipamento foi realizada antes de cada exame ${ }^{(28)}$ (12). O registro do traçado eletrocardiográfico foi obtido com ECG de 12 derivações (Cardio PerfecT PC-Based 12 Lead ECG, Welch Allyn, INC. Skaneateles Falls, NY, USA). Para coleta da amostra de gás exalado, foi utilizada interface com peça bucal com baixo volume de espaço morto $(20 \mathrm{ml})$, conectada ao módulo de gases por meio de uma linha de amostra acoplada em saída lateral. Foi monitorizada a oximetria de pulso de forma contínua, utilizando o equipamento Onyx (Model 9500- Nonin Medical Inc,Plymouth-MN, USA).

Após o preparo do equipamento e da instalação de todos os sensores de medição, o voluntário permanecia sentado no cicloergômetro durante 2 minutos em repouso, para coleta dos dados na condição basal. Em seguida, iniciava o exercício com movimentação dos pedais sem carga ("freewheel") por mais 2 minutos, sendo a partir de então aplicado incremento linear de carga na taxa de $15 \mathrm{~W} /$ minuto, até o limite de tolerância do indivíduo. Durante o exercício, a rotação do pedal deveria permanecer na frequência de 50 a 60 rotações por minuto (rpm). O objetivo era obter um teste com duração aproximada de 10 minutos. Após a manifestação de exaustão, a carga era retirada e ainda eram registrados mais 2 a 4 minutos da fase de recuperação (Fig.8).

Além da exaustão referida pelo voluntário, os seguintes critérios foram estabelecidos para interrupção do teste: (I) queda de SpO2 abaixo de $88 \%$, (II) pressão hipertensão arterial sistólica (PAS) acima $220 \mathrm{mmHg}$, (III) pressão arterial diastólica (PAD) acima de $120 \mathrm{mmHg}$, (IV) arritmias cardíacas previamente inexistentes, (V) tontura ou síncope, (VI) dor precordial, (VII) náuseas ou ainda (VIII) incapacidade de manter as rotações necessárias para a avaliação. 


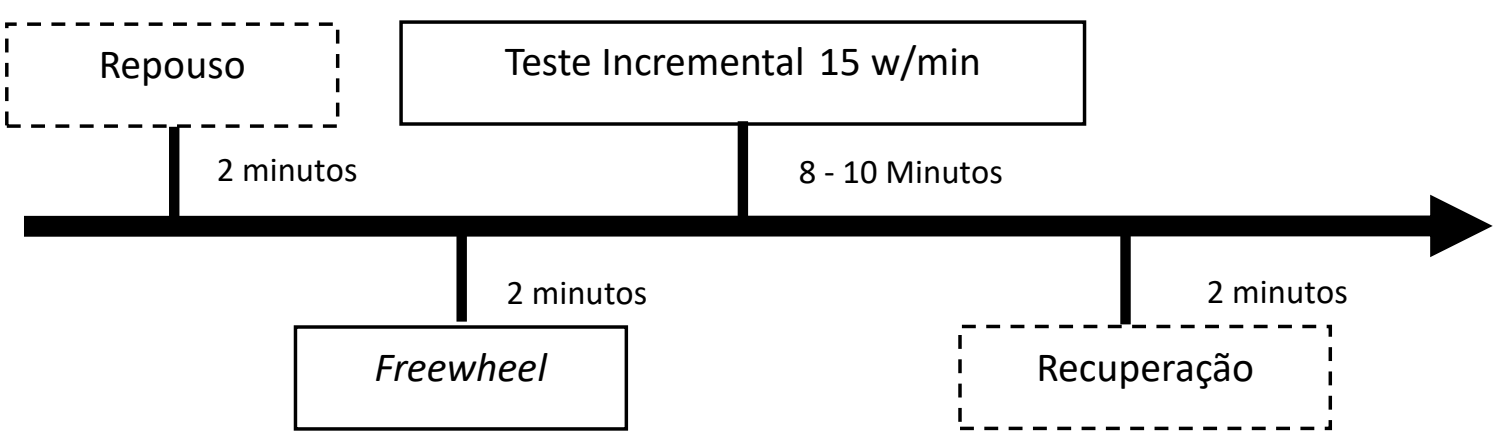

Fig.8- Esquema ilustrativo das fases de avaliação dinâmica durante o TCPE.

As variáveis respiratórias, metabólicas e cardiovasculares foram obtidas, incluindo: consumo de oxigênio (VO2), produção de gás carbônico (VCO2), quociente respiratório (RER), volume corrente (Vt), frequência respiratória $(\mathrm{Fr})$, ventilação minuto $(\mathrm{VE})$, frequência cardíaca $(\mathrm{FC})$ e pulso $\mathrm{O} 2$ $\left(\mathrm{VO}_{2} / \mathrm{FC}\right)$.

Os resultados de VO2 e carga no pico do esforço foram comparados com os valores esperados de acordo com equações de referência disponíveis na literatura: Neder et al, ${ }^{(55)}$, Blackie et al, ${ }^{(53)}$, Jones et al, e ${ }^{(54)}$, Wasserman et al ${ }^{(62)}$.

\subsubsection{Avaliação de dispneia e fadiga em membros inferiores}

A intensidade de dispneia e fadiga de membros inferiores foram avaliadas no repouso, a cada 2 minutos durante o esforço e no ato da interrupção do exercício, utilizando a Escala de Borg modificada (Fig.9). 


\begin{tabular}{|cc|}
\hline 0 & Nenhuma \\
0,5 & Muito, muito leve \\
1 & Muito leve \\
2 & Leve \\
3 & Moderada \\
4 & Pouco intensa \\
5 & Intensa \\
6 & \\
7 & Muito intensa \\
8 & \\
9 & Muito, muito intensa \\
10 & Máxima \\
\hline
\end{tabular}

Fig.9- Escala de Borg Modificada

\subsection{Análise estatística}

Foi considerado para o estudo amostra de conveniência, em razão disso não realizamos calculo de tamanho amostral. Os dados foram apresentados como média e desvio padrão (DP) para as variáveis que tiveram distribuição normal, definidas pelo teste de Kolmogorov-Smirnov. Os dados foram analisados em grupos separados por sexo. Os valores dos parâmetros funcionais obtidos na amostra de idosos saudáveis foram comparados com aqueles esperados de acordo com equações de referência pertinentes, selecionadas para cada parâmetro. Esta comparação foi realizada por meio de teste $\mathrm{T}$ de Student de amostras em pares, uma vez que todos os parâmetros apresentaram distribuição normal. Foi ainda utilizada técnica de Bland-Altman para avaliar a concordância entre os valores observados e esperados de acordo com as diversas equações de referência. $E$ para derivação das equações foram realizadas regressões lineares múltiplas para os principais parâmetros das variáveis de espirometria, volumes pulmonares, difusão e para dois parâmetros do TCPE. A análise estatística foi realizada utilizando-se o software SPSS versão 21.0.1 (IBM SPSS Statistics, Armonk, NY, EUA).

Os parâmetros observados na amostra de idosos foram classificados de acordo com as faixas de referências previstas e a proporção de alterações (frequência de casos fora da faixa de referência) foi determinada. $O$ intervalo 
de confiança da frequência de casos alterados foi calculado utilizando ferramenta estatística disponível no endereço eletrônico: www.vassarstats.net/propl.html.

O nível de significância adotado foi de $5 \%(p<0,05)$. 
5. Resultados 


\subsection{Casuística e características gerais}

Os voluntários saudáveis foram recrutados a partir dos centros de atenção à saúde com os quais foram acordadas parcerias. Todos os indivíduos que não apresentavam nenhum critério de exclusão foram convidados a participar do estudo, que teve início em abril de 2013.

Foram identificados 216 indivíduos elegíveis. Destes, 120 (52 homens e 75 mulheres) foram excluídos por diversas causas: recusa ou desinteresse em participar, dados de cadastro desatualizados da instituição, tabagistas ou ex-tabagistas, portadores de enfermidade limitante ao estudo, utilização de medicamentos $\beta$-bloqueadores. Assim, foram efetivamente recrutados 96 indivíduos (40 homens e 56 mulheres), que compareceram ao laboratório e foram submetidos aos procedimentos de avaliação. Posteriormente, foi excluída mais uma mulher, por não ter conseguido realizar adequadamente os testes de funcionais. Foram incluídos, portanto, 95 indivíduos (40 homens e 55 mulheres). Deste grupo, apenas 5 (1 homem e 4 mulheres) não tiveram analisados os dados de exercício por não manterem a rotação do pedal ou por necessitarem interromper precocemente por pico hipertensivo (Fig.10).

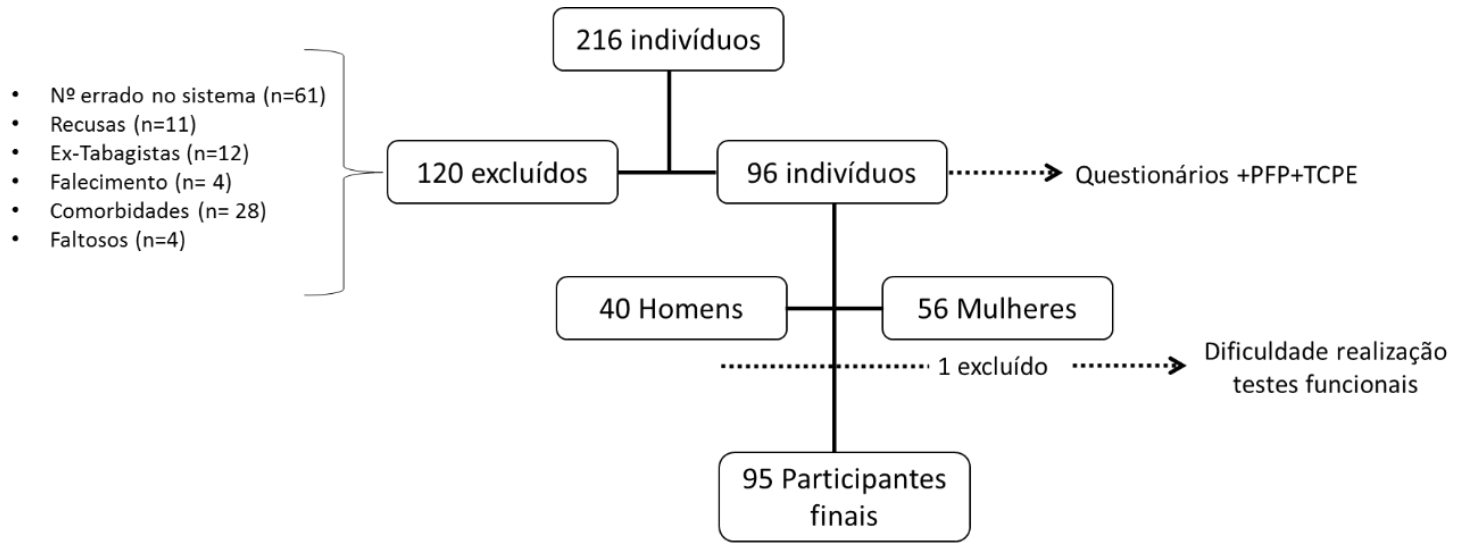

Fig.10. Fluxograma representativo do número de participantes recrutados para o presente estudo. 


\subsection{Caracterização da amostra}

As características demográficas dos indivíduos estudados estão na Tabela 1. Algumas características corroboram a representatividade da amostra como indivíduos saudáveis. O índice de Massa Corpórea (IMC) médio ficou na transição entre normal e sobrepeso para ambos os sexos. A prevalência de uso de medicamentos contínuos foi baixa, sobretudo considerando-se a média de idade dos grupos, e incluiu anti-hipertensivos, protetores gástricos e anticolesterolêmicos.

Os dados de função pulmonar em repouso, incluindo espirometria, volumes e difusão, estão representados na Tabela 2, enquanto os dados funcionais do pico do exercício obtidos pelo TCPE estão mostrados na Tabela 3.

No gráfico 1, teremos a distribuição em histograma por idades subdivididas em extratos de quinquênios de idades para ambos os sexos.

Tabela 1 - Caracterização demográfica dos indivíduos.

\begin{tabular}{|c|c|c|}
\hline Dados Demográficos & Masculino ( $n=40)$ & Feminino $(n=55)$ \\
\hline Idade (anos) & $74 \pm 6$ & $75,3 \pm 6$ \\
\hline Altura $(\mathrm{cm})$ & $167 \pm 6$ & $153 \pm 5,4$ \\
\hline Peso (kg) & $71 \pm 11$ & $61,3 \pm 11$ \\
\hline IMC $\left(\mathrm{kg} / \mathrm{m}^{2}\right)$ & $25,3 \pm 3,3$ & $26,2 \pm 4,4$ \\
\hline Questionário de Baecke & $8,08 \pm 1,23$ & $8,15 \pm 0,96$ \\
\hline Uso Medicações (proporção e IC 95\%) & $22,5 \%(12 \%-37 \%)$ & $25 \%(15,5 \%-37,6 \%)$ \\
\hline
\end{tabular}

Dados expressos em média \pm desvio padrão e em frequência. IMC: Índice de massa corporal; Baecke: Questionário que avalia atividade física habitual.

* Medicações referidas: protetor gástrico, anti-hipertensivos e anticolesterolêmicos. 
Tabela 2 - Média e desvio padrão dos valores absolutos da função pulmonar: espirometria, volumes pulmonares e difusão de ambos os sexos.

\begin{tabular}{|c|c|c|}
\hline & Masculino $(n=40)$ & Feminino $(n=55)$ \\
\hline CVF (L) & $3,73 \pm 0,66$ & $2,52 \pm 0,37$ \\
\hline VEF1 (L) & $2,73 \pm 0,47$ & $1,95 \pm 0,33$ \\
\hline VEF1/CVF & $0,73 \pm 0,06$ & $0,77 \pm 0,05$ \\
\hline FEF $25-75$ (L/s) & $2,10 \pm 0,72$ & $1,75 \pm 0,59$ \\
\hline FEF máximo (L/s) & $7,11 \pm 1,8$ & $4,96 \pm 1,26$ \\
\hline VVM (L/ min) & $111,5 \pm 31$ & $80 \pm 17,8$ \\
\hline CVL (L) & $3,82 \pm 0,66$ & $2,60 \pm 0,38$ \\
\hline $\mathrm{Cl}(\mathrm{L})$ & $2,57 \pm 0,43$ & $1,94 \pm 0,45$ \\
\hline CRF (L) & $3,95 \pm 0,77$ & $2,85 \pm 0,55$ \\
\hline CPT (L) & $6,45 \pm 0,95$ & $4,86 \pm 0,84$ \\
\hline $\operatorname{VR}(\mathrm{L})$ & $2,69 \pm 0,59$ & $2,30 \pm 0,74$ \\
\hline $\operatorname{Raw}\left(\mathrm{cmH}_{2} \mathrm{O} / \mathrm{L} / \mathrm{s}\right)$ & $1,49 \pm 0,76$ & $2,08 \pm 0,90$ \\
\hline $\mathrm{sGaw}\left(1 / \mathrm{cmH}_{2} \mathrm{O}^{* \mathrm{~s}}\right)$ & $0,24 \pm 0,29$ & $0,19 \pm 0,07$ \\
\hline $\mathrm{DL}_{\mathrm{CO}}(\mathrm{mL} / \mathrm{min} \cdot \mathrm{mmHg})$ & $25,36 \pm 5,9 d(t)$ & $\left.17,65 \pm 3,3^{*}\right)$ \\
\hline
\end{tabular}

Dados foram expressos em média \pm desvio padrão.

CVF: Capacidade vital forçada; VEF1: Volume expiratório no primeiro segundo; CPT: Capacidade Pulmonar Total; VR: Volume residual; $\mathrm{DL}_{\mathrm{CO}}$ : Difusão de monóxido de carbono.

Participantes: $n=40$ e $n=55$ para todos os parâmetros, exceto para $D L_{c o}$ onde $(t) n=36$ (masculino) e $\left(^{*}\right) n=53$ (feminino). 
Tabela 3 - Média e desvio padrão dos valores absolutos do Teste cardiopulmonar de esforço (TCPE): parâmetros funcionais no pico do esforço de ambos os sexos.

\begin{tabular}{c|cc}
\hline & Masculino $(\boldsymbol{n}=40)$ & Feminino $(\boldsymbol{n}=55)$ \\
\hline Carga (w) & $108,5 \pm 51$ & $69,16 \pm 0,21$ \\
$\mathrm{VO}_{2}$ (mL/min) & $1324,8 \pm 318,1$ & $890,78 \pm 212,7$ \\
$\mathrm{VO}_{2}$ (mL/kg.min) & $18,86 \pm 4,1$ & $14,67 \pm 3,2$ \\
$\mathrm{VCO}_{2}$ (mL/kg) & $15559,15 \pm 413,63$ & $1064,6 \pm 304,4$ \\
$\mathrm{VE}(\mathrm{L} / \mathrm{min})$ & $55,74 \pm 15,21$ & $37,56 \pm 10,22$ \\
$\mathrm{FR}$ (irpm) & $31,79 \pm 5,6$ & $35,35 \pm 10,85$ \\
$\mathrm{SpO}(\%)$ & $95,57 \pm 2,97$ & $96,01 \pm 2,45$ \\
RER & $1,18 \pm 0,13$ & $1,18 \pm 0,16$ \\
FC (bpm) & $130,73 \pm 19,47$ & $128,59 \pm 21,41$ \\
Pulso O $_{2}$ (mL/bpm) & $9,98 \pm 2$ & $7,16 \pm 2,15$ \\
Borg MMII & $4,46 \pm 2,51$ & $3,15 \pm 2,69$ \\
Borg Dispnéia & $2,46 \pm 2,10$ & $1,81 \pm 2,14$ \\
\hline
\end{tabular}

Dados expressos em média \pm desvio padrão.

$\mathrm{VO}_{2}$ : Consumo de oxigênio; $\mathrm{VCO}_{2}$ : Produção de gás carbônico; VE: Ventilação minuto; RER: Quociente Respiratório; FC: Frequência cardíaca; FR: Frequência respiratória; $\mathrm{SpO}_{2}$ : Saturação periférica de oxigênio; Pulso $\mathrm{O}_{2}$ : Consumo de oxigênio por frequência cardíaca; Borg: Escala modificada de percepção de cansaço em membros inferiores e dispneia.

\section{Gráfico 1- Histograma de distribuição das idades entre os grupos}
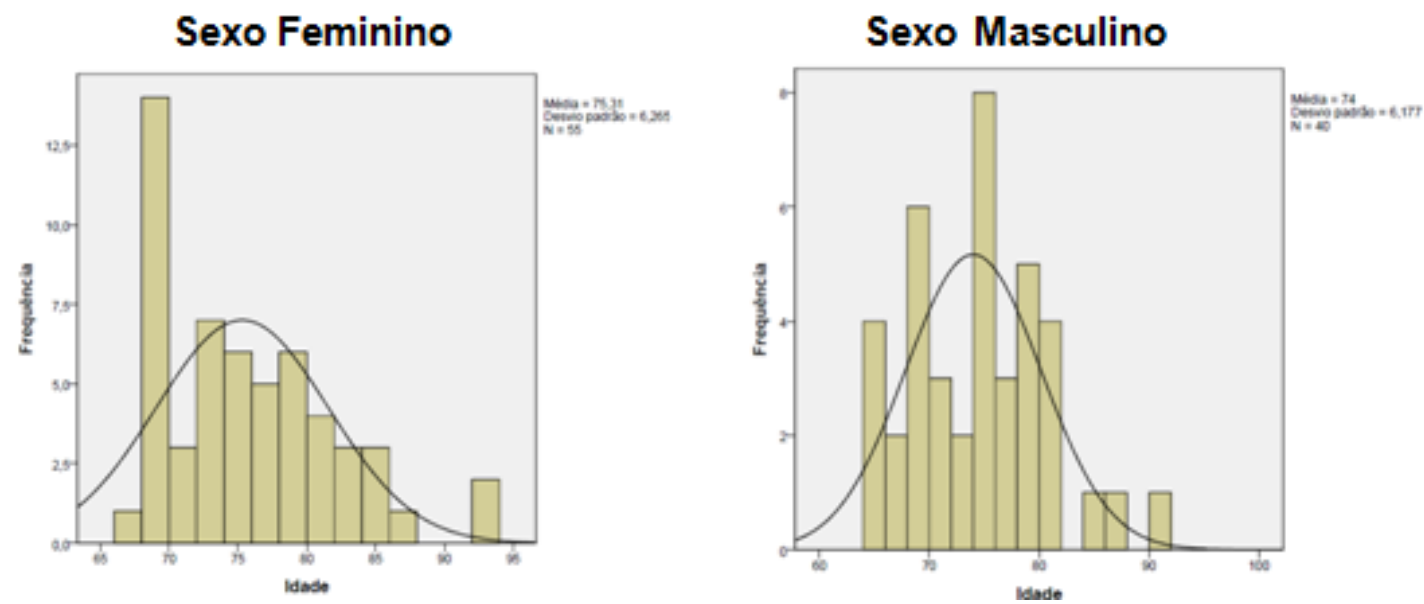


\subsection{Comparação entre os dados observados e equações de referência selecionadas: espirometria}

Para a avaliação dos dados espirométricos, foram selecionadas as equações de Pereira 2007, por representar equação robusta derivada para a população brasileira, as equações do National Health and Nutrition Survey (NHANES III) de 1999, recomendada para a população americana branca e as equações da Global Lung Initiative (GLI) de 2012, propostas pela European Respiratory Society como equações multiétnicas globais. Os resultados da comparação entre os resultados observados e esperados para os parâmetros espirométricos estão apresentados na Tabela 4 (para o sexo feminino) e na Tabela 5 (sexo masculino).

A comparação para o sexo feminino sugere ausência de diferença significativa entre os valores obtidos e os previstos por Pereira para CVF, VEF 1 e relação $V E F_{1} / C V F$, sendo este conjunto de equações o que apresentou melhor aderência. Em relação às equações NHANES III e $\mathrm{GLI}_{2012}$, foram caracterizadas diferenças significativas para CVF e VEF1 entre os valores observados e previstos. Não foi evidenciada diferença para a relação $\mathrm{VEF}_{1} / \mathrm{CVF}$ em relação ao previsto por $\mathrm{GLI}_{2012}$. 
Tabela 4 - Espirometria: comparação entre os parâmetros observados e derivados das equações de referência selecionadas para sexo feminino

\begin{tabular}{c|ccc}
\hline Teste Tstudent. Sexo feminino & Diferença (Média $\pm D P$ ) & IC 95\% & $p$ \\
\hline CVF Observada - Pereira (L) & $0,05 \pm 0,31$ & $(-0,03-0,14)$ & 0,235 \\
CVF Observada - NHANES (L) & $0,18 \pm 0,32$ & $(0,10-0,27)$ & $<0,001$ \\
\hline CVF Observada - GLI (L) & $0,17 \pm 0,30$ & $(0,09-0,25)$ & $<0,001$ \\
& & & \\
VEF1 Observada - Pereira (L) & $0,037 \pm 0,29$ & $(-0,042-0,11)$ & 0,353 \\
VEF1 Observada - NHANES (L) & $0,21 \pm 0,30$ & $(0,128-0,29)$ & $<0,001$ \\
VEF1 Observada - GLI (L) & $0,13 \pm 0,28$ & $(0,061-0,21)$ & 0,001 \\
& & & \\
VEF1/CVF Observada - Pereira & $-0,008 \pm 0,049$ & $(-0,021-0,006)$ & 0,253 \\
\hline VEF1/CVF Observada - NHANES & $0,026 \pm 0,05$ & $(0,012-0,040)$ & $<0,001$ \\
VEF1/CVF Observada - GLI & $-0,007 \pm 0,04$ & $(-0,020-0,007)$ & 0,316 \\
\hline
\end{tabular}

Teste $t$ Student de amostra em pares. Dados foram expressos em média \pm desvio padrão IC95\%: Intervalo de confiança de 95\%; p: nível de significância.

CVF: capacidade vital forçada; $\mathrm{VEF}_{1}$ : volume expiratório forçado do $1^{\circ}$ segundo.

Já para o sexo masculino, as equações de Pereira tendem a superestimar os valores de CVF e mais consistentemente de $\mathrm{VEF}_{1}$. Os valores previstos por NHANES III também não foram aderentes à amostra estudada. Somente o $\mathrm{VEF}_{1}$ determinado pela equação da GLI estimou adequadamente os valores obtidos no presente estudo. 
Tabela 5 - Espirometria: comparação entre os parâmetros observados e derivados das equações de referência selecionadas para o sexo masculino

\begin{tabular}{c|ccc}
\hline Teste T student. Sexo masculino & Diferença (Média \pm DP) & IC 95\% & $p$ \\
\hline CVF Observada - Pereira (L) & $-0,19 \pm 0,54$ & $(-0,36-0,01)$ & 0,031 \\
\hline CVF Observada - NHANES (L) & $0,14 \pm 0,53$ & $(-0,02-0,32)$ & 0,086 \\
CVF Observada - GLI (L) & $0,18 \pm 0,53$ & $(0,01-0,35)$ & 0,035 \\
& & & \\
VEF1 Observada - Pereira (L) & $-0,25 \pm 0,38$ & $(-0,37--0,13)$ & 0,000 \\
VEF1 Observada - NHANES (L) & $0,15 \pm 0,40$ & $(0,02-0,28)$ & 0,019 \\
VEF1 Observada - GLI (L) & $0,04 \pm 0,38$ & $(-0,07-0,17)$ & 0,423 \\
& & & $(-0,04-0,007)$ \\
VEF1/CVF Observada - Pereira & $-0,02 \pm 0,06$ & $(-0,01-0,02)$ & 0,008 \\
VEF1/CVF Observada - NHANES & $0,008 \pm 0,06$ & 0,386 \\
\hline VEF1/CVV Observada - GL & $-0,025 \pm 0,06$ & $(-0,04--0,005)$ & 0,012 \\
\hline
\end{tabular}

Teste $t$ Student de amostra em pares. Dados foram expressos em média \pm desvio padrão IC95\%: Intervalo de confiança de 95\%; p: nível de significância.

CVF: capacidade vital forçada; $V_{E F}$ : volume expiratório forçado do $1^{\circ} \stackrel{\text { segundo. }}{ }$

\subsection{Comparação entre os dados observados e equações de referência selecionadas: volumes pulmonares e difusão}

Foram selecionadas as equações de Neder e cols (1999), Crapo e da European Community for Coal and Steel (ECCS) de 1993 para avaliação dos volumes pulmonares estáticos e difusão. Trata-se de equações amplamente utilizadas, sendo uma delas (Neder 1999) derivada de amostra brasileira. Os dados comparativos para o sexo feminino e masculino estão apresentados nas Tabelas 6 e 7 respectivamente.

No caso do sexo feminino, a discrepância foi significativa para todos os autores comparados, tanto para os volumes pulmonares quanto para difusão. Já para o sexo masculino, houve aderência em relação à CPT para as 2 equações estudadas, porém o mesmo não ocorreu em relação às estimativas de CRF e, para o VR, apenas ECCS (VR) não apresentou diferença significativa. Quanto às estimativas de difusão, nenhuma das equações estudadas apresentou acurácia na predição dos dados derivados da amostra 
do presente estudo. Destaca-se que as diferenças entre as médias da amostra e prevista pelos autores foi de magnitude expressiva para diversos parâmetros funcionais analisados, remetendo à elevada probabilidade de impacto clínico significativo quando da utilização destes dados para finalidade diagnóstica.

Tabela 6 - Volumes pulmonares e difusão: comparação entre os parâmetros observados e derivados das equações de referência selecionadas para o sexo feminino

\begin{tabular}{|c|c|c|c|}
\hline Teste Tstudent. Sexo feminino & Diferença (Média $\pm D P$ ) & IC $95 \%$ & $p$ \\
\hline CPT Observada - Neder (L) & $0,430 \pm 0,76$ & $(0,22-0,63)$ & $<0,001$ \\
\hline CPT Observada - Crapo (L) & $0,375 \pm 075$ & $(0,17-0,58)$ & 0,001 \\
\hline CPT Observada - ECCS (L) & $0,556 \pm 0,75$ & $(0,35-0,76)$ & $<0,001$ \\
\hline VR Observado - Neder (L) & $0,807 \pm 0,69$ & $(0,62-0,99)$ & $<0,001$ \\
\hline VR Observado - Crapo (L) & $0,198 \pm 0,68$ & $(0,01-0,38)$ & 0,037 \\
\hline VR Observado - ECCS (L) & $0,553 \pm 0,75$ & $(0,35-0,75)$ & $<0,001$ \\
\hline CRF Observado - Neder (L) & $-0,025 \pm 0,53$ & $(-0,17-0,12)$ & 0,731 \\
\hline CRF Obervado - Crapo (L) & $0,30 \pm 0,52$ & $(0,15-0,44)$ & 0,000 \\
\hline CRF Obersvado - ECCS (L) & $-0,38 \pm 0,53$ & $(-0,52--0,24)$ & 0,000 \\
\hline DLco Obs - Neder ( $\mathrm{mL} / \mathrm{min} . \mathrm{mmHg})$ & $-4,47 \pm 2,88$ & $(-5,28--3,67)$ & $<0,001$ \\
\hline DLco Obs - Crapo (mL/min.mmHg) & $-2,33 \pm 2,76$ & $(-3,10--1,56)$ & $<0,001$ \\
\hline DLco Obs - ECCS (mL/min.mmHg) & $-6,00 \pm 2,75$ & {$[-6,77--5,23]$} & $<0,001$ \\
\hline
\end{tabular}

Teste $t$ Student de amostra em pares. Dados foram expressos em média \pm desvio padrão IC95\%: Intervalo de confiança de 95\%; p: nível de significância.

CPT: capacidade pulmonar total; VR: volume residual; $\mathrm{DL}_{\mathrm{CO}}$ : difusão. 
Tabela 7 - Volumes pulmonares e difusão: comparação entre os parâmetros observados e derivados das equações de referência selecionadas para o sexo masculino.

\begin{tabular}{c|ccc}
\hline Teste Tstudent. Sexo masculino & Diferença (Média \pm DP) & IC 95\% & $p$ \\
\hline CPT Observada - Neder (L) & $-0,032 \pm 0,96$ & $(-0,34-0,27)$ & 0,832 \\
\hline CPT Observada - Crapo (L) & $0,264 \pm 0,89$ & $(-0,02-0,55)$ & 0,071 \\
\hline CPT Observada - ECCS (L) & $0,903 \pm 0,89$ & $(0,61-1,19)$ & 0,000 \\
& & & \\
VR Observado - Neder (L) & $0,438 \pm 0,56$ & $(0,25-0,62)$ & 0,000 \\
VR Observado - Crapo (L) & $0,393 \pm 0,55$ & $(0,21-0,57)$ & 0,000 \\
VR Observado - ECCS (L) & $0,107 \pm 0,55$ & $(-0,07-0,28)$ & 0,232 \\
& & & \\
& & & 0,013 \\
CRF Observado - Neder (L) & $0,298 \pm 0,72$ & $(0,06-0,53)$ & 0,000 \\
\hline CRF Obervado - Crapo (L) & $0,531 \pm 0,70$ & $(0,30--0,75)$ & 0,050 \\
CRF Obersvado - ECCS (L) & $0,234 \pm 0,73$ & $(0,00-0,46)$ & \\
& & & 0,000 \\
\hline DLco Obs - Neder (mL/min.mmHg) & $-5,38 \pm 4,86$ & $(-7,02--3,73)$ & 0,050 \\
\hline DLco Obs - Crapo (mL/min.mmHg) & $-1,56 \pm 4,61$ & $(-3,12--0,002)$ & 0,003 \\
\hline DLco Obs - ECCS (mL/min.mmHg) & $2,50 \pm 4,72$ & $(0,91-4,10)$ & $0,0$. \\
\hline
\end{tabular}

Teste $t$ Student de amostra em pares. Dados foram expressos em média \pm desvio padrão IC95\%: Intervalo de confiança de 95\%; p: nível de significância.

CPT: capacidade pulmonar total; VR: volume residual; $\mathrm{DL}_{\mathrm{CO}}$ : difusão.

\subsection{Comparação entre os dados observados e equações de referência selecionadas: teste cardiopulmonar de exercício}

A seguir são apresentados dados funcionais de esforço. Preliminarmente foram analisados os dados do pico do esforço, especificamente a carga e consumo de oxigênio. Foram selecionadas equações de referência para comparação, de acordo com dados disponíveis na literatura derivados de estudos que utilizaram cicloergômetro. Os dados para o sexo feminino estão representados na Tabela 8 e para o sexo masculino na Tabela 9. 
Observa-se que a maioria das equações falhou em predizer os resultados observados na presente amostra. Para o sexo feminino, caracterizase aderência apenas em relação à equação de Blackie et al, para a carga máxima prevista e de Neder et al, para o consumo máximo de oxigênio. Já para o sexo masculino, a carga máxima prevista por Wasserman et al e o $\mathrm{VO}_{2}$ máximo previsto por Jones et al, mostrou-se aderentes, não ocorrendo o mesmo com os demais autores comparados.

Tabela 8 - Teste cardiopulmonar de esforço: comparação entre os parâmetros observados no pico do esforço com as equações de referência selecionadas para o sexo feminino.

\begin{tabular}{c|ccc}
\hline Teste Tstudent. Sexo feminino & Diferença (Média $\pm D P$ ) & IC 95\% & $p$ \\
\hline Carga pico Observada - Neder (W) & $-16,62 \pm 19,3$ & $(-22,06--11,18)$ & 0,000 \\
Carga pico Observada - Blackie (W) & $-2,07 \pm 19,3$ & $(-7,50-3,35)$ & 0,447 \\
\hline Carga pico Observada - Jones (W) & $-12,32 \pm 20,7$ & $(-18,17--6,47)$ & 0,000 \\
\hline Carga pico Observada - Wasserman (W) & $-62,2 \pm 26,4$ & $(-69,7--54,8)$ & 0,000 \\
\hline & & & \\
& & & \\
VO2pico Observada - Neder (mL/min) & $-37,05 \pm 162$ & $(-82,80-8,70)$ & 0,110 \\
VO2pico Observada - Blackie (mL/min) & $-1654,57 \pm 170$ & $(-1702,40--1606,64)$ & 0,000 \\
VO2pico Observada - Jones (mL/min) & $76,39 \pm 204$ & $(19,01-133,76)$ & 0,010 \\
\hline Vo2pico Observada - Wasserman (mL/min) & $398,3 \pm 192,6$ & $(344,07-452,6)$ & 0,000 \\
\hline
\end{tabular}

Teste $t$ Student de amostra em pares. Dados foram expressos em média \pm desvio padrão IC95\%: Intervalo de confiança de 95\%; p: nível de significância.

$\mathrm{VO}_{2}$ : consumo de oxigênio 
Tabela 9 - Teste cardiopulmonar de esforço: comparação entre os parâmetros observados no pico do esforço com as equações de referência selecionadas para o sexo masculino.

\begin{tabular}{c|ccc}
\hline Teste Tstudent. Sexo masculino & Diferença (Média \pm DP) & IC 95\% & $p$ \\
\hline Carga pico Observada - Neder (W) & $13,10 \pm 28,92$ & $(3,72-22,47)$ & 0,007 \\
\hline Carga pico Observada - Blackie (W) & $-20,02 \pm 27,7$ & $(-29,01--11,03)$ & 0,000 \\
\hline Carga pico Observada - Jones (W) & $-16,42 \pm 30,20$ & $(-26,21--6,62)$ & 0,002 \\
\hline Carga pico Observada - Wasserman (W) & $2,91 \pm 28,7$ & $(-6,39-12,21)$ & 0,531 \\
& & & \\
& & & \\
VO2pico Observada - Neder (mL/min) & $-89,88 \pm 280,1$ & $(-180,69-0,91)$ & 0,052 \\
\hline VO2pico Observada - Blackie (mL/min) & $-576,4 \pm 309,8$ & $(-676,86--475,97)$ & 0,000 \\
VO2pico Observada - Jones (mL/min) & $-64,66 \pm 435,3$ & $(-205,7-76,44)$ & 0,359 \\
\hline VO2pico Observada - Wasserman (mL/min) & $-306,4 \pm 311$ & $(-306,4-311,03)$ & 0,000 \\
\hline
\end{tabular}

Teste $t$ Student de amostra em pares. Dados foram expressos em média \pm desvio padrão IC95\%: Intervalo de confiança de 95\%; p: nível de significância.

$\mathrm{VO}_{2}$ : consumo de oxigênio

\subsection{Avaliação do potencial impacto das diferenças observadas na interpretação dos dados de função pulmonar.}

Diante das discrepâncias observadas entre os resultados obtidos no presente estudo e algumas das equações de referência estudadas para diversos parâmetros, considerou-se a possibilidade de eventual impacto clínico na interpretação dos dados de função pulmonar baseado nestas mesmas equações. Para estimar a relevância eventual deste aspecto, foi realizada classificação de cada um dos parâmetros funcionais avaliados, em relação a cada uma das equações de referência selecionadas, para todos os indivíduos estudados. Esta classificação consistiu em definir, para cada indivíduo, se determinado parâmetro estaria dentro ou fora da faixa de referência, de acordo com cada uma das equações. A frequência de indivíduos classificada como abaixo do limite inferior ou acima do limite superior previstos pôde assim ser determinada. 
Considerando a definição convencional dos limites inferior e superior das faixas de referência em função pulmonar, que equivalem respectivamente aos percentis 5 e 95 da população saudável, esperar-se-ia uma frequência de até $10 \%$ de parâmetros fora da faixa prevista, sendo $5 \%$ reduzidos em relação ao limite inferior e outros 5\% aumentados em relação ao limite superior previstos. Esta expectativa foi comparada com os dados reais observados. As proporções de casos identificados fora das faixas de referência para espirometria nos grupos feminino e masculino estão apresentadas nas Tabelas 10 e 11, respectivamente, para as diversas equações de referência estudadas. A mesma análise está apresentada nas Tabelas 12, 13 e 14, em relação às medidas de volumes pulmonares e difusão.

Tabela 10 - Espirometria: frequência de observação de valores fora da faixa de referência em relação às equações de referência selecionadas para o sexo feminino.

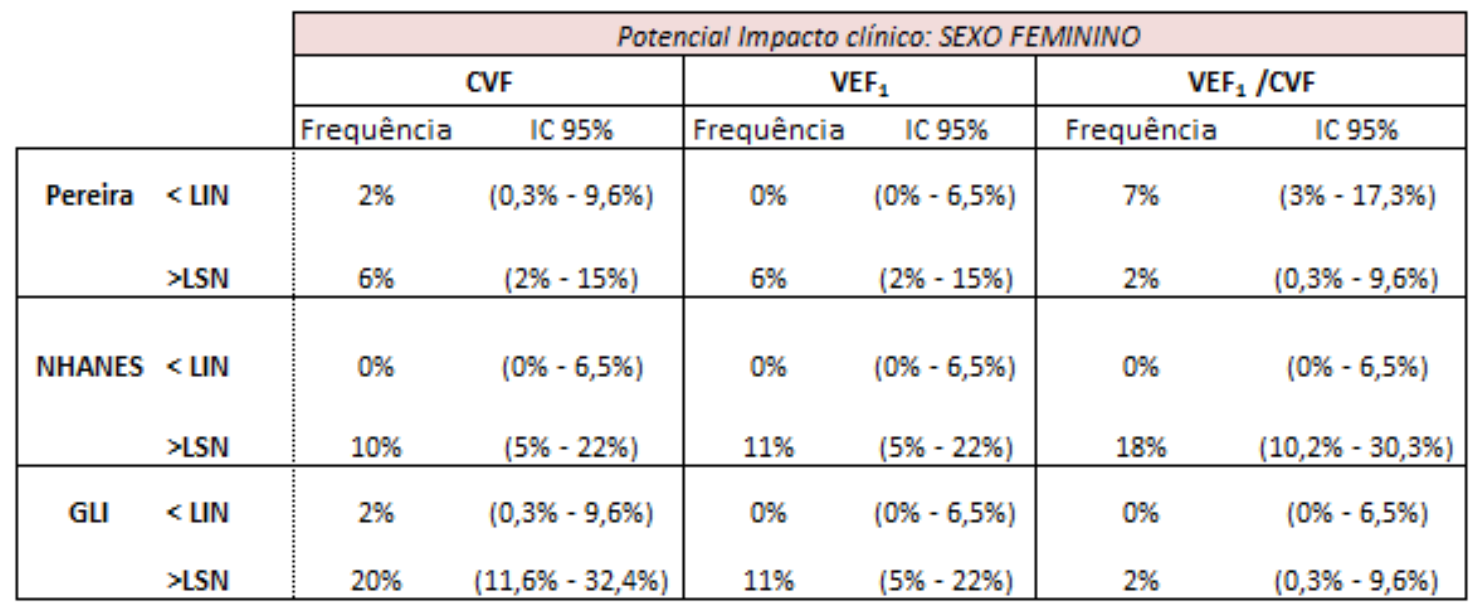

Proporção de casos fora da faixa de referência (acima do limite superior ou abaixo do limite inferior previsto), para as diferentes equações de valores previstos.

LIN: limite inferior da normalidade; LSN: limite superior da normalidade.

Os dados indicam a frequência observada de valores alterados e o intervalo de confiança de $95 \%$ desta proporção. 
Tabela 11- Espirometria: frequência de observação de valores fora da faixa de referência em relação às equações de referência selecionadas para o sexo masculino.

\begin{tabular}{|c|c|c|c|c|c|c|c|}
\hline & & \multicolumn{6}{|c|}{ Potencial Impacto clínico: SEXO MASCULINO } \\
\hline & & \multicolumn{2}{|c|}{ CVF } & \multicolumn{2}{|c|}{$\operatorname{VEF}_{1}$} & \multicolumn{2}{|c|}{$\mathrm{VEF}_{1} / \mathrm{CVF}$} \\
\hline & & Frequência & IC $95 \%$ & Frequência & IC $95 \%$ & Frequência & IC $95 \%$ \\
\hline \multirow[t]{2}{*}{ Pereira } & $<$ LIN & $5 \%$ & $(1,3 \%-16 \%)$ & $10 \%$ & $(4 \%-23 \%)$ & $22,5 \%$ & $(12,3 \%-37,5 \%)$ \\
\hline & $>\mathrm{LSN}$ & $2,5 \%$ & $(0,4 \%-13 \%)$ & $0 \%$ & $(0 \%-8,7 \%)$ & $2,5 \%$ & $(0,4 \%-13 \%)$ \\
\hline \multirow[t]{2}{*}{ NHANES } & $<$ LIN & $2,5 \%$ & $(0,4 \%-12,8 \%)$ & $2,5 \%$ & $(0,4 \%-13 \%)$ & $7,5 \%$ & $(2,5 \%-20 \%)$ \\
\hline & $>\mathrm{LSN}$ & $12,5 \%$ & $(5,4 \%-26 \%)$ & $10 \%$ & $(4 \%-23 \%)$ & $7,5 \%$ & $(2,5 \%-20 \%)$ \\
\hline \multirow[t]{2}{*}{ GLI } & $<$ LIN & $0 \%$ & $(0 \%-8,7 \%)$ & $0 \%$ & $(0 \%-8,7 \%)$ & $0 \%$ & $(0 \%-8,7 \%)$ \\
\hline & $>\mathrm{LSN}$ & $2,5 \%$ & $(0,4 \%-13 \%)$ & $0 \%$ & $(0 \%-8,7 \%)$ & $0 \%$ & $(0 \%-8,7 \%)$ \\
\hline
\end{tabular}

Proporção de casos fora da faixa de referência (acima do limite superior ou abaixo do limite inferior previsto), para as diferentes equações de valores previstos.

LIN: limite inferior da normalidade; LSN: limite superior da normalidade.

Os dados indicam a frequência observada de valores alterados e o intervalo de confiança de $95 \%$ desta proporção.

Tabela 12- Volumes pulmonares: Frequência de observação de valores fora da faixa de referência em relação às equações de referência selecionadas para o sexo feminino.

\begin{tabular}{|c|c|c|c|c|c|c|c|}
\hline & \multicolumn{6}{|c|}{ Potencial Impacto clínico: SEXO FEMININO } \\
\hline & & \multicolumn{2}{|c|}{ CPT } & \multicolumn{2}{|c|}{ VR } & \multicolumn{2}{|c|}{ CRF } \\
\hline & & Frequência & IC 95\% & Frequência & IC 95\% & Frequência & IC 95\% \\
\hline Crapo & $<$ LIN & $0 \%$ & $(0 \%-6,5 \%)$ & $4 \%$ & $(1 \%-12,1 \%)$ & $0 \%$ & $(0 \%-6,4 \%)$ \\
\hline & $>\mathrm{LSN}$ & $16 \%$ & $(9 \%-28,3 \%)$ & $18 \%$ & $(10,2 \%-30,3 \%)$ & $18 \%$ & $(10 \%-30 \%)$ \\
\hline \multirow[t]{2}{*}{ ECCS } & $<$ LIN & $0 \%$ & $(0 \%-6,5 \%)$ & $4 \%$ & $(1 \%-12,1 \%)$ & $20 \%$ & $(11 \%-32 \%)$ \\
\hline & $>\mathrm{LSN}$ & $22 \%$ & $(13 \%-34,4 \%)$ & $42 \%$ & $(30 \%-55 \%)$ & $4 \%$ & $(1 \%-12,1 \%)$ \\
\hline \multirow[t]{2}{*}{ Neder } & $<$ LIN & $4 \%$ & $(1 \%-12,1 \%)$ & $4 \%$ & $(1 \%-12,1 \%)$ & $34 \%$ & $(23 \%-47 \%)$ \\
\hline & $>\mathrm{LSN}$ & $27 \%$ & $(17,3 \%-40,2 \%)$ & $75 \%$ & $(62 \%-84 \%)$ & $29 \%$ & $(18,4 \%-41,4 \%)$ \\
\hline
\end{tabular}

Proporção de casos fora da faixa de referência (acima do limite superior ou abaixo do limite inferior previsto), para as diferentes equações de valores previstos.

LIN: limite inferior da normalidade; LSN: limite superior da normalidade.

Os dados indicam a frequência observada de valores alterados e o intervalo de confiança de $95 \%$ desta proporção. 
Tabela 13- Volumes pulmonares: Frequência de observação de valores fora da faixa de referência em relação às equações de referência selecionadas para o sexo masculino.

\begin{tabular}{|c|c|c|c|c|c|c|c|}
\hline & \multicolumn{6}{|c|}{ Potencial Impacto clínico: SEXO MASCULINO } \\
\hline & & \multicolumn{2}{|c|}{ CPT } & \multicolumn{2}{|c|}{ VR } & \multicolumn{2}{|c|}{ CRF } \\
\hline & & Frequência & IC 95\% & Frequência & IC $95 \%$ & Frequência & IC 95\% \\
\hline \multirow[t]{2}{*}{ Crapo } & $<$ LIN & $2,5 \%$ & $(0,4 \%-13 \%)$ & $0 \%$ & $(0 \%-8,7 \%)$ & $2,5 \%$ & $(0,4 \%-13 \%)$ \\
\hline & $>\mathrm{LSN}$ & $7,5 \%$ & $(2,5 \%-20 \%)$ & $43 \%$ & $(28,5 \%-58 \%)$ & $17,5 \%$ & $(8,7 \%-32 \%)$ \\
\hline \multirow[t]{2}{*}{ ECCS } & $<$ LIN & $2,5 \%$ & $(0,4 \%-20 \%)$ & $12,5 \%$ & $(5,4 \%-26 \%)$ & $5 \%$ & $(1,3 \%-16,5)$ \\
\hline & $>\mathrm{LSN}$ & $40 \%$ & $(26,3 \%-55,4 \%)$ & $10 \%$ & $(4 \%-23 \%)$ & $12,5 \%$ & $(5,4 \%-26 \%)$ \\
\hline \multirow[t]{2}{*}{ Neder } & $<$ LIN & $10,0 \%$ & $(4 \%-23 \%)$ & $0 \%$ & $(0 \%-8,7 \%)$ & $7,5 \%$ & $(2,5 \%-20 \%)$ \\
\hline & $>\operatorname{LSN}$ & $10 \%$ & $(4 \%-23 \%)$ & $50 \%$ & $(35,2 \%-65 \%)$ & $35 \%$ & $(22 \%-50 \%)$ \\
\hline
\end{tabular}

Proporção de casos fora da faixa de referência (acima do limite superior ou abaixo do limite inferior previsto), para as diferentes equações de valores previstos.

LIN: limite inferior da normalidade; LSN: limite superior da normalidade.

Os dados indicam a frequência observada de valores alterados e o intervalo de confiança de $95 \%$ desta proporção.

Tabela 14- Difusão: Frequência de observação de valores fora da faixa de referência em relação às equações de referência selecionadas para ambos os sexos.

\begin{tabular}{|c|c|c|c|c|c|}
\hline & \multicolumn{2}{|c|}{$D L_{c o}-$ Feminino } & \multicolumn{2}{|c|}{$D L_{c o}-$ Masculino } \\
\hline & & Frequência & IC $95 \%$ & Frequência & IC $95 \%$ \\
\hline \multirow[t]{2}{*}{ Crapo } & $<$ UIN & $16 \%$ & $(8,6 \%-29 \%)$ & $18 \%$ & $(8,7 \%-32 \%)$ \\
\hline & $>$ LSN & $0 \%$ & $(0 \%-6,4 \%)$ & $0 \%$ & $(0 \%-8 \%)$ \\
\hline \multirow[t]{2}{*}{ ECCS } & $<$ UIN & $68 \%$ & $(55 \%-78,6 \%)$ & $15 \%$ & $(7 \%-29 \%)$ \\
\hline & $>\mathrm{LSN}$ & $0 \%$ & $(0 \%-6,4 \%)$ & $25 \%$ & $(14 \%-40 \%)$ \\
\hline \multirow[t]{2}{*}{ Neder } & $<$ UIN & $66 \%$ & $(53 \%-77 \%)$ & $35 \%$ & $(22 \%-50 \%)$ \\
\hline & $>\mathrm{LSN}$ & $0 \%$ & $(0 \%-6,4 \%)$ & $0 \%$ & $(0 \%-8 \%)$ \\
\hline
\end{tabular}

Proporção de casos fora da faixa de referência (acima do limite superior ou abaixo do limite inferior previsto), para as diferentes equações de valores previstos.

LIN: limite inferior da normalidade; LSN: limite superior da normalidade.

Os dados indicam a frequência observada de valores alterados e o intervalo de confiança de $95 \%$ desta proporção. 


\subsection{Derivação de Novas equações de referência idade-específico para Idosos na população brasileira.}

Perante a pouca aderência e na falta de identificação de um conjunto de equações que expresse de maneira robusta o comportamento das variáveis funcionais na faixa etária estudada, considerou-se adequada a proposição de novas equações que contemplassem as mudanças fisiológicas adquiridas com a senescência. As tabelas 15, 16 e 17, apresentam os coeficientes extraídos dos modelos de regressão linear múltipla para as variáveis espirométricas, volumes pulmonares e difusão, assim como para as variáveis selecionadas de TCPE, para ambos os sexos. São também expressos os valores do desvio padrão do resíduo (DPR), que permite a determinação do limite inferior da normalidade. As equações obtidas atendem ao seguinte formato:

$$
Y=k 1 \times A(c m)+k 2 \times I(\text { anos })+k 3
$$

onde $Y$ representa a variável funcional em questão, k1 e k2 são os coeficientes que multiplicam respectivamente altura em centímetros e idade em anos e k3 é o coeficiente independente.

Os limites inferiores de normalidade são, portanto, determinados conforme o formato:

$$
\operatorname{LLN}(Y)=Y-1,645 \times \text { DPR }
$$

onde $Y$ representa a variável funcional e DPR o desvio padrão do resíduo daquela mesma variável. 
Tabela 15 - Espirometria: Coeficientes propostos para derivação das equações lineares das variáveis espirométricas para ambos os sexos.

\begin{tabular}{|c|c|c|c|c|c|c|c|c|}
\cline { 2 - 9 } \multicolumn{1}{c|}{} & \multicolumn{4}{c|}{ Homens } & \multicolumn{4}{c|}{ Mulheres } \\
\cline { 2 - 9 } \multicolumn{1}{c|}{} & k1 & k2 & k3 & DPR & k1 & k2 & k3 & DPR \\
\hline CVF & 0,036 & $-0,051$ & 1,503 & 0,511 & 0,028 & $-0,025$ & 0,12 & 0,300 \\
VEF $_{1}$ & 0,024 & $-0,035$ & 1,317 & 0,378 & 0,018 & $-0,022$ & 0,811 & 0,285 \\
VEF $_{1} /$ CVF & $-0,001$ & 0,001 & 0,77 & 0,061 & $-0,001$ & $-0,001$ & 1,065 & 0,049 \\
\hline
\end{tabular}

k 1 - Coeficiente de altura em cm; k 2 - Coeficiente de idade em anos; $\mathrm{k} 3$ - Constante

Tabela 16 - Volumes e Difusão Coeficientes propostos para derivação das equações lineares das variáveis volumes pulmonares e difusão para ambos os sexos.

\begin{tabular}{|c|c|c|c|c|c|c|c|c|}
\cline { 2 - 9 } \multicolumn{1}{c|}{} & \multicolumn{4}{c|}{ Homens } & \multicolumn{4}{c|}{ Mulheres } \\
\cline { 2 - 9 } \multicolumn{1}{c|}{} & k1 & k2 & k3 & DPR & k1 & k2 & k3 & DPR \\
\hline CPT & 0,056 & $-0,009$ & $-2,216$ & 0,885 & 0,07 & 0,011 & $-6,638$ & 0,755 \\
CRF & 0,05 & $-0,009$ & $-3,822$ & 0,699 & 0,036 & 0,005 & $-3,006$ & 0,525 \\
VR & 0,021 & 0,035 & $-3,387$ & 0,552 & 0,044 & 0,042 & $-7,487$ & 0,662 \\
DL & 0,461 & $-0,399$ & $-22,069$ & 4,470 & 0,203 & $-0,235$ & 4,319 & 3,236 \\
\hline
\end{tabular}

k 1 - Coeficiente de altura em cm; k 2 - Coeficiente de idade em anos; k 3 - Constante

Tabela 17 - TCPE: Coeficientes propostos para derivação das equações lineares das variáveis selecionadas de TCPE para ambos os sexos.

\begin{tabular}{|c|c|c|c|c|c|c|c|c|}
\cline { 2 - 9 } \multicolumn{1}{c|}{} & \multicolumn{4}{c|}{ Homens } & \multicolumn{4}{c|}{ Mulheres } \\
\cline { 2 - 9 } \multicolumn{1}{c|}{} & k1 & k2 & k3 & DPR & k1 & k2 & k3 & DPR \\
\hline W & 0,46 & $-2,924$ & 284,505 & 25,867 & 0,293 & $-1,611$ & 144,93 & 18,881 \\
VO $_{2}$ máx. & 7,782 & $-26,158$ & 1966,404 & 266,031 & 9,739 & $-14,091$ & 456,573 & 185,088 \\
\hline
\end{tabular}

k 1 - Coeficiente de altura em cm; k 2 - Coeficiente de idade em anos; k 3 - Constante 
6. Discussão 
O conhecimento dos limites entre saúde e doença constitui grande desafio clínico, particularmente na terceira idade, quando essas diferenças são mais estreitas. Especificamente em relação ao sistema respiratório, alterações funcionais progressivas acompanham o processo de senescência e sua determinação torna-se fundamental para a interpretação de testes clínicos que abordam as medidas de função respiratória em repouso e ao exercício. Ao mesmo tempo, têm-se que a grande maioria dos estudos que determinaram as equações de referência para os parâmetros funcionais em adultos adotou amostras populacionais de faixa etária ampla, abrangendo na mesma equação indivíduos adultos jovens e idosos, que pode eventualmente não contemplar particularidades do processo de envelhecimento. Valores de referência atuais ou correlações com outras variáveis da função pulmonar normalmente são estabelecidos em estudos com modesto número de participantes idosos ${ }^{(63)}$ (64) (65). Em razão disso, o presente estudo testou a aderência de equações frequentemente utilizadas para interpretação funcional em uma amostra idadeespecífica.

Este estudo, até onde seja do conhecimento dos autores, é pioneiro no Brasil, por envolver exclusivamente uma amostra com número significativo de idosos saudáveis nos quais foram realizados testes de função pulmonar em repouso e ao exercício. A amostra avaliada caracterizou-se por baixíssimos índices de comorbidades relevantes, ínfima frequência de utilização de medicações de uso contínuo, alta taxa de indivíduos ativos em relação ao escore de atividade física (Questionário de Baecke com escore médio próximo de 8) e ausência de obesidade. Apesar do risco para eventual dificuldade na realização de testes funcionais nesta faixa etária, não foram registradas perdas relevantes de dados decorrentes deste tipo de limitação.

\subsection{Análise da aderência entre as equações de referência disponíveis e a amostra de idosos saudáveis estudada}




\subsubsection{Teste de função pulmonar - Espirometria}

As comparações entre as médias das variáveis de função pulmonar obtidas com aquelas previstas pelos diversos autores testados revelaram baixa aderência. Entretanto, este resultado não foi uniforme entre os diversos parâmetros mensurados para um mesmo conjunto de equações por autor $\mathrm{e}$ para o mesmo sexo, tendo sido observada grande heterogeneidade de comportamento.

Para estudo dos parâmetros de espirometria, foram selecionadas as equações de referência de Pereira et al, NHANES III e GLI 2012 para comparação. ${ }^{(50)(47)(49)} \mathrm{Em}$ relação à $\mathrm{CVF}, \mathrm{VEF}_{1}$ e $V E F_{1} / C V F$, as equações de Pereira et al apresentaram boa aderência para o sexo feminino, com diferenças médias da ordem de $50 \mathrm{~mL}$ e $37 \mathrm{~mL}$ para CVF e VEF1 respectivamente. Já as equações propostas por NHANES III e $\mathrm{GLI}_{2012}$ apresentam resultados com diferenças significativas para estes mesmos parâmetros, quando preveem em média valores menores que aqueles observados no presente estudo. Esta tendência a subestimar os valores de $\mathrm{VEF}_{1}$ e CVF potencialmente pode resultar em subdiagnóstico de doenças com valores menores para indivíduos acima de 65 anos, resultando em possíveis diagnósticos falso-positivos para essa faixa etária. Quanto à relação $\mathrm{VEF}_{1} / \mathrm{CVF}$ apenas o estudo NHANES III, apresentou valores menores do que o esperado. Para o mesmo parâmetro, a equação derivada do estudo $\mathrm{GLI}_{2012}$ apresentou boa aderência com a população de idosos do sexo feminino.

Para o sexo masculino, os resultados foram menos aderentes à população estudada. Todos os parâmetros (CVF, VEF e VEF $_{1} / \mathrm{CVF}$ ) derivados da equação do Pereira et al apresentaram valores maiores do que o esperado para idosos saudáveis, tendendo a superestimar os valores obtidos, ocasionando em possíveis diagnósticos falsos-positivos. A equação do NHANES III apresentou dois parâmetros (CVF e VEF $1 / C V F$ ) e o $\mathrm{GLI}_{2012}$ um parâmetro $\left(\mathrm{VEF}_{1}\right)$, sem diferença estatisticamente relevante em relação à amostra. Os demais dados corroboram a hipótese do presente estudo. O VEF 1 
do NHANESIII e CVF do $\mathrm{GLI}_{2012}$ exibem valores abaixo do esperado para faixa etária acima de 65 anos. Já o $\mathrm{VEF}_{1} / \mathrm{CVF}$ do $\mathrm{GLI}_{2012}$, apresenta valores acima do esperado. Ambas as equações de referência testadas, tendem subestimar e superestimar valores favorecendo a diminuição da acurácia dos TPF em indivíduos idosos ${ }^{(50)(49)(47)}$.

Fundamentado nas divergências, o presente estudo, verificou a frequência com que o valor obtido na amostra de idosos saudáveis seria classificado como fora dos limites previstos estabelecidos na literatura. No caso das equações de Pereira et al para parâmetros de espirometria para o sexo feminino, a taxa de classificação de testes alterados está próxima daquela esperada, considerando a definição de normalidade adotada: foram identificados ao redor de $6 \%$ de casos acima do LSN tanto para CVF quanto para VEF1 e índice menor de casos abaixo do LIN. No entanto, o mesmo não ocorreu em relação às equações de NHANES III e GLI 2012 para estes mesmos parâmetros nas mulheres idosas, quando as taxas de indivíduos acima do LSN excederam $10 \%$ da amostra (chegando a $20 \%$ no caso da CVF- GLI), apontando para o risco de baixa sensibilidade do método e de testes falsonegativos neste contexto. Em relação à relação $V F_{1} / C V F$, parâmetro fundamental para diagnóstico de distúrbios ventilatórios obstrutivos, as equações de Pereira et al e GLI 2012 tiveram índices adequados de classificação, porém NHANES III apresentou 18\% das mulheres idosas acima do limite superior, novamente com risco de comprometer a sensibilidade do teste na detecção de obstrução ${ }^{(50)}(49)(47)$.

No sexo masculino, os parâmetros propostos por Pereira et al, identificaram uma frequência superior a $10 \%$ de casos de idosos saudáveis classificados abaixo dos respectivos limites inferiores de normalidade para $V F_{1}$ e $V F_{1} / C V F$, podendo gerar erros diagnósticos com possíveis falsopositivos para diagnóstico de doenças obstrutivas em indivíduos longevos saudáveis. As variáveis calculadas de acordo com a equação proposta por NHANES III mantiveram a tendência de elevadas frequências de casos classificados acima dos limites superiores previstos, assim como ocorreu na 
amostra feminina, novamente diminuindo a sensibilidade do teste para a detecção de doenças. Contudo, todas as variáveis testadas da equação $\mathrm{GLI}_{2012}$, encontraram-se dentro dos limites de normalidades ${ }^{(49)}$ (47).

Sendo assim, ainda que em alguns casos a concordância tenha sido satisfatória e as equações tenham apresentado boa aderência com amostra de idosos saudáveis, a análise de concordância através dos gráficos de BlandAltman apontam para resultado unânime entre os 3 autores testados, sugerindo que quanto maior a capacidade vital dos "idosos normais", menor é sua representatividade nas equações de normalidade estudadas.

Possíveis justificativas para as divergências observadas incluem o fato de que os estudos, na maioria das vezes, são derivados de uma única equação para população adulta geral. Em linha com a hipótese deste estudo, eventualmente este modelo pode falhar em capturar comportamento específico deste extremo etário. Soma-se a isto a constatação de que há grande heterogeneidade metodológica entre os diversos estudos considerados, dificultando sua comparabilidade. Como exemplo, destaca-se que tanto as equações de NHANES III quanto as de $\mathrm{GLI}_{2012}$ foram derivadas a partir de dados coletados em diversos equipamentos diferentes. No caso de GLI, o estudo foi retrospectivo e seu banco de dados constituído por diversas fontes fornecidas por estudos anteriores que coletaram dados de função pulmonar em centros diferentes, com técnica e equipamento potencialmente diversos também. No caso de NHANHES III apenas 18\% da população era acima de 50 anos e $\mathrm{GLI}_{2012}$, como destacado pelos próprios autores, houve baixa representatividade de idosos principalmente daqueles com idades acima de 75 anos. Já no estudo do brasileiro, proposto por Pereira et al, a equação de referência foi realizada em uma população restrita caucasiana, em um país extremamente miscigenado, com variação etária de 20-85 anos sendo apenas $10 \%$ da sua amostra com idade acima de 75 anos.

Com base em todas essas diferenças observadas, o atual estudo, derivou suas próprias equações específicas para idosos, para os parâmetros 
de $C V F, V_{E F}$ e $V F_{1} / C V F$, através de equações de regressões lineares múltiplas, derivando coeficientes específicos para as variáveis de altura e idade.

\subsubsection{Teste de função pulmonar - Volumes pulmonares}

Para os parâmetros de volumes pulmonares (CPT, VR e CRF), o presente estudo verificou baixa aderência das equações avaliadas em relação à amostra de indivíduos acima de 65 anos de idade estudada. Houve comportamento sob certo aspecto uniforme em evidenciar tendência a subestimar os valores reais a partir das equações de Neder et al, Crapo et al e ECCS, todos com diferença estatisticamente significativa. Este desvio sugere que as equações não capturam adequadamente o comportamento longitudinal de propriedades como a progressiva perda de retração elástica pulmonar, as alterações de complacência de caixa torácica e modificações de força muscular adquiridas com a senescência (51) (48) (46) (66). As equações avaliadas parecem tender a superestimar o impacto destes efeitos, produzindo valores esperados inferiores àqueles observados na presenta amostra. No caso dos volumes pulmonares esta discrepância ocorreu como regra tanto para homens quanto para mulheres, com diferenças entre as médias que frequentemente ultrapassou 300 ou $400 \mathrm{~mL}$ e em alguns casos atingiu até aproximadamente $900 \mathrm{~mL}$, reforçando novamente a possibilidade de equívoco de interpretação no contexto de avaliação diagnóstica.

Para sexo feminino, a CPT foi determinada em valores abaixo daqueles mensurados na amostra do presente estudo, sendo esta tendência homogênea entre os autores Neder et al, Crapo et al e ECCS. Contudo o VR do Neder et al e do ECCS tendem a apresentar resultados acima do esperado. Para o parâmetro de CRF, Neder et al, foi o único que apresentou boa correlação. A CRF previsto por Crapo et al, encontra-se abaixo do valor previsto para faixa etária de idosos, enquanto que, o parâmetro de CRF do ECCS, apresenta-se com valor acima do esperado para este mesmo grupo. Esses resultados 
divergentes minimizam a sensibilidade do exame em reproduzir valores fidedignos dos volumes pulmonares em mulheres acima de 65 anos de idade (51) (48) (46)

Entretanto, para o sexo masculino, nota-se boa estimativa para CPT por Neder et al e desempenho marginal da equação de Crapo et al em relação aos dados obtidos na amostra do presente estudo; por outro lado, a CPT do ECCS, possui médias de valores abaixo do previsto para os idosos. Já o VR demonstrou semelhança entre os autores Neder et al e Crapo et al, em expressar valores subestimados para população idosa, ao passo que o VR de ECCS apresentou boa aderência com amostra ${ }^{(51)}(48)(46)$.

Um estudo europeu, publicado em 2009, randomizado, com indivíduos saudáveis não fumantes, também derivou equações idade-específicas (65 e 85 anos), para volumes pulmonares. Na comparação realizada pelos autores com outras equações, este estudo identificou volumes pulmonares (CPT, VR e $\mathrm{CRF}$ ) inferiores àqueles previstos por Crapo et al e ECCS, que portanto tenderia a superestimar valores para essa faixa etária. Estes resultados são discrepantes aos do presente estudo, que por outro lado evidenciou tendência das equações comparadas a subestimar valores de volumes pulmonares para essa faixa etária ${ }^{(67)}$.

Vale ressaltar, que o estudo ECCS não foi baseado em dados originais e gerou equações de referência a partir de outros levantamentos que incluíram amostras populacionais de fumantes e ex-fumantes e suas variáveis de CPT, VR e CRF, portanto, podem não ser representativos de indivíduos não tabagistas saudáveis ${ }^{(67)}$. Além disso, pode haver limitação na comparação dos valores previstos derivados por Crapo et al e por Neder et al, dadas as diferenças metodológicas em relação ao presente estudo: nos dois estudos mencionados a mensuração de volumes pulmonares foi feita por meio da técnica de diluição de Hélio e no caso do presente estudo foi utilizou a técnica de pletismografia de corpo inteiro. Reconhecidamente o método pletismográfico tende a produzir valores maiores de volumes pulmonares ${ }^{(68)}$. 
Já a equação derivada por Neder et al, propôs valores para população adulta geral (20-80 anos), subdividindo em 6 estratos etários, contudo para tentar contemplar os substratos etários, o estudo do Neder et al, beneficiou-se de um pequeno número de participantes. Talvez por isso, seus coeficientes para idosos, não alcançaram resultados mais expressivos de representatividade na população estudada ${ }^{(51)}$.

Á semelhança do que foi realizado para as variáveis espirométricas, e considerando a tendência discordante entre os resultados do presente estudo e das equações testadas, foi explorado o potencial impacto clínico da utilização destas equações se aplicadas para interpretação dos testes da amostra de idosos saudáveis. Foram identificados resultados semelhantes para todas as variáveis de volumes pulmonares em ambos os sexos. Onde, as médias dos valores tendem a estar acima do LSN, dificultando possíveis diagnósticos precoces de doenças restritivas quando considerada a análise da CPT ou da presença de aprisionamento aéreo quando considerado o VR, com tendência a produzir resultados falso-negativos em idosos, diminuindo a acurácia do exame (51) (48) (46)

Para Neder et al, quando verificada a frequência de indivíduos do presente estudo que estariam fora dos limites de normalidade na análise de volumes pulmonares do sexo feminino, evidenciou-se taxas de $27 \%$ e $75 \%$ de idosas mulheres acima dos limites superiores previstos para CPT e VR, respectivamente. Para estes mesmos parâmetros observa-se também frequências elevadas no caso de ECCS et al, nominalmente $22 \%$ e $42 \%$ para as variáveis de CPT e VR respectivamente. Crapo et al apresentou índices menores de CPT e VR acima dos limites superiores de normalidade, (16\% e $18 \%$ ), embora igualmente significativos considerando a definição aceita de normalidade que prevê até $5 \%$ dos indivíduos saudáveis nesta condição. Esta tendência foi uniforme entre os autores e reforça o risco de diagnósticos comprometidos relacionados ao teste ${ }^{(51)(48)(46)}$.

Tal avaliação feita no sexo masculino evidencia percentuais maiores de probabilidades de indivíduos saudáveis acima de 65 anos estarem fora dos 
limites de normalidade. Para o parâmetro de CPT proposto por ECCS, estes indivíduos encontram-se $40 \%$ de vezes acima do LSN. Já nos parâmetros de VR e CRF para Neder et al, evidenciou-se frequências de $50 \%$ e $35 \%$, respectivamente ${ }^{(51)(48)}$.

Contudo, por mais que em alguns casos, os autores apresentem boa aderência com o público de idosos hígidos, quando esses dados são plotados no Bland-Altman, o resultado da representatividade é unânime: quanto maior CPT, VR para o sexo feminino e CRF, VR para o sexo masculino, maior é dispersão dos dados e o distanciamento da média em ambos os sexos. A partir de todas essas diferenças observadas no presente estudo, foram derivadas equações específicas para idosos, através de equações de regressões lineares múltiplas para volumes pulmonares (CPT, VR e CRF). Foram determinados coeficientes específicos para as variáveis de altura e idade, sendo que para CPT e CRF novos coeficientes foram negativos para idade no sexo masculino. Já para o sexo feminino todas as variáveis apresentaram coeficientes positivos para idade.

\subsubsection{Teste de função pulmonar - Difusão}

Para a $\mathrm{DL}_{\mathrm{CO}}$, o comportamento das equações dos autores Neder et al, Crapo et al e ECCS foram ainda mais homogêneos em evidenciar a média dos valores acima do esperado para idosos saudáveis, superestimando valores para essa faixa etária específica nos exames diagnósticos, com exceção apenas do ECCS no sexo masculino, que demonstrou valores abaixo do predito para essa mesma população. Essa distribuição fica nítida quando feita analise de concordância pelo o Bland-Altman ${ }^{(52)(69)(46)}$.

O estudo do Neder et al, Crapo et al, e ECCS, para $\mathrm{DL}_{\mathrm{CO}}$, já descritos anteriormente, caracterizam-se por representatividade relativamente baixa de idosos, além do fato de já haver transcorrido tempo significativo de suas respectivas publicações. Este fato permite a especulação acerca da 
possibilidade da falta de acurácia identificada no presente estudo se dever, não somente às particularidades de comportamento no envelhecimento no extremo de idade, mas também por um efeito de tendência secular de variação da função pulmonar, independentemente do contexto etário específico. Este argumento pode ser aventado, não somente em relação à difusão, obviamente, mas também em relação aos demais parâmetros estudados (52) (70).

Estudo publicado em 2012, realizado com ampla amostra (262 mulheres e 169 homens) de indivíduos saudáveis, não fumantes e com idades entre 6585 anos, corrobora os dados do presente estudo, evidenciando que praticamente todos os valores de referência obtidos pela extrapolação de equações para adultos de meia idade, superestimaram capacidade de difusão dos voluntários idosos saudáveis. Esse erro no valor de referência é visto rotineiramente nos laboratórios assistências e em pesquisas clínicas ${ }^{(70)}$.

Comparativamente, quando feito o calculo de probabilidade dos indivíduos idosos saudáveis, do presente estudo, estarem acima ou abaixo dos limites de normalidades, evidenciou-se alta taxa de mulheres idosas abaixo dos LIN para todos os autores testados (chegando a frações expressivas, da ordem de dois terços da amostra nos casos de Neder et al e ECCS). Para o sexo masculino, a chance dos indivíduos saudáveis estudados estarem distantes desses limites foi menor, embora ainda significativa. Para Neder et al, 35\% dos homens idosos estariam abaixo do LIN enquanto para Crapo et al e ECCS esse percentual foi de $18 \%$ e $15 \%$ respectivamente. Entretanto, para ECCS $25 \%$ dos homens estariam acima do LSN, potencialmente aumentando o risco também de diagnósticos falso-negativos ${ }^{(52)(69)(46)}$.

Fundamentado em todas essas diferenças observadas, o presente estudo derivou equações específicas para idosos, de $\mathrm{DL}_{\mathrm{co}}$, a partir de equações de regressões lineares múltiplas, originando coeficientes específicos para as variáveis de altura e idade (ver nos resultados). Dessa forma, foram evidenciados que os novos coeficientes para altura e idade apresentaram-se maiores que os coeficientes das demais equações já citadas anteriormente. 


\subsubsection{Teste cardiopulmonar de esforço}

Foi observado que para as variáveis de carga (W) no sexo feminino, os autores, Neder et al, Jones et al e Wasserman et al, demonstraram valores maiores que os resultados esperados para idosos saudáveis, entretanto, apenas o resultado da equação de Blackie et al, não apresentou diferença estatisticamente significativa ${ }^{(55)(53)(54)(62) .}$

O $\mathrm{VO}_{2}$ máx. do Neder et al, no sexo feminino, não teve diferença estatisticamente significativa na média dos valores. Já para o Blackie et al, Jones et al e Wasserman et al todos os resultados foram estatisticamente significativos, representados pela baixa aderência à população de idosos saudáveis do presente estudo. O resultado expresso por Blackie et al, foi maior que o esperado para a população de idosos saudáveis, já os valores de Jones et al e Wasserman et al apresentaram valores abaixo do esperado para a população estudada (55) (53) (54) (62). Esse comportamento pode ser visto na análise de concordância no Bland-Altman.

Contudo, no sexo masculino a variável de carga do Wasserman et al, não apresentou resultado com significância estatística. Já os dos demais autores, divergiram entre si, sobre o comportamento dessa variável, no qual a carga do Neder et al, apresentou valores menores do que os esperados, possivelmente subestimando a carga predita para essa população. Em contrapartida, os autores, Blackie et al e Jones et al, convergiram, exibindo resultados com tendência a superestimar estes valores (55) (53) (54) (62). Esse comportamento pode ser visto na análise de concordância no Bland-Altman.

Ainda no sexo masculino, foi constatado que, para as variáveis de $\mathrm{VO}_{2}$ máx, os autores, Neder et al, Blackie et al e Wasserman et al apresentaram valores maiores que os resultados esperados determinando possivelmente valores superestimados para a população de idosos estudada. Apenas Jones et al, não apresentou diferença estatisticamente significativa ${ }^{(55)(53)(54)(62)}$. Esse comportamento pode ser visto na análise de concordância no Bland-Altman. 
Ressaltando a hipótese inicial do presente estudo, os valores de Wasserman et al, não apresentam nenhum critério para poder utilizar suas variáveis como representativas em idosos saudáveis, pois sua população foi predominante de adultos-jovens (média de idade de 54 anos), tabagistas ou extabagistas, que atuavam diretamente com trabalho braçais de estaleiros. (62) Neder et al, aceitou indivíduos com história prévia de tabagismo $<15$ anos/maço, em razão disso, podem não ser representativos de indivíduos saudáveis. Além disso, este estudo foi realizado há mais de 10 anos e a soma destes fatores pode constituir argumentos para apontar a ausência de adequação dos valores de referência para indivíduos acima de 65 anos de idade da presente amostra ${ }^{(55)}$.

Já as equações americanas Jones et al e Blackie et al publicadas em 1989, tiveram representatividade apenas em uma na variavél do sexo masculino (um para carga e outro para $\mathrm{VO}_{2}$ máx.). O primeiro estudo teve faixa etária ampla (20-70 anos) com média de idade de 48 anos. Provavelmente em razão da maioria presente ser de adultos-jovens, os valores podem não representar as alterações fisiológicas dinâmicas encontradas no idoso saudável. Blackie et al realizou seu estudo com indivíduos acima de 55 anos de idade (média de idade de 66 anos), porém foram incluidos tagabistas e extabagistas na amostra, podendo ser um viés para a representatividade da população de saudáveis estudada ${ }^{(53)(54)(62)}$.

Com base em todas as diferenças observadas, foram derivadas novas equações específicas para idosos saudáveis, para valores de carga e $\mathrm{VO}_{2}$ máx. a partir de equações de regressões lineares múltiplas, produzindo assim, coeficientes específicos para as variáveis de altura e idade. $O$ diferencial destas novas equações de referência foi a ausência de coeficientes para peso, além de ser observado a não linearidade para a formulação das equações préexistentes.

As equações derivadas do Neder et al, apresentaram as 3 variáveis, sendo altura, idade e peso para os valores de carga do sexo masculino e apenas altura e idade para o sexo feminino, que não teve o peso como variável relevante no modelo. Em relação às equações de referência do $\mathrm{VO}_{2}$ máx, foi 
observada ausência da variável altura e presença apenas das variáveis de idade e peso.

As equações para carga e $\mathrm{VO}_{2}$ máx. do Wasserman et al, apresentaram apenas as variáveis de peso e idade, não utilizando a altura como variável de correlação. Blackie et al, contempla as 3 variáveis para a formulação de suas equações de carga e $\mathrm{VO}_{2}$ máx., e Jones et al apresenta as variáveis de peso e idade para derivar os valores de carga. Para os valores de $\mathrm{VO}_{2}$ máx. foram usadas as 3 variáveis para a formulação de suas equações.

\subsection{Limitação do estudo e pontos fortes}

Algumas limitações do presente estudo merecem ser destacadas. Talvez a limitação relevante seja tratar-se de um estudo pequeno, com 96 indivíduos, para se derivar equações de referência que contemplem o máximo de indivíduos dos mais diferentes perfis de idosos; porém esta limitação é em consequência do que consideramos o ponto mais forte do trabalho: os critérios bastante rígidos de inclusão e exclusão, que caracterizam nossa população de saudáveis com o mínimo de interferências para derivarmos padrões de normalidade, resultando em dados confiáveis ao envelhecimento normal em uma população urbana.

Ainda em relação à amostra, outra particularidade pode ter comprometido sua representatividade: o histograma de distribuição etária das mulheres mostra uma relativa concentração de voluntárias na faixa ao redor de 70 anos, reduzindo a uniformidade de distribuição desta variável. Outra limitação a ser considerada é o fato de o estudo ter sido realizado com base em amostra de conveniência, sem um cálculo de tamanho amostral realizado previamente para aumentarmos a acurácia e a eficiência da representatividade dos valores obtidos para utilizarmos como padrão ouro para indivíduos acima de 65 anos. 
Apesar das limitações apontadas, entendemos que o presente estudo, constituiu desafio em contribuir com uma lacuna nesta área do conhecimento, e que as informações geradas têm grande potencial de aplicabilidade clínica. Reconhecemos a necessidade de ampliação deste estudo e também de novos estudos complementares a este para o estabelecimento e validação de equações de referência idade-específicas. 
7.Conclusão 
Verificamos a pouca aderência das equações de referência disponíveis para função pulmonar e teste cardiopulmonar de esforço quando aplicada a uma amostra específica de idosos saudáveis.

Concluímos que em razão das eventuais discrepâncias observadas sobre a interpretação dos dados de função pulmonar e dos dados funcionais de exercício, há possibilidade de erros diagnósticos com diminuição da sensibilidade e/ou supradiagnósticos patológicos nos testes aplicados. Dessa forma, derivamos novas equações idade-específicas para as variáveis de espirometria, volumes pulmonares, difusão e para dois parâmetros de TCPE (carga (W) e VO $\mathrm{V}_{2}$ áx.). 
8.Anexos 
HOSPITAL DAS CLINICAS DA FACULDADE DE MEDICINA DA UNTVERSTDADE DE SÃO PAULO-HCRMUSP

TERMO DE CONSENTIMENTO LIVRE E ESCLARECIDO

DADOS DE IDENTIFICAÇAO DO SUJEITO DA PESQUISA OU RESPONSAVEL LEGAL

1. NOME:

DOCUMENTO DE IDENTIDADE No SEXO: M $\quad$ F $\square$

DATANASCIMENTO

ENDEREÇO

BAIRRO:

$\mathrm{N}^{0}$

APTO:

CEP

CIDADE

)

2.RESPONSAVEL LEGAL

NATUREZA (grau de parentesco, tutor, curador etc- -

DOCUMENTO DE IDENTIDADE:

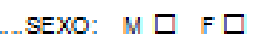

DATANASGIMENTO:

ENDEREÇO:

BAIRRO:

N.... $\mathrm{N}^{\circ}$

APTO

CEP:

TEIFFONE:DDD (-... CIDADE:

DADOS SOBRE A PESQUISA

1. TITULO DO PROTOCOLO DE PESQUISA.n. Emvehecimento pumonar: aspectos observados a tomograta

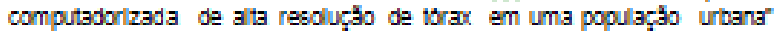

2. PESQUISADORES:

a. Prof. Dr. Mario Terra Filho

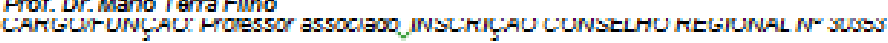

b. Dr. Andra Luis Paraira de Allouquerque

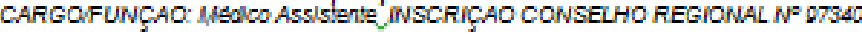

c. Lullana Marins Rocha

Filsioterapeuta/ Pesquilsadora Estaglarla do Laboratorio de Funçä Pulmonar CREFrTo 121020

3. UNIDADE DO HCFMUSP: Serviço de Pneumologla

4. aValaÇao do RISCO DA PESQUISA:
i. RISCO MINIMOX
RISCO MEDIO
II. RISCO BADXO
RISCOMAIOR

5. DURAÇAO DA RESQUUSA; 42 meses 
1 - Deeenho do estudo e objetivolel: Com o aumento da ldade nosso corpo val mudando, e no pulmăo năo e

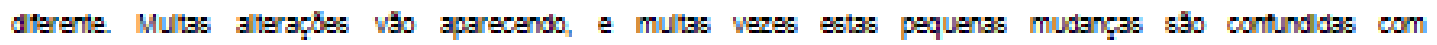
doenç35. O objetwo deste projeto e Identffcar quals săo as alteraçס̄es que aparecem no pulmăo a medida que envehecemos, usando para lsto a tomograța computadorizada de alta resoluçăo, que e um exame que usa varlos ralos $x$ para mostrar a parte interna do nosso corpo.

2 - Descriçä dos procedimentos que serao reallzados, com seus propositos $\theta$ identificaça dos que forem experimentale e nào rotineiros:

(Vole Item 8 abalxo)

3 - Relaça dos procedimentos rotineiros $\theta$ como 830 reallzados:

a) Voce sera entrevistado para o preenchimento de questionario com dados sobre sua sajde; b) Sera submetido a exame medico clinico, como numa consulta normal e de rotina; c) Realzaçăo de exames: sera falo um ecocardlograma, que e un exame que senve para avallar o coraçăo; para realza-lo, coloca-6e uma pasta pareclda com gelatina no pelo, por onde desilzara um pequeno apareho. Depols, sera sollcitajo que voce sopre en uma maquina para que possamos avallar sua capacidade pumonar. Em segulda, sera fata uma radiograta de 1orax e uma tomograta sem contraste, exame que conslste de una serle de ralos $x, 60$ que e fato deltado e năo e necessario tomar nenhuma injeçăo; d) ApDs esses procedmentos sera fato um exame na biclcleta ergometrica, onde voce tera que pedalar durante alguns minutos; 35 informaçð̌es deste teste permittrăo avallar sua capacldade de exercicio e 35 respostas cardlac3s e pulmonares do seu organlsmo. Com estes exames poderemos Imterpretar se ediste alguma anormaldade Imlerna 02.8eus pulmర̋es; e) todos estes exames săo rothelros, nenhum sendo experimental.

4-Descriça dos desconfortos e rlecos esperados nos procedlmentos:

Năo devera haver nenhum descontorto relacionado a realzaçăo dos procedmentos de questonario, cposulth. ecocardlograma e funçăo pulmonar (thens a, b, c acima). Estes exames serăo Indolores, e năo causam nenhum

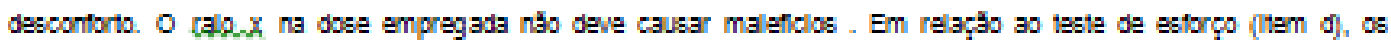
descontortos esperados săo relaclonados ao cansaço geral e das pernas que ocorrem com o aumento gradual de Imtensldade de exercldio durante o teste. Flscos malores, como arnitmlas ou dores toraclcas sfo acompannados a.

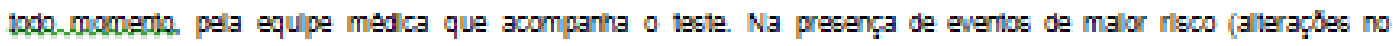
eletrocardograma ou pressäo arterial muto ata), 0 leste sera interromplido.

\section{5 - Beneficlos para o participante:}

Se for Identicado alguma.problena nos exames, ine sera oferecido tratamento no HCFMUSP, visto voce ja ser paclente desta insthulçăo. Os resultados da pesqulsa poderăo contribulr para mehor compreendermos os efalos do envehecimento, sobre o nosso pulmâo, o que possiblitara que nos possamos tratar meinor 35 pes603s de mals ldade, năo contundindo alteraçס̌es do envelnecimento com doenç3s 
8-Ralegoec de prosedimantoc altarnativoc que poccam cervantajococ, paloc quelc o peolents pode opter. Ndo existem

7 - Garantia de aoscro: em quelquer etape do estudo, voce teit acesso aos profssionels responstvels pela pesquise pera esclerecimento de eventuels dovides. Opthclpel investgedor to DrMeto Tenra Filno que pode ser

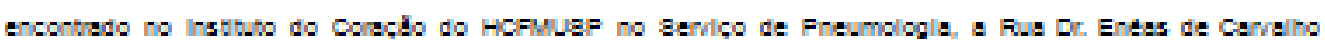
Agular 44. Teletone 30695805 ae voce tver elgume considerecto ou dovida sobre a efica da pesqulsa, ente em conteto com o comits de Evice em Fesquise (CEF) - Rus Ovidlo Fires de Cempos, $225-5^{\circ}$ ander - tel.: 3069 -

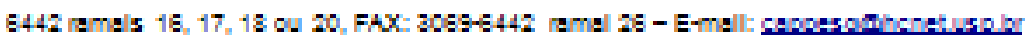

8 - E gerantida a liberdede de retirada de concentimanto a qualquar momanto o dabar de pertiolper do ectudo, cam qualquar prejulzo a continuldade de cau tratemanto na inctituloso.

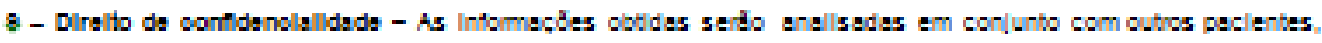
nio sendo divulgado a ldentficacto de nenhum paciente:

10 - Direlito de cer mantido atuallzado cobre oc recultedoc parolalc dac pecqulcac, quando am actudoc abertoc, ou de recultadoc que calam do conhesimanto doc pecqulcedorec

Voce terd o direlto de se menter informedo sobre o andemento da pesquisa e dos resultados, conforme o estudo for caminhando. Fare isso, os pesquisadores envolvidos, e com os quels voce tert contato durente a realize; dos procedimentos do estudo, esterdo a disposiçlo pare te informer.

11 - Decpecac o compencagob: ndo he despeses pessoels pera o perticlpente em quelquer tese do estudo, Inclulndo exemes e consultes. Tembem ndo ha compenseçio finencelia relecionsda a sua paticipectio. ae existir Quelquer despess adicionel, ela serd absonide pelo orçemento de pesquise.:

12 - Em ceso de deno pessoel, diretamente ceusedo pelos procedimentos ou tretamentos propostos neste estudo (nexo ceusel comprovedo), o peticlpante tem direlto a tretamento medlco na instbulcto por apul ser mettculado meis especificamente na Discipling de Fneumologla incor HCFMuap, bem como ts indenlzecdes legaimente

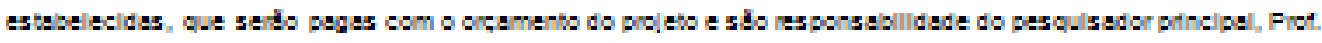
De. Meto Terra Fino.

13 - Compromileco do pecqulcador de utilizar oc dedoc o o material colatedo comente pera ecta pecquice. Neste ato, os pesquisadores envolvidos se comprometem a uflizer os resultados obbdos somente pera esta pesquisa, no be sendo utllzados pera outes finalldades de quelquer natureze. 
Acredito ter sido suffientemente informedo a respelto des informeçes que II ou que foram llides pera mim, descrevendo o estudo "Envelinaolmanto pulmonar: acpaotoc obcarvadoc a fomografla computadorizada de alte recoluglo de torsx am ums populaglo urbens.z Eu discut com o Dr. Meto Terre Fino ou com O De. Andre Luls Ferelia de Albuguerque ou com a pesquisedore Julland Matins focha sobre a minha decis do em pettclper nesse estudo. Ficarem claros pera mim quels sdo os proptsibos do estudo, os procedimentos a serem realizados, seus desconfortos e itscos, es geranties de confdenclaldade e de exclarecimentos peimenentes. Flcou claro tambem que minha particlpocilo e isenta de despeses e que tenho garants do acesso a tatamento hospltaler quando necessato. Concordo voluntalamente em peticlper deste estudo e poderel retirar o meu consentimento a qualquer momento, antes ou durente o mesmo, sem peneldades ou prejulas ou peide de qualquer beneficlo que eu posse ter adquildo, ou no meu atendimento neste aervico.

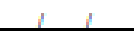

Assinatura da testanunha

Deta

para c3505 de paclentes menores de 18 anos, analtabetos, semlanaltabetos ou portadores de detclancla audtiva ou visual.

\section{(Somente para o responsavel do proletio)}

Declaro que obtve de forma apropriada e voluntaria o Consentimento Uwre e Eaclarecido deste paclente ou representante legal para a particlpaçăo neste estudo. 


\section{Anexo 2 - Carta de Aprovação da CAPPesq}

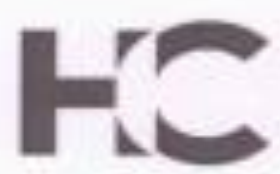

mastrinu ass cuincas

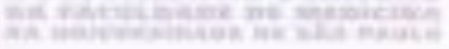

Ac

Depariamento de Cardíopneumalogla

Coardenadar da Corrissobo de Etico para Analse de Projelos de Pesquisa - CAPPesa da Duretoria Cinica do Hospita das Clinicas da Facutidade de Medicina do Universiclade de 500 Poulo, em 12.09.11, farnou conhocimento que o Protocolo de Pesquisa $n^{2}$ 0142/0a. intitulado: "Envelhecimente pulmonor: aspectos observados à tomogrefie computadorizoda de alla resoluçáo de tórax em uma populaçầ urbano" contempla o sub-projeto intifulado "Estudo das equaçes de normalldade dos parámetros de funçao pulmonar em repouso e oo exercicio em amostra de idosos higidos da populaç̧o Brasileira", que sera tese de Doutorado da akuno Jullana Mafins Recho. fendo como orientador 9 Pr. Mário Terra Filho,

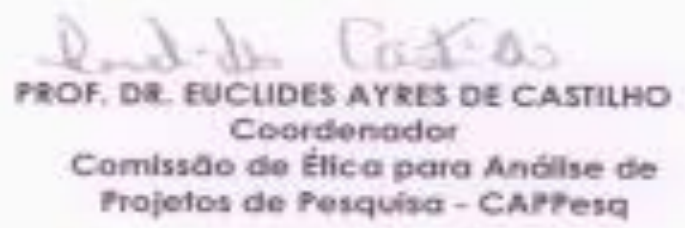

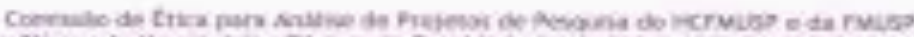

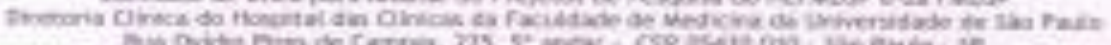

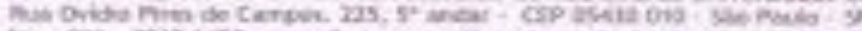

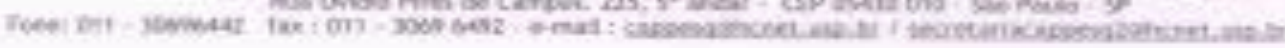




\section{Anexo 3- Triagem feita por telefone - Avaliação Inicial}

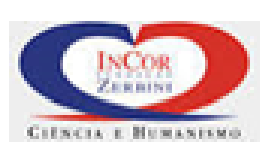

"Estudo das equações de normalidade dos parâmetros de função pulmonar em repouso e ao exercício em amostra de idosos hígidos da população Brasileira."

Nome:

Data:

RGHC: Id ade:

Sexo F / M

( ) Não Teve alguma doença "grave" na infância?

( ) Não Tem alguma doença

( ) Não Fez alguma cirurgia?

( ) Não Toma algum Medicamento?

( ) Não Pratica atividade Física?

( ) Não Tem alguma alergia?

( ) Não Toma bebida alcoólica?

( ) Não Fuma?

( ) Não Tomou todas as vacinas? 


\section{Anexo 4 - Questionário de nível de atividade Física - Questionário de}

\section{Baecke}

\section{QUESTIONÁRIO DE ATIVIDADE FISICA}

Por favor, pensando na sua atividade física no trabalho nos últimos 12 meses, circule a resposta apropriada para cada questăo:

\begin{tabular}{|c|c|c|c|c|c|c|}
\hline 1) & Qual foi sua principal ocupação? & & & & & \\
\hline 2) & $\begin{array}{l}\text { No trabalho eu sentava: } \\
\text { nunca / raramente / algumas vezes / } \\
\text { freqüentemente / sempre }\end{array}$ & 1 & 2 & 3 & 4 & 5 \\
\hline 3) & $\begin{array}{l}\text { No trabalho em ficava em pé: } \\
\text { nunca / raramente / algumas vezes / } \\
\text { freqüentemente / sempre }\end{array}$ & 1 & 2 & 3 & 4 & 5 \\
\hline 4) & $\begin{array}{l}\text { No trabalho eu andava: } \\
\text { nunca / raramente / algumas vezes / } \\
\text { freqūentemente / sempre }\end{array}$ & 1 & 2 & 3 & 4 & 5 \\
\hline 5) & $\begin{array}{l}\text { No trabalho eu carregava carga pesada: } \\
\text { nunca / raramente / algumas vezes / } \\
\text { frequientemente / sempre }\end{array}$ & 1 & 2 & 3 & 4 & 5 \\
\hline 6) & $\begin{array}{l}\text { Após o trabalho me sentia cansado: } \\
\text { muito freqüentemente / freqüentemente / algumas } \\
\text { vezes / raramente / nunca }\end{array}$ & 5 & 4 & 3 & 2 & 1 \\
\hline 7) & $\begin{array}{l}\text { No trabalho eu suava: } \\
\text { muito frequientemente / frequentemente / algumas } \\
\text { vezes / raramente / nunca }\end{array}$ & 5 & 4 & 3 & 2 & 1 \\
\hline \multirow[t]{2}{*}{ 8) } & $\begin{array}{l}\text { Em comparação com outros da minha idade eu } \\
\text { penso que meu trabalho foi fisicamente: } \\
\text { muito pesado / mais pesado / tão pesado quanto / } \\
\text { mais leve / muito leve }\end{array}$ & 5 & 4 & 3 & 2 & 1 \\
\hline & $\begin{array}{l}\text { Pensando nos esportes/exercicios fisicos praticados } \\
\text { responda: }\end{array}$ & & imo & & & \\
\hline \multirow[t]{3}{*}{ 9) } & $\begin{array}{l}\text { Vocé praticou esporte/exercicio fisico: } \\
\text { sim / năo }\end{array}$ & & & & & \\
\hline & $\begin{array}{l}\text { - Qual modalidade vocé praticou } \\
\text { mais freqüentemente? }\end{array}$ & 1 & & 3 & & 5 \\
\hline & - Quantas horas por semana? & $<1$ & $1-2$ & $2-3$ & $3-4$ & $>4$ \\
\hline
\end{tabular}


- Quantos meses por ano?

$<1 \quad 1-3 \quad 4-6 \quad 7-9 \quad>9$

Se vocé fez uma segunda modalidade:

- Qual modalidade foi esta?

- Quantas horas por semana?

$\begin{array}{lllll}<1 & 1-2 & 2-3 & 3-4 & >4\end{array}$

- Quantos meses por ano?

10) Em comparação com outros da minha idade eu penso que minha atividade fisica durante as horas de lazer foi:

muito maior / maior / a mesma / menor / muito menor

11) Durante as horas de lazer eu suava:

muito frequientemente / freqüentemente / algumas vezes / raramente / nunca

12) Durante as horas de lazer eu praticava esporte/exercicio fisico:

nunca / raramente / algumas vezes / freqūentemente / muito frequentemente

13) Durante as horas de lazer eu vejo televisão:

nunca / raramente / algumas vezes / frequientemente / muito freqüentemente

14) Durante as horas de lazer eu ando:

nunca / raramente / algumas vezes / frequientemente / muito frequientemente

15) Durante as horas de lazer eu ando de bicicleta:

nunca / raramente / algumas vezes / frequientemente / muito freqüentemente

16) Durante quantos minutos por dia vocé anda a pé ou de bicicleta indo e voltando do trabalho, escola $\begin{array}{lllll}<1 & 1-3 & 4-6 & 7-9 & >9\end{array}$ $\begin{array}{lllll}5 & 4 & 3 & 2 & 1\end{array}$ ou compras:

$\begin{array}{ccccc}5 & 4 & 3 & 2 & 1 \\ 1 & 2 & 3 & 4 & 5 \\ 1 & 2 & 3 & 4 & 5 \\ 1 & 2 & 3 & 4 & 5 \\ & & & & \\ 1 & 2 & 3 & 4 & 5 \\ & & & & \\ <5 & 5- & 16- & 31- & >45 \\ & 15 & 30 & 45 & \end{array}$


Fórmulas para cálculo dos escores do questionário Baecke de AFH

Exercicios fisicos no lazer (EFL)

Cálculo da primeira questão referente à prática de esportes/exercícios físicos:

- Intensidade (tipo de modalidade) = 0,76 para modalidades com gasto energético leve ou 1,26 para modalidades com gasto energético moderado ou 1,76 para modalidades com gasto energético vigoroso (determinado pela resposta do tipo de modalidade: 0 gasto energético da modalidade deve ser conferido no compêndio de atividades fisicas de Ainsworth ${ }^{13}$ )

- Tempo (horas por semana) = 0,5 para menos de uma hora por semana ou 1,5 entre maior que uma hora e menor que duas horas por semana ou 2,5 para maior que duas horas e menor que três horas por semana ou 3,5 para maior que três e até quatro horas por semana ou 4,5 para maior que quatro horas por semana (determinado pela resposta das horas por semana de prática)

- Proporção (meses por ano) = 0,04 para menor que um mês ou 0,17 entre um e três meses ou 0,42 entre quatro e seis meses ou 0,67 entre sete e nove meses ou 0,92 para maior que nove meses (determinado pela resposta dos meses por ano de prática)

Para o cálculo do escore desta questão, os valores devem ser multiplicados e somados: Modalidade 1 - (Intensidade Tempo*Proporção) + Modalidade 2 - (Intensidade*Tempo *Proporção)

Para o valor final, será estipulado um escore de acordo com os valores obtidos na fórmula: 0 (sem exercício físico) = 1/entre 0,01 até $<4=2 /$ entre 4 até $<8=3 /$ entre 8 até $<12=4 / 212,00=5$

Os escores das questōes dois a quatro serão obtidos de acordo com as respostas das escalas de Likert

0 escore final de EFL deverá ser obtido de acordo com a fórmula especificada abaixo:

$$
\text { Escore de EFL }=\frac{\text { questão } 1+\text { questão } 2+\text { questão } 3+\text { questão } 4}{4}
$$

\section{Atividades fisicas de lazer e locomoção (ALL)}

Os escores das questōes cinco a oito serão obtidos de acordo com as respostas das escalas de Likert 0 escore final de ALL deverá ser obtido de acordo com a fórmula especificada abaixo:

$(6$ - questão 5$)+$ questão 6 + questão 7 + questão 8

4

Escore total $(\mathrm{ET})=\mathrm{EFL}+\mathrm{ALL}$ 


\section{Referências Bibliográficas}


1. Santos, S.S.C Concepções teórico-filosóficas sobre o envelhecimento, velhice, idoso e enfermagem gerontogeriátrica. Rev Bras Enferm. 2010;63(6):1035-9.

2. Fechine, B.R.A. e Trompieri, N .O processo de envelhecimento: as principais alterações que acontecem com o idoso com o passar dos anos. Revista Científica Internacional. 2012;1(20)

3. Estatuto do Idoso.Casa Civil. Brasil. Lei oํ 10,741 de 1ํ de outubro de 2003. .[Online] Outubro de 2003. http://www.planalto.gov.br/ccivil_03/leis/2003/L10.741.htm/.

4. Manzaro, Simone de Cássia Freitas.Envelhecimento: Idoso, velhice ou terceira idade. S/D.

\section{American College os Sports Medicine and the American Heart} Association.ACSM/AHA. Recommendations. [Online] 2016. https://www.acsm.org/docs/current-comments/physiologyofaging.pdf..

6. Kuh D, Karunananthan S, Bergman H, Cooper R. A life-course approach to healthy ageing: maintaining physical capability. Proc Nutr Soc. 2014;73(2):237248.

7. Díaz-López Mdel P, López-Liria R, Aguilar-Parra JM, Padilla-Góngora D. Keys to actve ageing: New communication technologies and lifelong learning. SpringerPlus. 2016;5(Suppl 1):768

8. Cento Internacional de Longevidade Brasil. Envelhecimento Ativo: Um Marco Político em Resposta á Revolução da Longevidade. [Online] 2015. [Citado em: 2016.] http://sbgg.org.br/wp-content/uploads/2014/11/Envelhecimento-AtivoUm-Marco-Pol--tico-ILC-Brasil_web.pdf.

9. Bousquet J, Kuh D, Bewick $M$, Standberg $T$, Farrell J, Pengelly $R$, Operational Definition of Active and Healthy Ageing (AHA): A Conceptual Framework. Active and Healthy Ageing (AHA)., J Nutr Health Aging, 2015;19(9):955-60.

10. Ministério da Saúde. Concepção do Tema: Saúde. [Online] 1990. Disponível em:http:// portal.mec.gov.br/seb/arquivos/pdf/livro092.pdf.

11.Cupertino, A.P.F.B, Rosa, F.H.M, Ribeiro, P.C.C Definição de Envelhecimento Saudável na Perspectiva de Indivíduos Idosos Psicologia. Psicol. Reflex. Crit. 2007;20(1):81-86 
12. Balady GJ, Arena R, Sietsema K, Myers J, Coke L, Fletcher GF et al Clinician's Guide to Cardiopulmonary Exercise Testing in Adults A Scientific Statement From the American Heart Association. Circulation. 2010;122(2):191-225.

13. World Health Organization - Envelhecimento ativo: uma política de saúde / World Health Organization; tradução Suzana Gontijo. - Brasília: Organização Pan-Americana da Saúde, 2005. 60p

14.Abdullah B, Wolbring G Analysis of Newspaper Coverage of Active Aging through the Lens of the 2002 World Health Organizations Active Ageing Report: A Policy Framework and the 2010 Toronto Charter for Physical Activity: A Global Call for Action. Int J Environ Res Public Health. 2013;10(12):6799-819.

15.Lunenfeld B, Stratton $P$. The clinical consequences of an ageing world and preventive strategies. Best Pract Res Clin Obstet Gynaecol.. 2013;27(5): 643-659.

16. Borges, G M; Ervatti, L R; Jardim, AP.(IBGE), Instituto Brasileiro de Geografia e Estatística. Mudança Demográfica no Brasil no início do século XXI: Subsídios para as projeções da população. Estudos e análises . Rio de Janeiro : s.n., 2015.

17. Kalache, A; Veras, R.P; Ramos, L.R. O envelhecimento da população mundial. Um desafio novo. Rev. Saúde públ. 1987;21(3):200-10.

18. Camargos MC, Gonzaga MR. Live longer and better? Estimates of healthy life expectancy in the Brazilian population. Cad Saude Publica. 2015;31(7):1460-1472.

19. Organização das Nações Unidas (ONU) . Centro de Notícias da ONU. [Online] 30 de julho de 2015. Disponível em: www.unric.org/pt/actualidade/31919-onu-projeta-que-populacao-mundialchegue-aos-85-mil-milhoes-em-2030

20. Belon AP, Lima MG, Barros MB. Gender diferences in healthy life expectancy among Brazilian elderly. Health Qual Life Outcomes. 2014;12:88

21. Instituto Brasileiro de Geografia e Estatística (IBGE). Censo Demográfico . [Online] . Disponível em: http://censo2010.ibge.gov.br/.

22. Instituto Brasileiro de Geografia e Estatística (IBGE). Estimativas da população residente nos municípios brasileiros. [Online] 1ํ de julho de 2015. Dispinível em:

http://www.ibge.gov.br/home/estatistica/populacao/estimativa2015/estimativa d ou.shtm 
23. Instituto Brasileiro de Geografia e Estatística (IBGE). Pesquisa Nacional por amostra de Domicílio (PNAD). [Online]. Disponível em:http://ibge.gov.br.

24.Camarano, A.A. Envelhecimento da população brasileira: uma contribuição demográfica. Rio de Janeiro:IPEA, 2002 (Texto para Discussão, 858).

25. Prata, Mario. "100 Crônicas". São Paulo : Cartaz Editorial/Jornal O Estado de São Paulo, 1997.

26. Tojo, N. Pulmonary function testing: history up to the present . Rinsho Byori. 2014;62(12):1205-11.

27. Diretrizes para Teste de Função Pulmonar. Tisiologia., Sociedade Brasileira de Pneumologia . J Pneumol. 2002;28(Suppl 3):S1-S238.

28. Teste de Exercício Cardiopulmonar. Tisiologia., Sociedade Brasileira de Pneumologia e. J Pneumol. 2002;28(Suppl 3).

29.Janssens JP, Pache JC, Nicod LP Physiological change in respiratory function associated with ageing. Eur Resp J . 1999;13:197-205.

30.Ruivo, S., Viana, P., Martins C., Baeta, C. Effects of aging on lung function. A comparison of lung function in healthy adults and the elderly. Rev Port Pneumol . 2009; XV (4): 629-653

31.Janssens JP Aging of the Respiratory System: Impact on Pulmonary Function Tests and Adaptation to Exertion. Clin Chest Med. 2005;262(3):469 484.

32. Jensen D, Ofir D, O'Donnell DE. Effects of pregnancy, obesity and aging on the intensity of perceived breathlessness during exercise in healthy humans. Respir Physiol Neurobiol. 2009;167(1):87-100

33. Zeleznik J. Normative aging of the respiratory system. Clin Geriatr Med . 2003;19(1):1-18.

34. Bonomo L1, Larici AR, Maggi F, Schiavon F, Berletti R. Aging and the respiratory system. Radiol Clin North Am. 2008;46(4):685-702.

35.Lalley PM The aging respiratory system:Pulmonary structure, function and neural control. Respir Physiol Neurobiol. 2013;187(3):199-210

36.Montero-Fernández N, Serra-Rexach JA. Role of exercise on sarcopenia in the elderly. Eur J Phys Rehabil Med. 2013;49(1):131-43.

37.Woo JS, Derleth C, Stratton JR, Levy WC.. The Influence of Age, Gender, and Training on Exercise Efficiency. J Am Coll Cardiol.. 2006;47(5): 1049-57 
38.Gravelle BM, Murias JM, Spencer MD, Paterson DH, Kowalchuk JM Adjustments of pulmonary $\mathrm{O} 2$ uptake and muscle deoxygenation during ramp incremental exercise and constant-load moderate-intensity exercise in young and older adults. J Appl Physiol. 2012;113(9):1466-1475.

39. Vaz Fragoso CA, Gill TM, McAvay G, Quanjer PH, Van Ness PH, Concato J.. Respiratory impairment in older persons: when less means more. . Am J Med.. 2013;126(1): 49-57.

40. Fleg JL, Morrell CH,Bos AG, Brant LJ, Talbot LA, Wright JG, et al. Accelerated Longitudinal Decline of Aerobic Capacity in Healthy Older Adults Circulation. 2005; 112(5):674-82.

41.Stratton JR, Levy WC, Cerqueira MD, Schwartz RS, Abrass IB. Cardiovascular responses to exercise. Effects of aging and exercise training in healthy men. . Circulation. 1994;89(4):1648-165.

42.Pellegrino R, Viegi G, Brusasco V, Crapo RO, Burgos F, Casaburi R. Interpretative strategies for lung function tests. Eur Respir J, 2005;26(5):948968.

43.Oyarzún G,M Función respiratoria en la senectud. Rev Méd Chile. 2009;137(3):411-418.

44.Burr ML, Phillips KM, Hurst DN. Lung function in the elderly. Thorax. 1985;40:54-59.

45.Fowler RW, Pluck RA, Hetzel MR.. Maximal expiratory flow-volume curves in Londoners aged 60 years and ove. Thorax 1987;42(3):173-182 .

46. Quanjer PH,Tammeling GJ,Cotes JE,Pedersen OF, Peslin R, Yernault JC. Lung volumes and ventilatoryflows. Report Working Party "Standardization of Lung Function Tests", European Community for Steel and Coal and European Respiratory Society. Eur Respir J Suppl.. 1993;16:5-40.

47. Hankinson JL, Odencrantz JR, Fedan KB. Spirometric Reference values from a sample os the general U.S. Population. Am J Respir Crit Care Med.. 1999;159(1):179-87.

48.Crapo RO, Morris AH, Gardner RM. Reference spirometric values using techniques and equipment that meet ATS recommendations. Am Rev Respir Dis. 1981;123(6):659-64.

49. Quanjer PH, Stanojevic S, Cole TJ, Baur X, Hall GL,Culver BH, Mult-ethnic reference values for spirometry for 3-95-yr age range: The global lung function 2012 equations. Eur Respir J . 2012;40(6):1324-1343. 
50. Pereira, C.A.C. e Sato, T., Rodrigues, S.C. Novos valores de referência para espirometria forçada em brasileiros adultos de raça branca. $\boldsymbol{J}$ Bras Pneumol 2007;33(4):397-406.

51.Neder JA, Andreoni S, Castelo-Filho A and Nery LE. Reference values for lung function test. I. Static Volumes. Braz J Med Biol Res. 1999;32(6):703-717.

52.Neder JA, Andreoni S, Peres C, Nery LE.. Nery. Reference values for lung function Test. III. Carbon monoxide diffusing capacity (transfer fator). Braz J Med Biol Res .1999;32(6):729-737.

53.Blackie SP, Fairbarn MS, McElvaney GN, Morrison NJ, Wilcox PG, Pardy RL. Prediction of Maximal Oxygen Uptake and Power during Cycle Ergometry in Subjects Older Than 55 years of Age. Am Rev Respir Dis. 1989;139(6):14241429.

54.Jones NL,Summers E, Killian KJ. Influence of age and stature on exercise capacity during incremental cycle ergometry in men and women. Am Rev Respir Dis. 1989;140(5):1373-1380.

55.Neder JA, Nery LE, Castelo A, Andreoni S, Lerario MC, Sachs A, et al. Prediction of metabolic and cardiopulmonar responses to maximum cycle ergometry: a randomised study. Eur Respir J. 1999;14(6):1304-1313.

56.Neder JA, Nery LE, Peres C, Whipp BJ. Reference values for dynamic responses to incremental cycle ergometry in males and females aged 20 to 80 . Am.J. Respir Crit. Care Med. 2001;164:1481-1486.

57.Schneider J Age dependency of oxygen uptake and related parametrs in exercise testing and expert opnion on reference values suitable for adults.. Lung, 2013;191(5):449-458.

58.Baecke JA, Burema J, Frijters JE. A short questionnaire for the measurement of habitual physical activity in epidemiological studies. Am J Clin Nutr.. 1982;36(5):936-942.

59.Farinatti, PTV. Apresentação de uma versão em português do Compêndio de Atividades Físicas: Uma Contribuição aos pesquisadores e profissionais em Fisiologia do Exercício. Revista Brasileira de Fisiologia do Exercício.2003

60.Checa, FM. Validação de um questionário para avaliação do nível de atividade física pela internet. São Paulo : s.n., 2010.

61.Lung Function Testing: Selection os reference values and interpretative strategies. American Thoracic Society (ATS). Am Res Respir Dis. 1991;144(5):1202-1218. 
62.Wasserman K, Hansen JE, Sue DY, Casaburi R, Whipp BL Principles of Exercise Testing and Interpretation. Lea \& Febiger. 1994;2:479

63. Gulshan S, James G. Effect os agindo n Respiratory system Physiology and immunology. Clin Interv Aging. 2006;3:253-260.

64. Galetke W, Feier C, Muth T, Borsch-Galetke E, Rühle KH, Randerath W. Comparison of pulmonary compliance and the work of breathing with pulmonary function parameters in men. Pneumologie. 2008;62(2):67-73.

65. Ben Saad H, El Attar MN, Hadj Mabrouk K, Ben Abdelaziz A, Abdelghani A, Bousarssar M,et al. The recent multi-ethnic global lung Initiative 2012 (GLI2012) reference values don't reflect contemporary adult's North African spirometry. Respir Med.. 2013;107(12):2000-2008.

66. Golshan M, Amra B, Soltani F, Crapo RO. Reference Values for Lung Volumes in an Iranian Population: Introducing a New Equation Model. Arch Iran Med. 2009;12(3):256 - 261.

67. Garcia-Rio F, Dorgham A, Pino JM, Villasante C, Garcia-Quero C, AlvarezSala R. Lung Volume Reference Values for women and men 65 to 85 years of age. Am J Respir Crit Care Med.. 2009;180(11): 1083-91.

68. Coertjens, PC, Knorst, MM, Dumke, A, Pasqualoto, AS, Riboldi, J, Barreto, SSM Pode o método de diluição do hélio em respiração única estimar os volumes pulmonares medidos pela pletismografia de corpo inteiro? J Bras Pneumo. 2013;39(6):675-685.

69. Crapo RO, Forster RE Reference spirometric values using techniques and equipment that meet ATS recommendations: Carbon monoxide diffusing capacity.. Clin Chest Med. 1989;2(10):187-198.

70. Garcia-Rio F, Dorgham A, Galera R, Casitas R, Martinez E, Alvarez-Sala R, Pino JM. Prediction equations for single-breath diffusing capacity in subjects aged 65 to 85 years. Chest .2012;142(1):175-84. 
10. Suplemento 
1.Suplemento. Gráfico comparativo do Bland- Altman dos parâmetros de espirometria para o sexo feminino.

Espirometria. Sexo Feminino

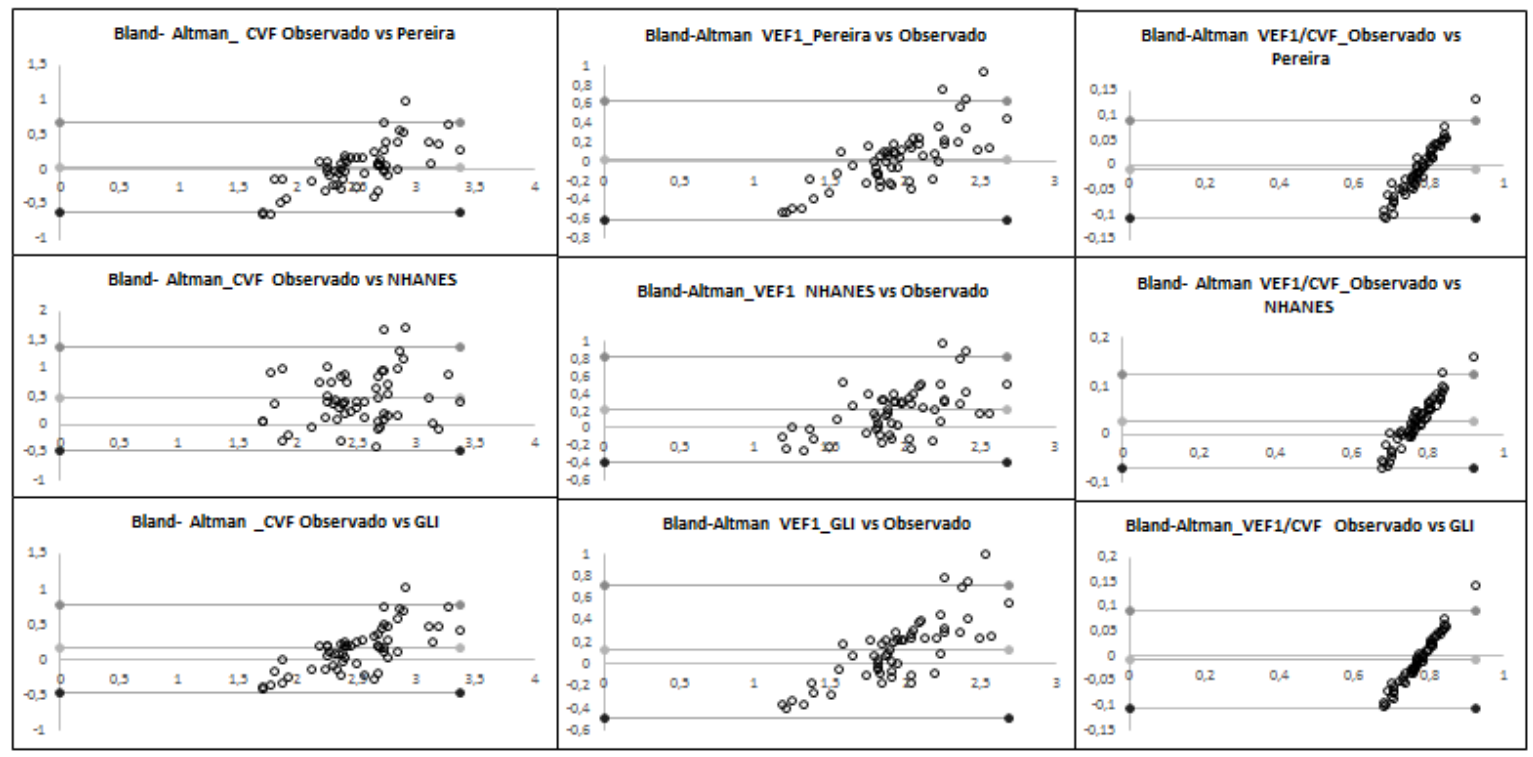

2. Suplemento. Gráfico comparativo do Bland- Altman dos parâmetros de espirometria para o sexo masculino.

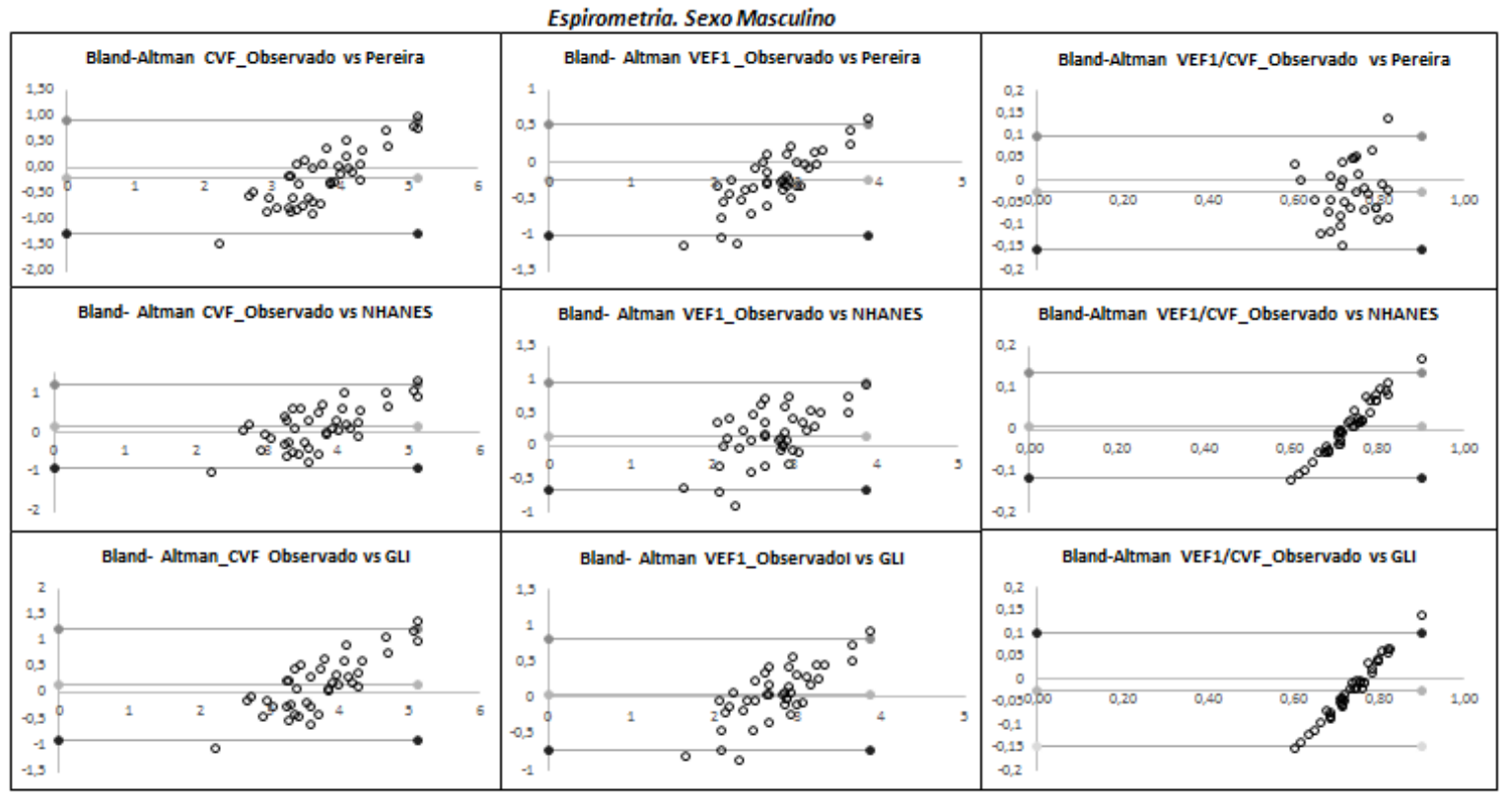


3. Suplemento Gráfico comparativo do Bland- Altman dos parâmetros de volumes pulmonares para o sexo feminino.

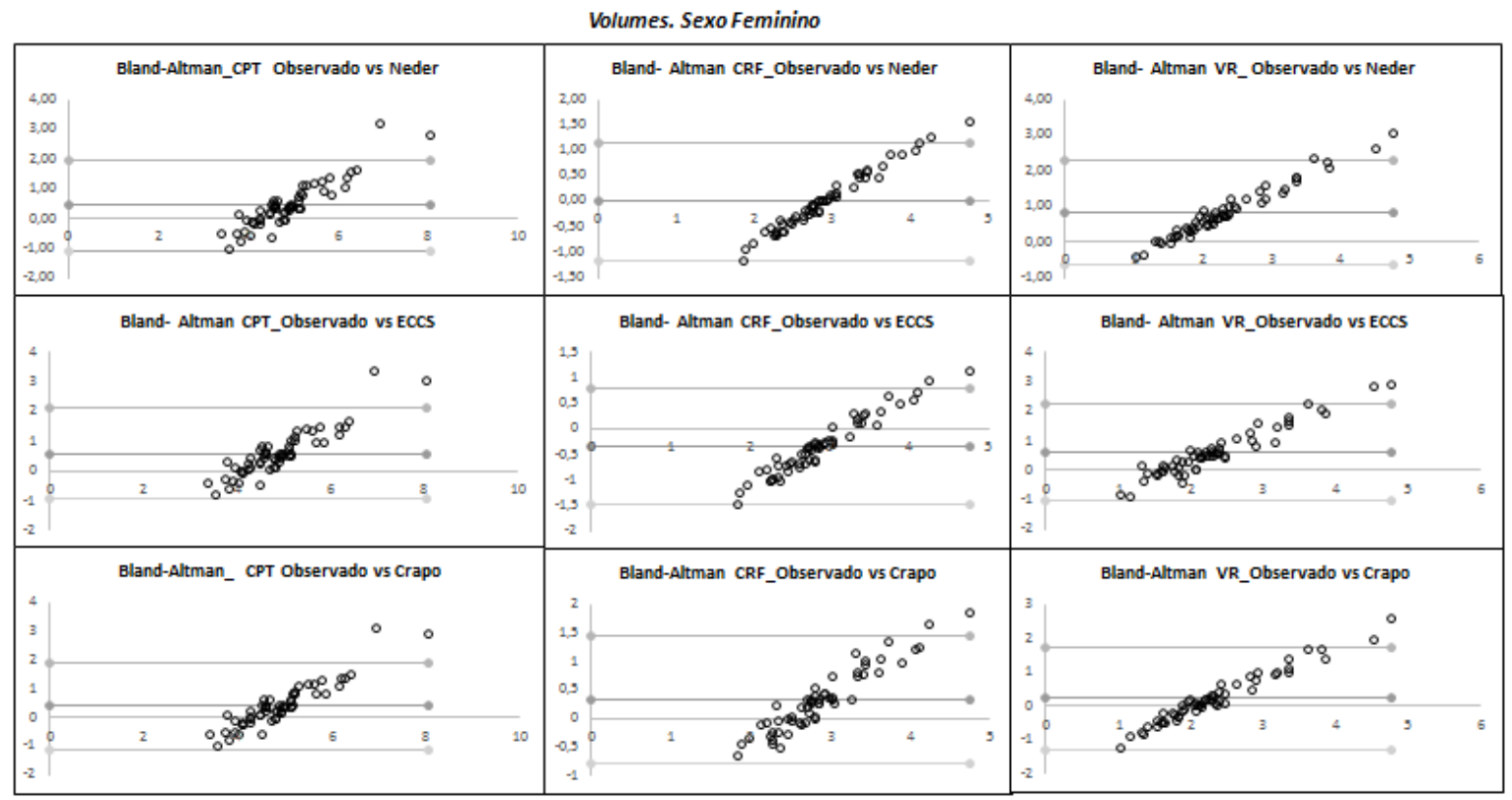

4. Suplemento. Gráfico comparativo do Bland- Altman dos parâmetros de volumes pulmonares para o sexo masculino

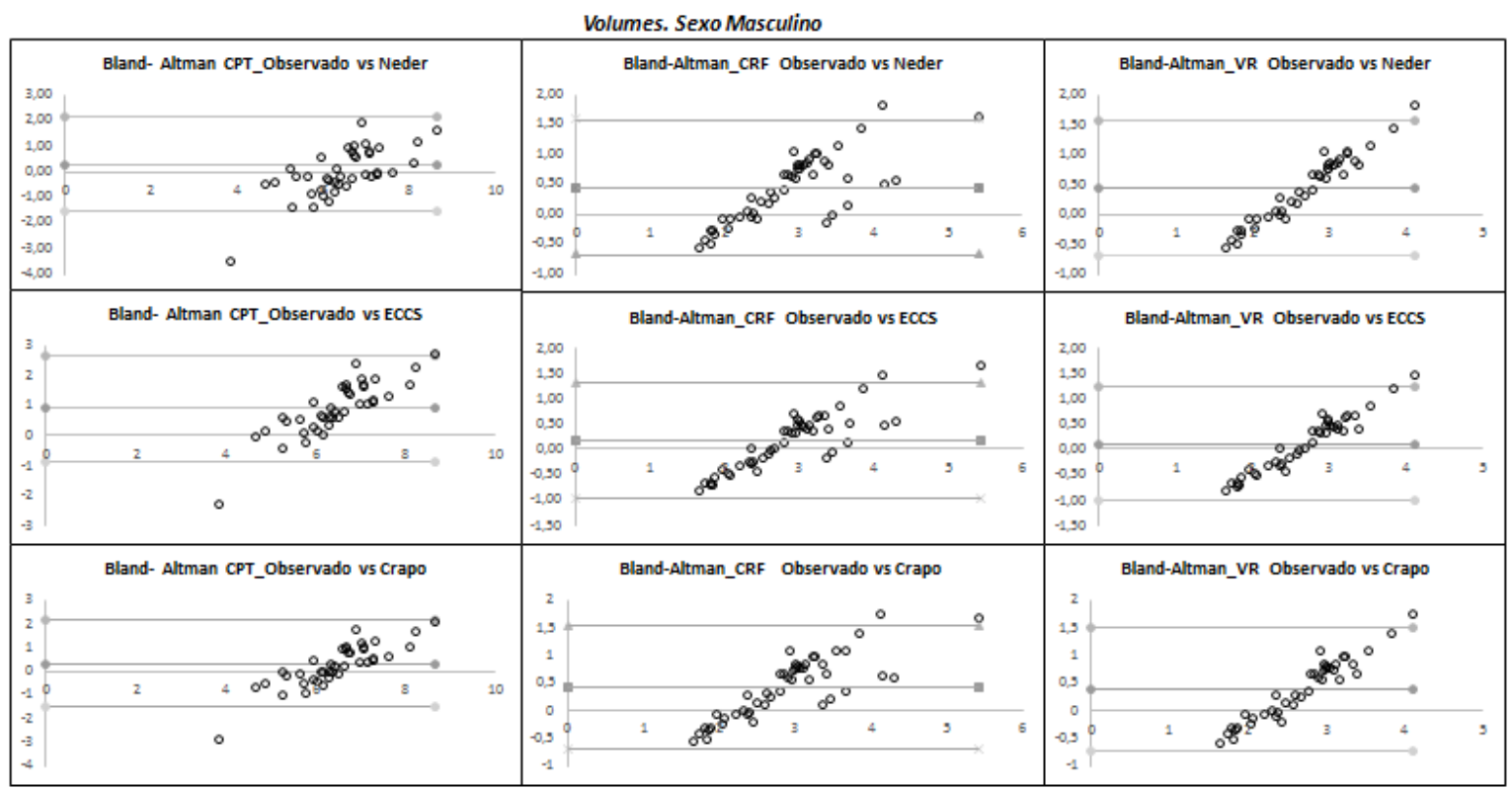


5. Suplemento. Gráfico comparativo do Bland- Altman do parâmetro de DLco para ambos os sexos.

DLco. Sexo Masculino

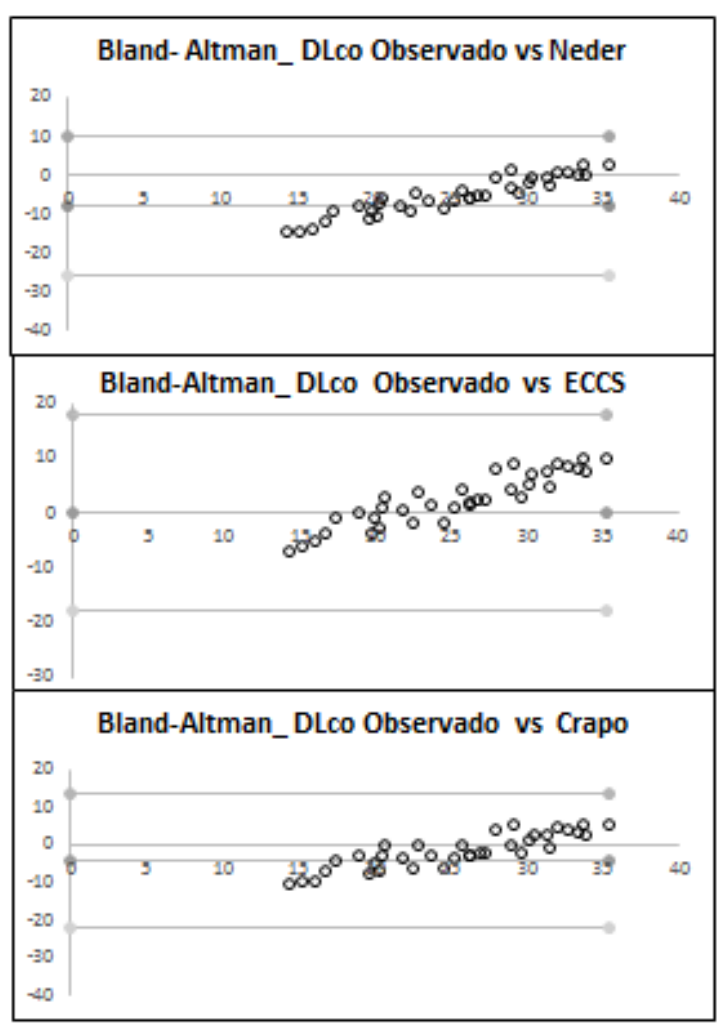

DLco. Sexo Feminino

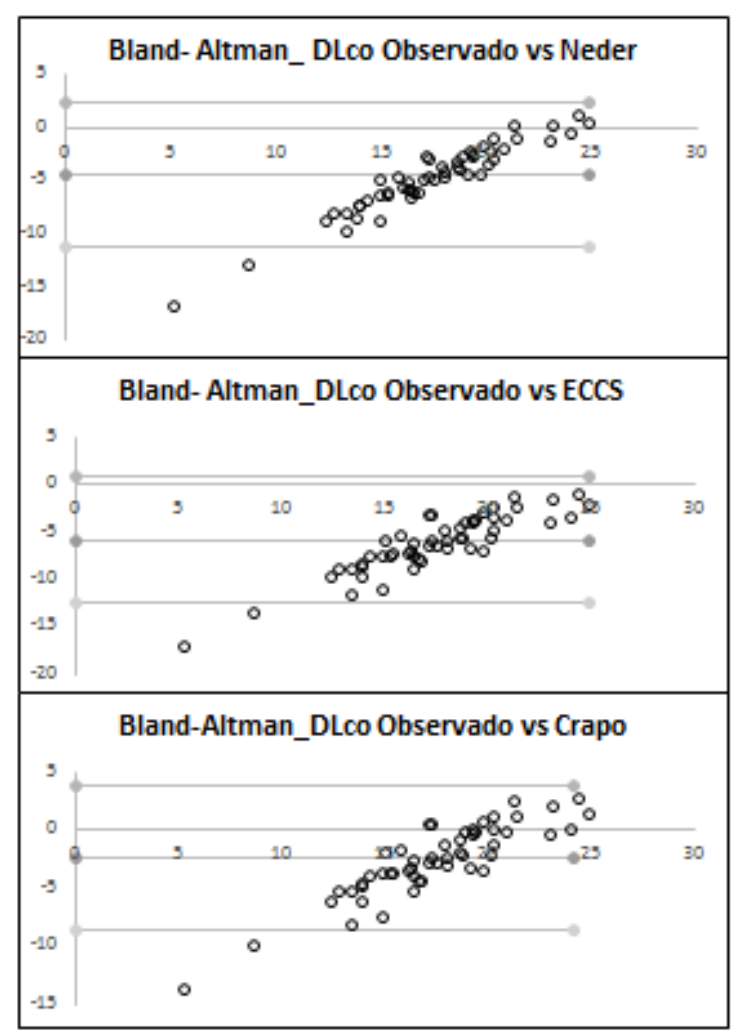


6. Suplemento. Gráfico comparativo do Bland- Altman dos parâmetros de Teste Cardiopulmonar de esforço para o sexo feminino.

TCPE Sexo Feminino

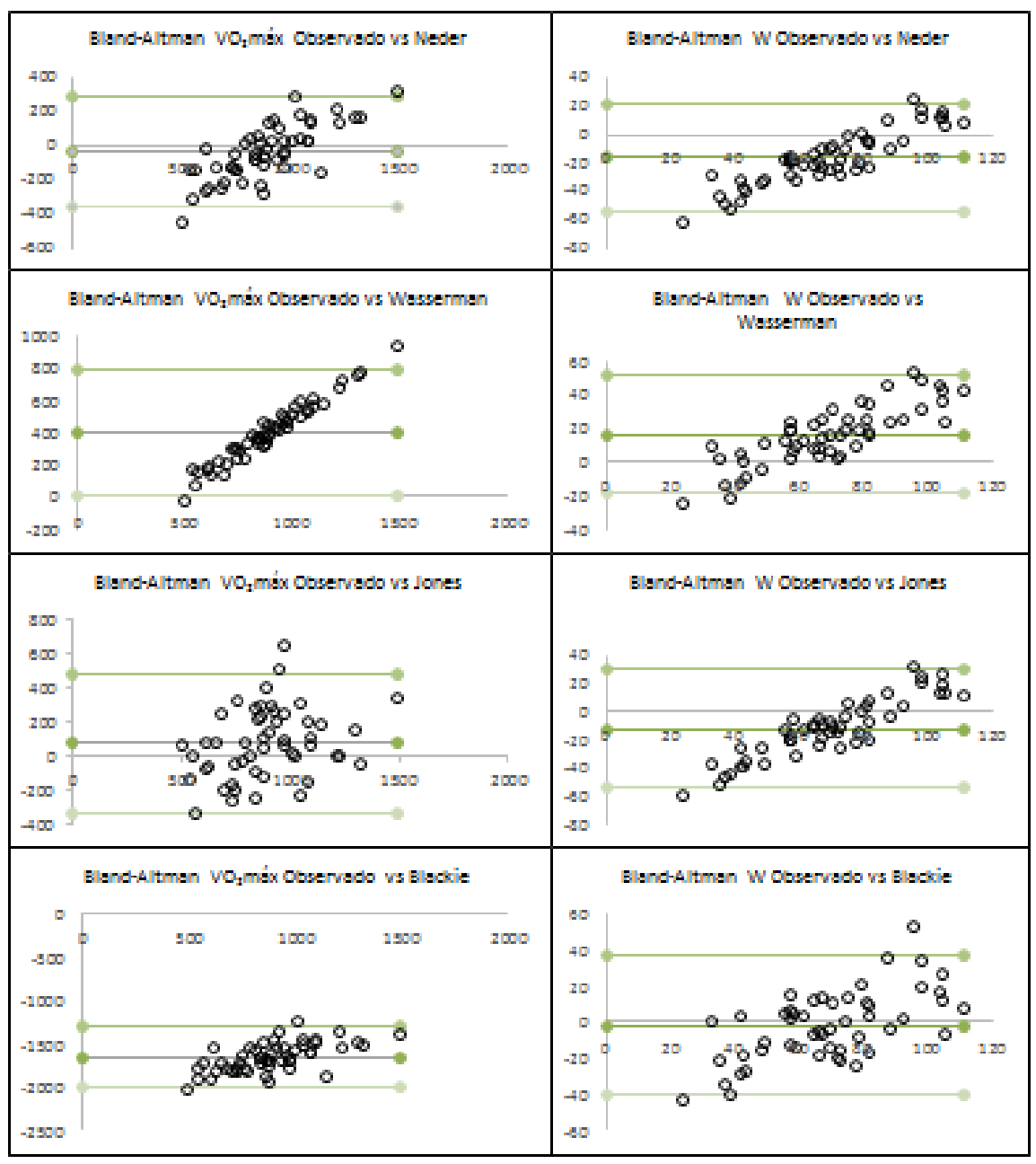


7. Suplemento. Gráfico comparativo do Bland- Altman dos parâmetros de Teste Cardiopulmonar de esforço para o sexo masculino.

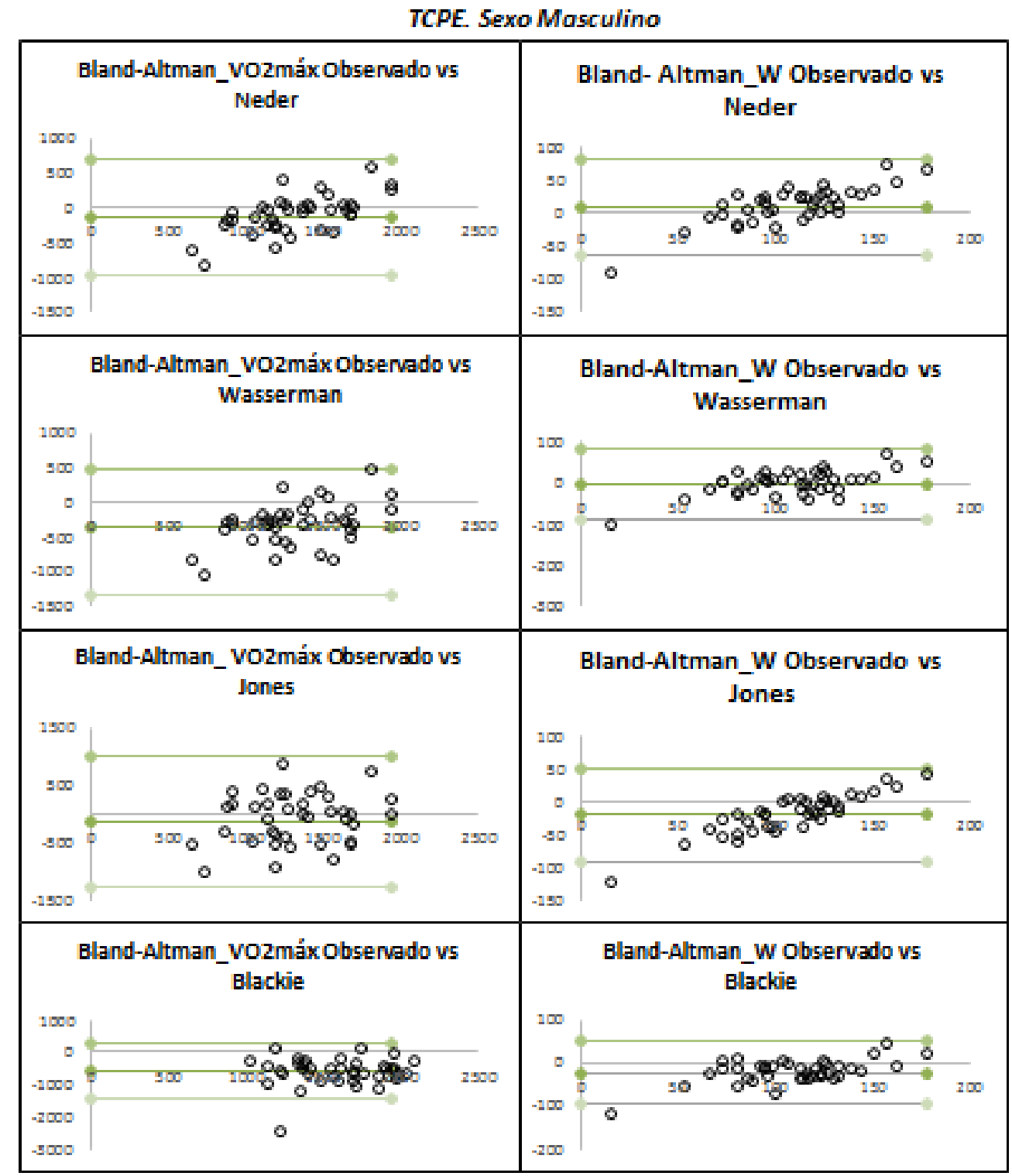


8. Suplemento. Comparação de características físicas de populações de referência.

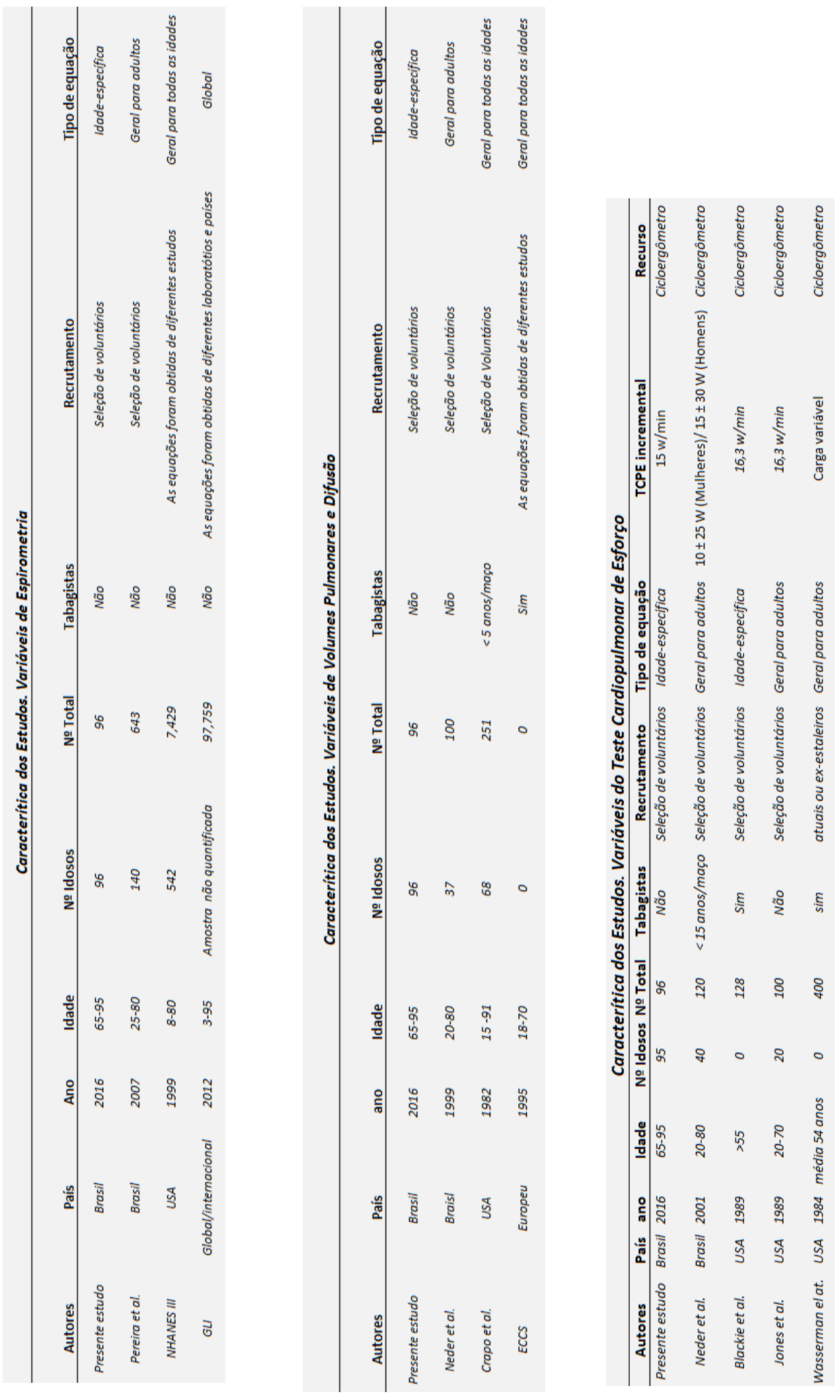


9. Suplemento. Tabela contemplando as principais equações de referência utilizadas neste estudo, assim como nossa equação proposta para as variáveis espirométricas em ambos os sexos.

\begin{tabular}{|c|c|c|c|}
\hline Referência & Sexo & Variável & Espirometria. Equação \\
\hline Presente estudo & Feminino & CVF & $((0,028 *$ Altm $)+(-0,025 *$ Idade $))+0,12$ \\
\hline Presente estudo & Masculino & CVF & $\left(\left(0,036^{*}\right.\right.$ Altm $)+\left(-0,051^{*}\right.$ Idade $\left.)\right)+1,503$ \\
\hline Presente estudo & Feminino & VEF1 & $\left(\left(0,018^{*}\right.\right.$ Altm $)+(-0,022 *$ Idade $\left.)\right)+0,811$ \\
\hline Presente estudo & Masculino & VEF1 & $\left(\left(0,024^{*}\right.\right.$ Altm $)+\left(-0,035^{*}\right.$ Idade $\left.)\right)+1,317$ \\
\hline Presente estudo & Feminino & VEF1/CVF & $\left(\left(-0,001^{*}\right.\right.$ Altm $)+\left(-0,001^{*}\right.$ Idade $\left.)\right)+1,065$ \\
\hline Presente estudo & Masculino & VEF1/CVF & $((-0,001 *$ Altm $)+(0,001 *$ Idade $))+0,77$ \\
\hline Pereira et al. & Feminino & CVF & $((0,0441 *$ altcm $)+(-0,0189 *$ idade $)+($ peso* 0$))-2,848$ \\
\hline Pereira et al. & Masculino & CVF & $\left(\left(0,0517^{*}\right.\right.$ altcm $)+\left(-0,0207^{*}\right.$ idade $)+($ peso*0 $\left.)\right)-3,18$ \\
\hline Pereira et al. & Feminino & VEF1 & $\left(\left(0,0314^{*}\right.\right.$ altcm $)+\left(0,0203^{*}\right.$ idade $)+($ peso*0 $\left.)\right)-1,353$ \\
\hline Pereira et al. & Masculino & VEF1 & $\left(\left(0,0338^{*}\right.\right.$ altcm $)+\left(0,00252^{*}\right.$ idade $)+($ peso*0 $\left.)\right)-0,789$ \\
\hline Pereira et al. & Feminino & VEF1/CVF & $\left(\left(\left(-0,14^{*}\right.\right.\right.$ altcm $)+\left(-0,158^{*}\right.$ idade $)+($ peso* $\left.\left.)\right)+111,5\right) / 100$ \\
\hline Pereira et al. & Masculino & VEF1/CVF & $\left(\left(\left(-0,175^{*}\right.\right.\right.$ altcm $)+\left(-0,197^{*}\right.$ idade $)+($ peso* $\left.\left.)\right)+120,3\right) / 100$ \\
\hline NHANES III & Feminino & CVF & $\left(\left(0,0187^{\bullet}\right.\right.$ idade $\left.)+\left(\left(\text { idade }^{\wedge} 2\right)^{\bullet}-0,000382\right)+\left(\left(\text { altcm }^{\wedge} 2\right)^{\bullet} 0,00014815\right)\right)+0,356$ \\
\hline NHANES III & Masculino & CVF & $\left(\left(0,00064^{*}\right.\right.$ idade $\left.)+\left(\left(\text { idade }^{\wedge} 2\right)^{*}-0,000269\right)+\left(\left(\text { altcm }^{\wedge} 2\right)^{\bullet} 0,00018642\right)\right)-0,1933$ \\
\hline NHANES III & Feminino & VEF1 & $\left(\left(-0,00361^{*}\right.\right.$ idade $)+\left(\left(\right.\right.$ idade $\left.\left.\left.^{\wedge} 2\right)-0,000194\right)+\left(\left(\text { altcm }^{\wedge} 2\right)^{\bullet} 0,00011496\right)\right)+0,4333$ \\
\hline NHANES III & Masculino & VEF1 & $\left(\left(-0,01303^{*}\right.\right.$ idade $)+\left(\left(\right.\right.$ idade $\left.\left.^{\wedge} 2\right)-0,000172\right)+\left(\left(\right.\right.$ altcm $\left.\left.\left.^{\wedge} 2\right) \bullet 0,00014098\right)\right)+0,5536$ \\
\hline NHANES III & Feminino & VEF1/CVF & $\left(90,809+\left(-0,2125^{*}\right.\right.$ idade $\left.)\right) / 100$ \\
\hline NHANES III & Masculino & VEF1/CVF & $(88,066+(-0,2066 *$ idade $)) / 100$ \\
\hline GL & Feminino & CVF & $2,7183^{\wedge}\left(-10,403+\left(2,2633^{*} \log\right.\right.$ altcm $)+\left(0,0234^{*} \log\right.$ idade $)+$ Mspline $)$ \\
\hline GLI & Masculino & CVF & CVF $02,7183^{\wedge}\left(-11,2281+\left(2,4135^{*} \operatorname{logaltcm}\right)+\left(0,0865^{*}\right.\right.$ logidade $)+$ Mspline $)$ \\
\hline GLI & Feminino & VEF1 & $2,7183^{\wedge}\left(-9,6987+\left(2,1211^{*} \log\right.\right.$ Itcm $\left.)\right)+\left(-0,0270^{*}\right.$ logidade $)+$ Mspline $)$ \\
\hline GLI & Masculino & VEF1 & $2,7183^{\wedge}\left(-10,342+\left(2,2196^{*} \log\right.\right.$ altcm $\left.)\right)+\left(-0,0574^{*} \log\right.$ idade $)+$ Mspline $)$ \\
\hline GLI & Feminino & VEF1/CVF & $2,7183^{\wedge}\left(0,5506+\left(-0,1078^{*} \log\right.\right.$ altcm $)+\left(-0,0544^{*}\right.$ logidade $)+$ Mspline $)$ \\
\hline GL & Masculino & VEF1/CVF & $2,7183^{\wedge}\left(0,7403+\left(-0,1595^{*} \operatorname{logaltcm}\right)+\left(-0,0366^{*} \log\right.\right.$ idade $)+$ Mspline $)$ \\
\hline
\end{tabular}

10. Suplemento. Tabela contemplando as principais equações de referência utilizadas neste estudo, assim como nossa equação proposta para as variáveis de difusão em ambos os sexos.

\begin{tabular}{|c|c|c|c|}
\hline Referência & Sexo & Variável & Difusão. Equação \\
\hline Presente estudo & Feminino & DLco & $\left(\left(0,203^{*}\right.\right.$ altcm $)+\left(-0,235^{*}\right.$ idade $\left.)\right)+4,319$ \\
\hline Presente estudo & Masculino & DLco & $\left(\left(0,461^{*}\right.\right.$ altcm $)+\left(-0,399^{*}\right.$ idade $\left.)\right)-22,069$ \\
\hline Neder et al. & Feminino & DLco & $\left(\left(0,180^{*}\right.\right.$ altcm $)+\left(-0,075^{*}\right.$ Idade $\left.)\right)+0,200$ \\
\hline Neder et al. & Masculino & DLco & $\left(\left(0,320^{*}\right.\right.$ altcm $)+\left(-0,130^{*}\right.$ Idade $\left.)\right)-13,07$ \\
\hline Crapo et al. & Feminino & DLco & $\left(\left(0,256^{*}\right.\right.$ altcm $)+\left(-0,1444^{*}\right.$ Idade $\left.)\right)-8,36$ \\
\hline Crapo et al. & Masculino & DLco & $\left(\left(0,416^{*}\right.\right.$ Altcm $)+\left(-0,219^{*}\right.$ Idade $\left.)\right)-26,34$ \\
\hline ECCSet al. & Feminino & DLco & $\left(\left(0,244^{*}\right.\right.$ altcm $)+\left(-0,146^{*}\right.$ Idade $\left.)\right)-8,206$ \\
\hline ECCSet al. & Masculino & DLco & $\left(\left(0,332^{*}\right.\right.$ altcm $)+\left(-0,197^{*}\right.$ Idade $\left.)\right)-18,02$ \\
\hline
\end{tabular}


11. Suplemento. Tabela contemplando as principais equações de referência utilizadas neste estudo, assim como nossa equação proposta para as variáveis de volumes pulmonares em ambos os sexos.

\begin{tabular}{|c|c|c|c|}
\hline Presente estudo & Masculino & CPT & $\left(0,056^{*}\right.$ Altcm $)+\left(-0,009^{*}\right.$ Idade $)-2,216$ \\
\hline Presente estudo & Masculino & CRF & $\left(0,05^{*}\right.$ Altcm $)+\left(-0,009^{*}\right.$ Idade $)-3,822$ \\
\hline Presente estudo & Feminino & VR & $\left(0,044^{*}\right.$ Altcm $)+\left(0,042^{*}\right.$ Idade $)-7,487$ \\
\hline Neder et al. & Feminino & CPT & $\left(0,07^{*}\right.$ Altcm $)+\left(-0,00983^{*}\right.$ Idade $)-5,98$ \\
\hline Neder et al. & Masculino & $\mathrm{CPT}$ & $\left(0,0709^{*}\right.$ Altcm $)+\left(-0,0068^{*}\right.$ Idade $)-5,172$ \\
\hline Neder et al. & Feminino & CRF & $(1,30 *$ Altm $)+(0,0091 *$ idade $)+0,21$ \\
\hline Neder et al. & Masculino & CRF & $\left(2,78^{*} \mathrm{altm}\right)+(0,0092+$ idade $)-1,83$ \\
\hline Neder et al. & Feminino & VR & $\left(0,0259^{*}\right.$ Altcm $)+\left(0,0091^{*}\right.$ Idade $)-3,15$ \\
\hline Crapo et al. & Masculino & CPT & $\left(\left(0,0795^{*}\right.\right.$ Altcm $)+\left(0,0032^{*}\right.$ Idade $\left.)\right)-7,33$ \\
\hline Crapo et al. & Feminino & CRF & $\left(\left(0,036^{*}\right.\right.$ Altcm $)+\left(0,0031^{*}\right.$ Idade $\left.)\right)-3,182$ \\
\hline Crapo et al. & Masculino & CRF & $((0,0472 *$ Altcm $)+(0,009 *$ Idade $))-5,29$ \\
\hline Crapo et al. & Feminino & VR & $\left(\left(0,0197^{*}\right.\right.$ Altcm $)+\left(0,0201^{*}\right.$ Idade $\left.)\right)-2,421$ \\
\hline Crapo et al. & Masculino & VR & $\left(\left(0,0216^{*}\right.\right.$ Altcm $)+\left(0,0207^{*}\right.$ Idade $\left.)\right)-2,84$ \\
\hline ECCS et al. & Feminino & CPT & $(0,06602 \bullet A l t m)-5,791$ \\
\hline ECCS et al. & Masculino & CPT & $(0,07992 *$ Altm $)-7,081$ \\
\hline ECCS et al. & Feminino & CRF & $\left(\left(0,02245^{*}\right.\right.$ Altm $)+(0,001 *$ Idade $\left.)\right)-1,003$ \\
\hline ECCSet al. & Masculino & CRF & $\left(\left(0,02348^{*}\right.\right.$ Altm $)+\left(0,009^{*}\right.$ Idade $\left.)\right)-1,093$ \\
\hline ECCSet al. & Feminino & VR & $\left(\left(0,01812^{*}\right.\right.$ Altm $)+\left(0,016^{*}\right.$ Idade $\left.)\right)-2,003$ \\
\hline ECCSet al. & Masculino & VR & $\left(\left(0,0131^{*}\right.\right.$ Altm $)+\left(0,022^{*}\right.$ Idade $\left.)\right)-1,232$ \\
\hline
\end{tabular}


12.Suplemento. Tabela contemplando as principais equações de referência utilizadas neste estudo, assim como nossa equação proposta para as variáveis de teste cardiopulmonar de esforço em ambos os sexos.

\begin{tabular}{|c|c|c|c|}
\hline Referência & Sexo & Variável & TCPE. Equação \\
\hline Presente estudo & Feminino & w & $\left(\left(0,293^{*}\right.\right.$ altcm $)+(-1,611 *$ idade $\left.)\right)+144,93$ \\
\hline Presente estudo & Masculino & W & $((0,46 *$ altcm $)+(-2,924 *$ idade $))+284,505$ \\
\hline Presente estudo & Feminino & $\mathrm{VO}_{2}$ máx. & $((9,739 *$ altcm $)+(-14,091 *$ idade $))+456,573$ \\
\hline Presente estudo & Masculino & $\mathrm{VO}_{2}$ máx. & $((7,782 *$ altcm $)+(-26,158 *$ idade $))+1966,404$ \\
\hline Neder et al. & Feminino & $\mathrm{W}$ & $((0,96 *$ altcm $)+(-1,19 *$ idade $))+28,1$ \\
\hline Neder et al. & Masculino & W & $((1,36 *$ altcm $)+(-1,78 *$ idade $)+(0,65 *$ peso $))-45,4$ \\
\hline Neder et al. & Feminino & $\mathrm{VO}_{2}$ máx. & $((-0,04 *$ idade $)+(0,08 *$ peso $))+5,1$ \\
\hline Neder et al. & Masculino & $\mathrm{VO}_{2}$ máx. & $((-0,09 *$ idade $)+(0,09 *$ peso $))+10,1$ \\
\hline Blackie et al. & Feminino & $\mathrm{W}$ & $\left((7,4 *\right.$ altcm $)+\left(-13^{*}\right.$ idade $)+(3,78 *$ peso $\left.\left.)\right)+52\right) * 0,163$ \\
\hline Blackie et al. & Masculino & w & $((6,1 *$ altcm $)+(-26,1 *$ idade $)+(0,04 *$ peso $))+1704) * 0,163$ \\
\hline Blackie et al. & Feminino & $\mathrm{VO}_{2}$ máx. & $(((0,0142 *$ altcm $)+(-0,0115 *$ idade $)+(0,00974 *$ peso $))+0,651) * 100$ \\
\hline Blackie et al. & Masculino & $\mathrm{VO}_{2}$ máx. & $\left(\left((0,0142 *\right.\right.$ altcm $)+(-0,0494 *$ idade $)+\left(0,00257^{*}\right.$ peso $\left.\left.)\right)+3,015\right) * 100$ \\
\hline Jones et al. & Feminino & w & $\left(\left((\text { altcm } / 100)^{\wedge} 2,8\right)^{*} 969 *(-0,43 * \text { idade })\right)^{*} 0,163$ \\
\hline Jones et al. & Masculino & w & $\left(\left((\text { altcm } / 100)^{\wedge} 2,7\right)^{*} 1506 *(-0,48 *\right.$ idade $\left.)\right) * 0,163$ \\
\hline Jones et al. & Feminino & $\mathrm{VO}_{2}$ máx. & $\left(\left(0,025^{*}\right.\right.$ altcm $)+\left(-0,018^{*}\right.$ idade $)+(\text { peso*0,01) }-2,26)^{*} 1000$ \\
\hline Jones et al. & Masculino & $\mathrm{VO}_{2}$ máx. & $((0,034 *$ altcm $)+(-0,028 *$ idade $)+($ peso $* 0,022)) * 1000$ \\
\hline Wasserman et al. & Feminino & W & $((($ peso +43$) *(22,78+(-0,17 *$ idade $)+(-5,8 *$ peso* -151$)) / 10,1$ \\
\hline Wasserman et al. & Masculino & w & $(($ peso $*(50,72-0,372 *$ idade $)-5,8 *$ peso*-151)/10,1 \\
\hline Wasserman et al. & Feminino & $\mathrm{VO}_{2}$ máx. & $(($ peso $+43 *(22,78+(-0,17 *$ idade $)))$ \\
\hline Wasserman et al. & Masculino & $\mathrm{VO}_{2}$ máx. & $\left(\left(\right.\right.$ peso $\left.\left.^{*}(50,72-(0,372))\right)\right)$ \\
\hline
\end{tabular}

